\title{
Unravelling mechanisms linking plant diversity to
}

\section{plant-disease suppression}

\author{
Dissertation \\ zur Erlangung des mathematisch-naturwissenschaftlichen Doktorgrades \\ "Doctor rerum naturalium" \\ der Georg-August-Universität Göttingen
}

im Promotionsprogramm Biologie

der Georg-August University School of Science (GAUSS)

vorgelegt von

Dipl.-Biol. Ellen Latz

aus Heidelberg

Göttingen, 2015 


\section{Betreuungsausschuss}

Prof. Dr. Stefan Scheu, Tierökologie, J.F. Blumenbach Institut für Zoologie und Anthropologie Prof Dr. Ulrich Brose, Systemische Naturschutzbiologie, J.F. Blumenbach Institut für Zoologie und Anthropologie

Dr. Alexandre Jousset, Tierökologie, J.F. Blumenbach Institut für Zoologie und Anthropologie

Mitglieder der Prüfungskommission

Referent: Prof. Dr. Stefan Scheu, Tierökologie, J.F. Blumenbach Institut für Zoologie und Anthropologie

Korreferent: Prof Dr. Ulrich Brose, Systemische Naturschutzbiologie, J.F. Blumenbach Institut für Zoologie und Anthropologie

Weitere Mitglieder der Prüfungskommision:

Prof. Dr. Nico Eisenhauer, Tierökologie, J.F. Blumenbach Institut für Zoologie und Anthropologie PD Dr. Christoph Scherber, Agrarökologie, Department für Nutzpflanzenwissenschaften PD Dr. Mark Maraun, Tierökologie, J.F. Blumenbach Institut für Zoologie und Anthropologie PD Dr. Marko Rohlfs, Tierökologie, J.F. Blumenbach Institut für Zoologie und Anthropologie

Tag der mündlichen Prüfung: 05.06.2015 


\section{Contents}

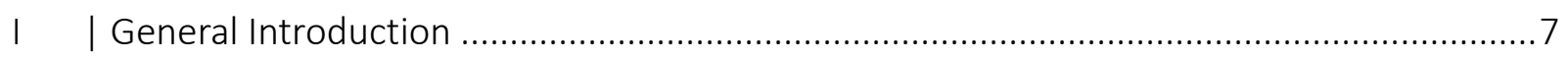

1.1 Economic importance of soil-borne phytopathogens .................................................

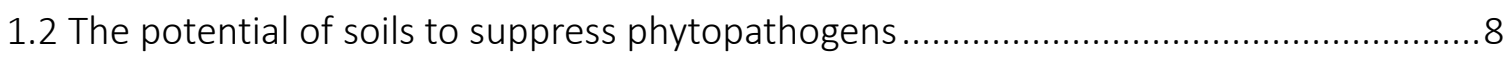

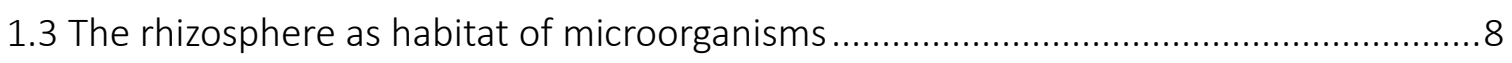

1.4 Phytopathogens and plant-pathogen antagonistic microbes.....................................

1.5 The role of predation in disease suppression ............................................................10

1.6 The role of plant diversity in shaping microbial communities .....................................11

1.7 Plant identity and soil suppression ...........................................................................12

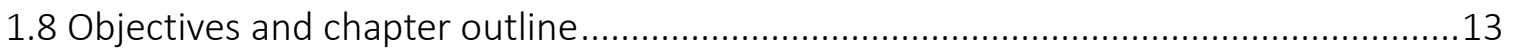

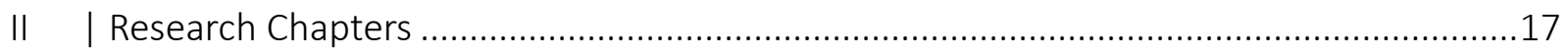

2.1 Research Chapter 1 Plant identity drives the expression of biocontrol factors in a rhizosphere bacterium across a plant diversity gradient....................................................17

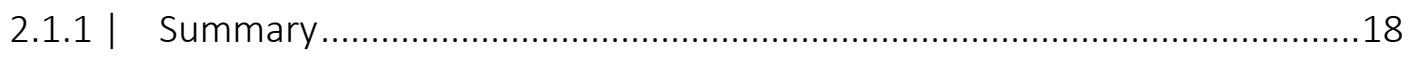

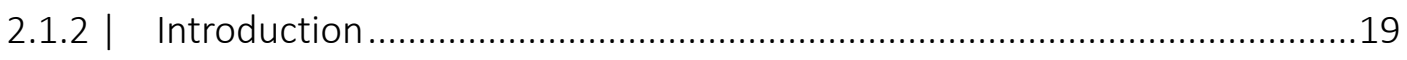





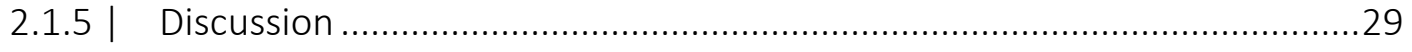

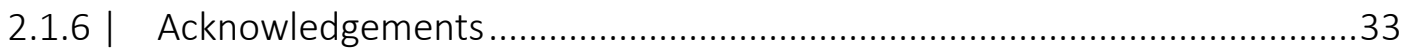

2.2 Research Chapter 2 Assessing Plant Pathogen Infection Rates in Natural Soils: Using

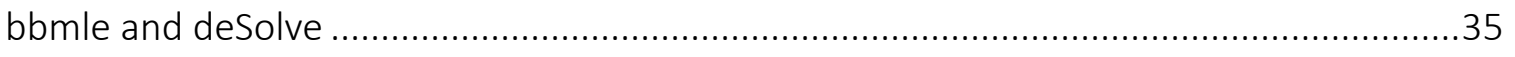

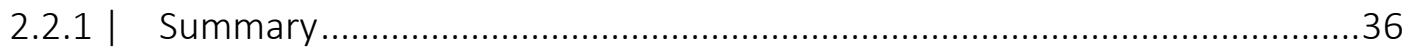

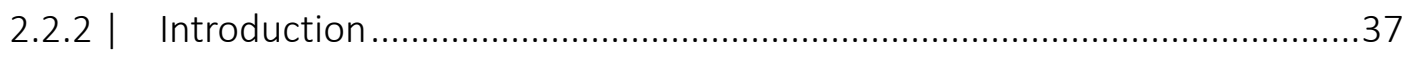

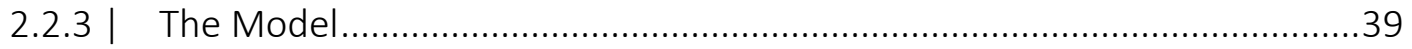

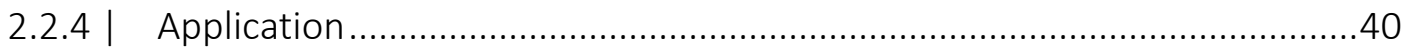

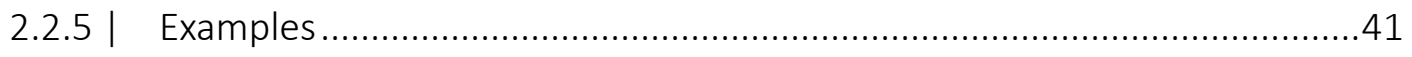

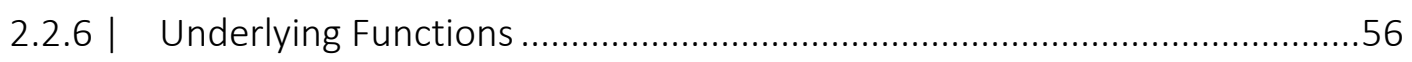

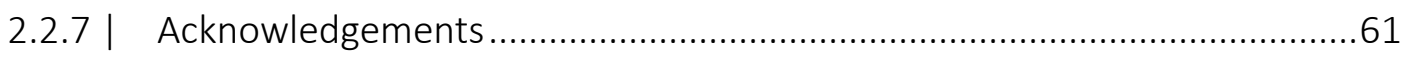

2.3 Research Chapter 3 Mechanistic links between plant community composition and the pathogen-suppressive potential of soils. 


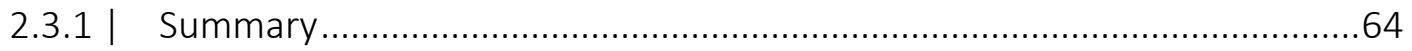

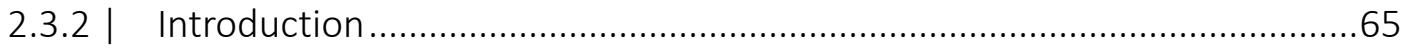

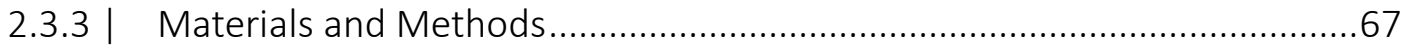

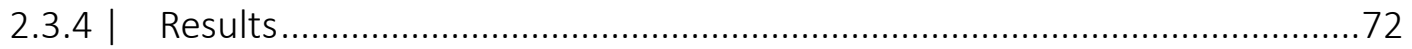

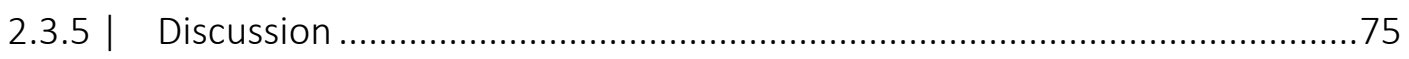

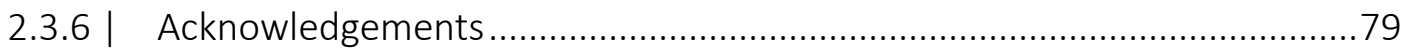

2.4 Research Chapter 4 Intercropping and soil protozoa interactively shape soil function

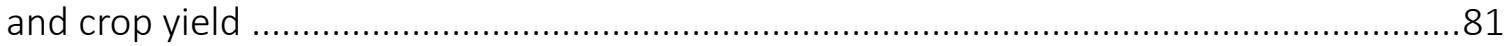

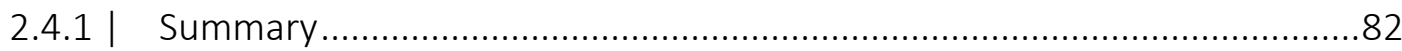

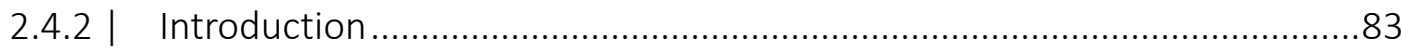

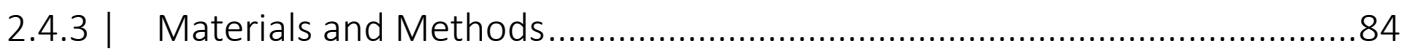

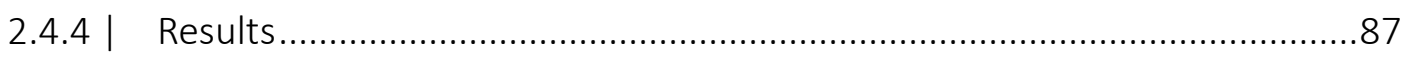

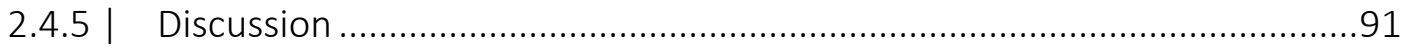

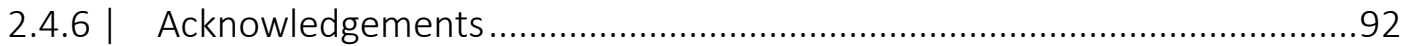

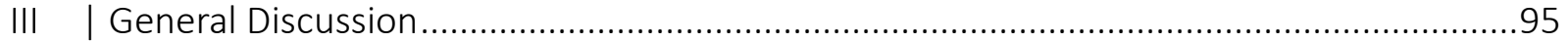

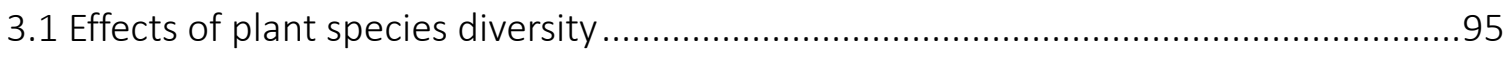

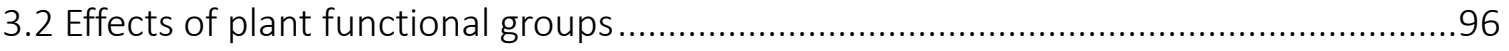

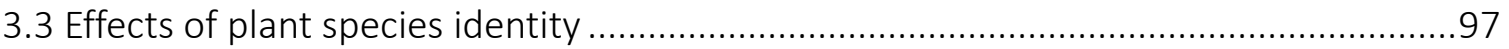

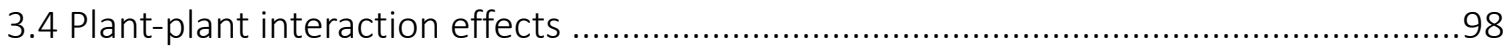

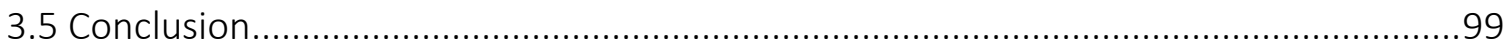

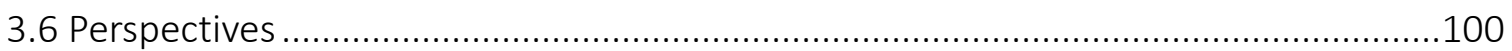

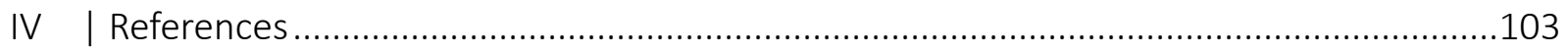

V | Supplementary Material .........................................................................................119

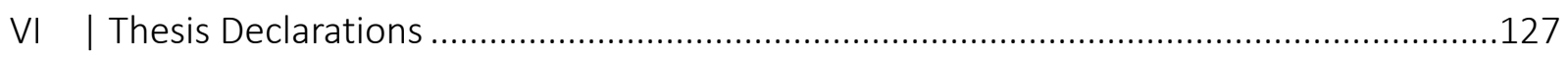

7.1 Declaration of the author's own contribution to manuscripts ....................................127



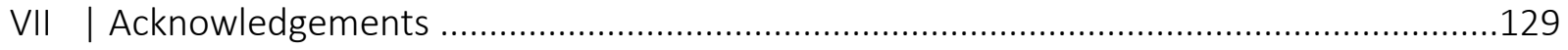


„Ein Gelehrter in seinem Laboratorium“... „ist vor den Naturgesetzen wie ein Kind vor der Märchenwelt."

Marie Curie 



\section{I | General Introduction}

\subsection{Economic importance of soil-borne phytopathogens}

Soil-borne plant pathogens, in particular fungi, pose a global threat to crop production (PéchyTarr et al. 2008; Raaijmakers et al. 2009; Philippot et al. 2013). Plant species can be affected by various diseases such as root rot, root blackening, wilt, stunting or seedling damping-off and new diseases constantly appear (Haas \& Defago 2005). An average yield loss of $7-15 \%$ was estimated for the most important food-crops maize, potato, rice, soybean and wheat (Oerke 2006). Well known aggressive pathogens such as Fusarium, Pythium or Rhizoctonia can even cause losses up to 20-35\% (Cook 1987; Cook, Schillinger \& Christensen 2002; Smiley et al. 2005), underlining the necessity for soil-borne disease control.

Since pathogenic fungi are susceptible to heat, heat-steaming was a common practice in greenhouses to improve vegetable yields, but this technique got restricted due to increasing energy-costs (Raaijmakers et al. 2009). Chemical pesticides are rarely effective in controlling root diseases sustainably and besides high costs, concern for the environment and human health restricts their application (Baehler et al. 2005; Lugtenberg \& Kamilova 2009). However, some more harmless pesticides are still in use, while their application has uncontrolled sideeffects on the whole microbial community (both, harmful and beneficial microorganisms are affected), e.g., their composition and development (Raaijmakers et al. 2009). Consequently, the interest in former cultural-practices such as crop rotation and tillage became renewed in order to reduce disease severity in a more sustainable and environmentally friendly way (Janvier et al. 2007). Crop rotation with non-hosts is effective for the suppression of rather specialist pathogens with a low saprophytic survival capacity (Cook et al. 2002; Janvier et al. 2007). Further, specific tillage practices (Sturz, Carter \& Johnston 1997; Pankhurst et al. 2002), intercropping (Trenbath 1993) as well as residue destruction (Baird, Watson \& Scruggs 2003) and organic amendments (Tilston, Pitt \& Groenhof 2002) have decreased disease severity. Interestingly, also long-term mono-cropping accompanied by severe disease outbreaks can result in increased pathogen suppression (Weller et al. 2002; Postma, Scheper \& Schilder 2010; Mendes et al. 2011). However, the link between cultural practices and disease suppression is 
rarely made and it still remains challenging to unravel mechanisms linking crop management to the disease suppressive potential of soils (Janvier et al. 2007; addressed in Chapter 2.4).

\subsection{The potential of soils to suppress phytopathogens}

Suppressive soils are soils in which plant-disease severity is reduced or plants even resist certain diseases, although disease-causing pathogens are present (Haas \& Defago 2005). In those soils, pathogens have low fitness, grow poorly and thus cause little damage to plants (Baker \& Cook 1974; Weller et al. 2002). Virtually all soils have the potential to suppress diseases to some extent, which is due to the overall activity of the autochthonous soil microbial community. Whereas, specific pathogen suppression is rather caused by a distinct biological mechanism (Weller et al. 2002).

Most prominently, plant-pathogen antagonistic rhizobacteria have been discussed in respect of their potential to suppress pathogens (Garbeva, van Veen \& van Elsas 2004; Janvier et al. 2007; van der Heijden, Bardgett \& van Straalen 2008). Further, in addition to biotic factors, abiotic factors have been shown to alter disease suppressiveness of soils (Garbeva et al. 2004; Berg \& Smalla 2009; Philippot et al. 2013). Pathogenic as well as pathogen antagonistic microbial organisms have specific pH-optima and therefore react specifically sensitive to changes in soil $\mathrm{pH}$ (Rousk et al. 2010). Further, soil-water content affects microorganisms, with some being more resistant to drought or, on the other extreme, oxygen-deficiency then others (Hinsinger et al. 2009; Bardgett \& van der Putten 2014). In addition, macro- and micronutrients as well as physicochemical soil characteristics have been shown to influence soil suppressiveness (Janvier et al. 2007). However, the importance of abiotic factors is far from being clear, which might be due to the fact that they are often intercorrelated, and the complexity of mechanisms driving soil properties (Janvier et al. 2007; addressed in Chapter 2.3).

\subsection{The rhizosphere as habitat of microorganisms}

The rhizosphere is the narrow soil-zone around the root-surface that is influenced by the plant (Bais et al. 2006; Lugtenberg \& Kamilova 2009; Raaijmakers et al. 2009). Here, the abundance 
and activity of soil microorganisms is much higher compared to surrounding bulk-soil (Hiltner 1904). Plants provide a carbon-rich environment, $5-21 \%$ of the fixed carbon is secreted as root exudates or enters the soil as other root-derived resources summarized as rhizodeposits (Marschner 2011). Root exudates provide a cocktail of amino-acids, fatty-acids, nucleotides, organic-acids, sugars and phenolic compounds and other nutritional compounds that attract microorganisms (Uren 2007; Lugtenberg \& Kamilova 2009). Rhizodeposits also contain toxic compounds that restrict microbial colonization (Bais et al. 2006). Further, soil pH, which is an important driver of soil microbial communities, can change up to two units due to rootsecretion or uptake of ions (Hinsinger et al. 2009). Interestingly, electric potentials in plantroots have been shown to attract spores of pathogenic oomycetes to swim towards hosts (van West et al. 2002). Plants further affect microbial growth in the rhizosphere via influencing a soils oxygen status which might be indirectly driven by soil properties such as soil aggregation and soil-water contend (Hinsinger et al. 2009). Thereby, plants essentially form the habitat of plant-beneficial as well as plant-pathogenic microorganisms (Raaijmakers et al. 2009; addressed in Chapters 2.1 and 2.3).

\subsection{Phytopathogens and plant-pathogen antagonistic microbes}

Phytopathogens and plant-pathogen antagonistic microbes are natural competitors for nutrients and niches. Therefore, rhizosphere competence is one of the most important issues for plant-infection by pathogens as well as suppression of pathogens by antagonistic microbes (Haas \& Defago 2005; Lugtenberg \& Kamilova 2009). Rhizosphere microorganisms have evolved strategies to improve their competitiveness, some grow in tight biofilms thereby preventing competitors to capture a site (Rudrappa et al. 2008), others show high mobility which enables them to rapidly colonize new sites (Czaban, Gajda \& Wroblewska 2007). Some bacteria have evolved ingenious strategies to take-up resources more quickly, thereby outcompeting other root-colonizers (e.g., iron-chelators; Schippers, Bakker \& Bakker 1987). Interestingly, some bacteria are able to interfere communication of their competitors (AHL-signal degredation; Dong \& Zhang 2005). Further, exoenzymes such as chitinases and proteases that damage fungal cell-walls contribute significantly to the antifungal activity of bacteria (Haas \& Keel 2003; Kielak et al. 2013). However, the most effective strategy in pathogen suppression presumably is the 
synthesis of antibiotic compounds (Haas \& Defago 2005). Streptomyces spp., Bacillus spp. and Pseudomonas spp. are known to produce highly effective antibiotics (Weller et al. 2002). In particular, Pseudomonas spp. have been intensively studied (Weller 2007). Pseudomonads are ubiquitous rhizosphere colonizers, easy to isolate and cultivate, and can be modified genetically. Thus, Pseudomonads represent ideal model organisms for investigating mutualistic interactions between plants and rhizosphere bacteria (Lugtenberg, Dekkers \& Bloemberg 2001). Their ability to suppress pathogens is mainly ascribed to the production of antibiotic compounds including phloroglucinols, phenazines, pyoluteorin, pyrrolnitrin, lipopeptides, and hydrogen cyanide (Haas \& Keel 2003). These antibiotics present antihelminthic, antifungal and antibacterial activities (Raaijmakers, Vlami \& de Souza 2002), and contribute to plant protection by directly inhibiting pathogens (Haas \& Defago 2005) and eliciting plant defenses (induced systemic resistance; lavicoli et al. 2003). Despite their capability to suppress pathogens, in most cases, bacteria have been shown to be ineffective when applied to the field, arguing for the existence of additional mechanisms and regulators of the suppressive-ability of bacteria (Lugtenberg \& Kamilova 2009; addressed in Chapters 2.1 and 2.3).

\subsection{The role of predation in disease suppression}

To be a successful root-colonizer, bacteria do not only need to compete with other microorganisms but also to escape predation by indigenous microfauna (Lugtenberg \& Kamilova 2009). Predation by protozoa exerts a high pressure on bacterial communities in the rhizosphere, and causes up to 50\% productivity loss (Foissner 1999). Since grazing on bacteria is selective, protozoa feed mainly medium-sized bacterial cells that lack defense-mechanisms, they essentially shape microbial communities and their functioning (Rønn et al. 2002; Jousset et al. 2009). Especially nutrient cycling and the ability to suppress pathogens by bacteria are affected by protozoan grazing (Bonkowski 2004; Müller, Scheu \& Jousset 2013). However, the role of predation in plant-growth and health promotion by bacteria is only beginning to be understood (Dubuis, Keel \& Haas 2007; addressed in Chapter 2.4). 


\subsection{The role of plant diversity in shaping microbial communities}

Diverse plant communities are generally more productive than monocultures, an effect that strengthens through time (Cardinale et al. 2007). This phenomenon has been extensively studied over the last decades, but the underlying mechanisms are not yet fully resolved (van der Heijden et al. 2008; Reich et al. 2012; Ebeling et al. 2014; Tilman, Isbell \& Cowles 2014). The increasing probability of including and becoming dominated by species with a high impact on a given function with increasing diversity levels (sampling-effect; Aarssen 1997; Tilman, Lehman \& Thomson 1997; Huston 1997) and a more complementary resource-use or species facilitation (complementarity-effect; Loreau et al. 2001) have been most prominently discussed. To predict complementarity effects between species, functional traits, i.e. morphological, phenological or physiological characteristics affecting the performance of organisms, have been used (Ebeling et al. 2014). However, it remains unresolved which trait differences matter, if species number can be used to summarize those differences, or if functional group affiliation or phylogenetic relatedness is providing additional information (Tilman et al. 2014).

Plant community composition and diversity shape belowground microbial communities (Kowalchuk, de Souza \& van Veen 2002; Zul et al. 2007). Generally, plant diversity increases the diversity, abundance and activity of soil microorganisms (Stephan, Meyer \& Schmid 2000; Zak et al. 2003; Liu et al. 2008; Eisenhauer et al. 2010a). Effects of soil microorganisms on plant growth, such as positive effects through nutrient provisioning or negative effects through pathogen pressure, have been suggested to be plant diversity dependent (Mitchell 2003; Schnitzer et al. 2011; Eisenhauer, Reich \& Scheu 2012). Soil enzyme activities that reflect the ability of microorganisms to contribute to soil health and quality are increased in diverse grasslands (Bandick \& Dick 1999). In addition, bacteria involved in pathogen suppression are more abundant in diverse plant communities and likely contribute to decreased disease severity observed associated with diverse grassland systems (Garbeva et al. 2006; Weller 2007; Latz et al. 2012).

Generally, effects of plant diversity on microbial communities have been suggested to be due to increased plant productivity accompanied by increased resource quantity (Spehn et al. 2000; Zak et al. 2003; de Deyn, Quirk \& Bardgett 2011). On the other hand, specific ecosystem functions are assumed to depend on resource composition and the quality of specific 
resources, driven by variation in plant species richness and identity (de Deyn et al. 2011; Latz et al. 2012, 2015). However, the exact patterns driving plant diversity effects on rhizosphere microbial communities need further investigation (addressed in Chapters 2.1 and 2.3).

\subsection{Plant identity and soil suppression}

The importance of plant species identity in shaping rhizosphere microbial communities is receiving increased attention. Some microbial species are highly specific in their association with specific plant groups or even single plant species. Rhizobia-legume as well as pathogenhost interactions represent examples of high specificity (Long 2001; Bais et al. 2006).

Root exudates that are highly plant-species specific may be the driving force for this phenomenon, but the role of single compounds is only beginning to be understood (Berg \& Smalla 2009). Certain root exudates prevent colonization by pathogenic microorganism while attracting others, or attract a couple of microorganisms with differing consequences to the plant (Bais et al. 2006). For example, flavonoids in soybean root exudates attract a pathogen as well as its antagonist (Tomasi et al. 2008). Plants growing in nutrient-poor environments have been shown to attract nutrient-acquiring microorganisms (Dakora \& Phillips 2002). Further, plants shape the rhizosphere microbial community via exudation of toxic compounds. As a consequence, specific microbes resistant to the toxin(s), or microbes that are able to degrade the toxin(s) colonize the roots (Kowalchuk, Hol \& van Veen 2006; Bressan et al. 2009).

In addition, root morphology and plant biomass effects have been shown to be plant species specific and drive rhizosphere microbial communities (de Deyn et al. 2011; Philippot et al. 2013). Notably, the root surface is only fragmentally colonized by bacteria. Bacterial populations preferentially grow in root-zones that are especially rich in root exudates (Bais et al. 2006). Borders between epidermal cells and side-root bifurcations are popular sites for bacterial colonization (Dubuis et al. 2007).

Interestingly, growth and resource allocation of plants growing without competitors (for resources and niches) differ markedly from plants growing in competition with other species (Semchenko, Hutchings \& John 2007). In the presence of competitors, plants invest more in root exudates provide certain functions, such as nutrient foraging, facilitative plant-plant communication and allelopathy, which on the other hand likely shape the rhizosphere microbial 
community (Bais et al. 2006).

Indeed, not only plant induced shifts in the microbial community (Garbeva et al. 2004; Bakker et al. 2012; Mendes, Garbeva \& Raaijmakers 2013), but also plant induced changes in the activity of bacteria in producing antifungal compounds (de Werra et al. 2008; Rochat et al. 2010) alters soil suppressiveness. However, if the production of antibiotics observed in dependence on specific plant species also occurs in multi-species plant communities, remains to be investigated (Latz et al. 2015; addressed in Chapter 2.1).

\subsection{Objectives and chapter outline}

In this thesis, I investigated the role of plant diversity in driving disease suppression (Figure 1). First, I analysed whether plant diversity per se or plant functional group affiliation, plant identity or interaction effects are the main drivers of biocontrol bacteria and their activity in producing antifungal compounds. Second, I investigated abiotic factors and protozoan predators as mediators of plant community composition effects on plant-disease suppression.

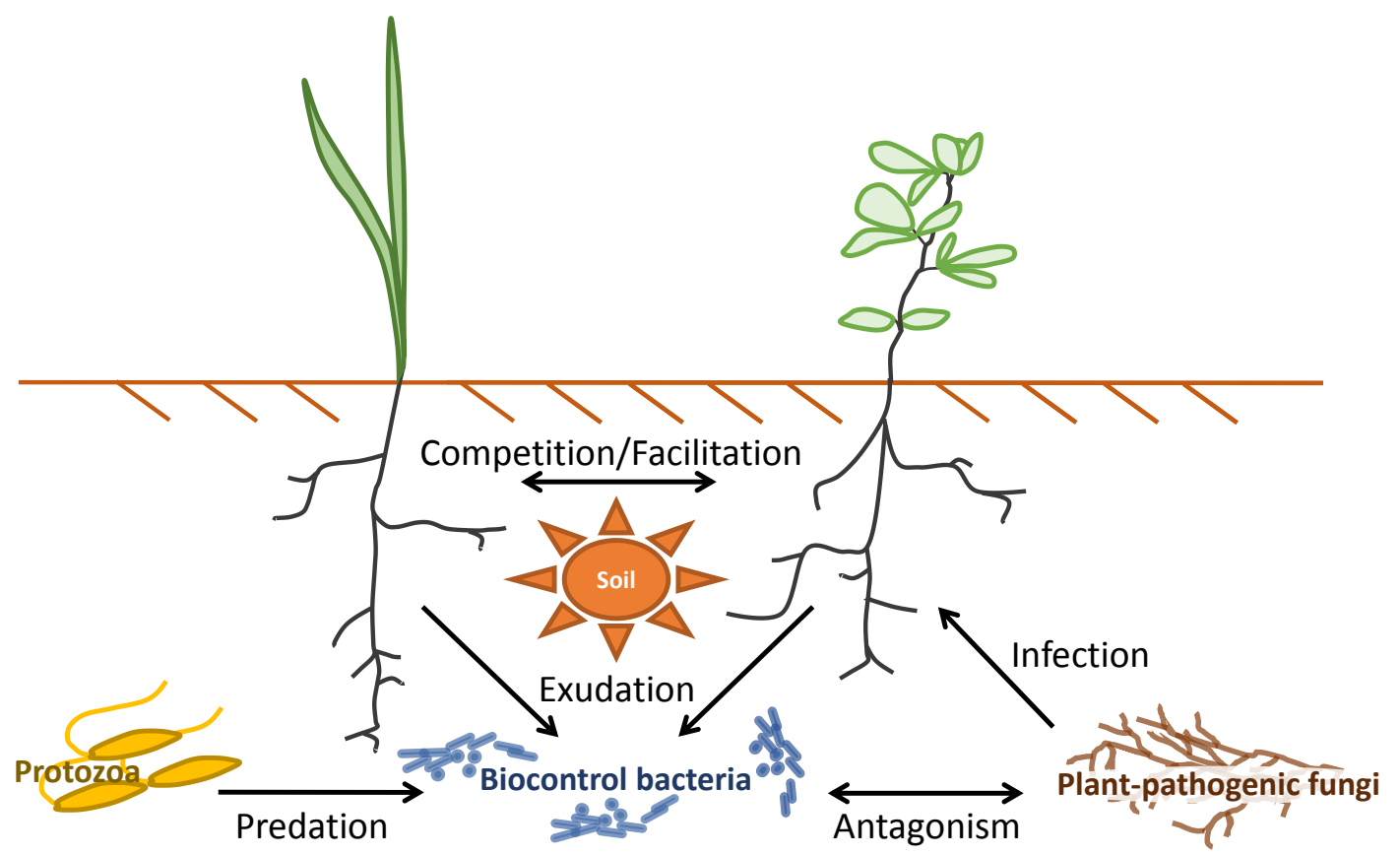

Figure 1. Interactions taking place in the rhizosphere of plants. Plant-pathogenic fungi cope with the antagonism of biocontrol bacteria. Bacteria are influenced by plants and their community composition is driven by protozoanpredation. The whole system is influenced by the plant-roots surrounding soil. 
In RESEARCH CHAPTER 1 the role of plant diversity in driving the expression of antifungal traits by biocontrol bacteria is evaluated. I measured the effect of plant diversity on the expression of genes responsible for the production of the most important antifungal compounds $(2,4-$ diacetylphloroglucinol [DAPG], Pyrrolnitrin [PRN] and hydrogen cyanide [HCN]) in strain Pseudomonas protegens $\mathrm{CHAO}$ grown in gnotobiotic cultures. Further, I related the expression of genes to biomass effects that I expected to increase with plant diversity and in turn increase bacterial activity in producing antifungal compounds. I hypothesised plant diversity to increase plant productivity and assumed this effect to increase bacterial abundances that in turn increase their activity and thereby contribute to increased disease suppression. Results of this study showed expression to be driven mainly by plant identity, an effect that persisted along the plant diversity gradient for all tested genes. While the expression of the gene coding for DAPG showed to be primarily directly driven by plant identity effects, expression of the genes coding for PRN and HCN were more pronounced indirectly driven by high density microbial communities. Interestingly, the effect-direction of certain plant identities varied between the three tested genes, indicating a selective impact of plant species on bacterial gene expression. This study shows that the presence of certain plant species within a community disproportionately impact biocontrol traits expressed by rhizosphere bacteria, providing new insight into our understanding of the patterns driving plant health and productivity.

In RESEARCH CHAPTER 2 a newly developed two-pathogen infection model is presented. Bioassays are a standard method to evaluate plant-breeding or pesticide-application efficacy, and further are used to estimate the potential of natural-soils to suppress soil-borne plant diseases. Generally, in such assays, plants are exposed to a pathogen and infections are rated over time. Using natural soils causes the problem that additional infections might be caused by a naturally occurring pathogen, which might bias the exact estimation of infection rates. The developed model enables to evaluate disease suppression in natural soils by allowing to incorporate infection rates of control treatments. Further, the model makes infection start and infection rate measures in different soils comparable.

In RESEARCH CHAPTER 3 the role of plant diversity in driving the composition of microbial communities with antifungal activity is evaluated and their abundances are related to disease suppression. I used cultivation dependent methods to investigate if plant diversity promotes 
the abundance of Pseudomonas, Streptomyces and Bacillus spp, the three main groups of biocontrol bacteria in natural soil. Further, I related the abundances of the biocontrol groups to abiotic soil properties and investigated their impact on disease suppression by conducting a standardized infection assay and determined the infection start by using the two-pathogen infection model (CHAPTER 2.2). I hypothesised plant diversity to increase plant productivity and assumed this effect to increase bacterial abundances thereby contributing to increased disease suppression. Further, I assumed plant diversity to affect abiotic soil parameters that in turn influence the biocontrol microbial community and thereby the disease suppressive potential of soils. The results indicate that among an important indirect role of plant communities in shaping soil-disease suppression (e.g., via changes in root biomass, soil pH and the abundance of important biocontrol groups), plants interactively, directly affect the suppressive potential of soils. This study represents an important step in understanding the complexity of mechanisms linking plant community composition and disease suppression.

In RESEARCH CHAPTER 4 the role of intercropping and predation pressure by protozoa in driving plant-growth promoting enzyme activities and therewith plant productivity is assessed.

In cooperation with the Universidad Nacional de Quilmes (Buenos Aires, Argentina) I used a soybean-maize intercropping system and scrutinized the links between crop richness, soil enzymes involved in pathogen suppression and nutrient supply, and yield. Further, I related enzymatic activities to abundances of the three main taxa of protozoan-predators amoeba, ciliates and flagellates. I hypothesized intercropping to increase protozoan abundance and to improve enzyme activity, thereby increasing crop yield. I observed that indeed mixing soybean and maize increased crop yield. In addition, this study provides first evidences that cropping regime interactively with soil protozoa shapes soil functioning by influencing soil enzyme activities and thereby crop yield.

\section{AIM OF THIS THESIS}

This thesis aimed at a mechanistic understanding of the effect of plant diversity and plant community structure on the abundance and activity of soil bacteria responsible for soil-borne plant disease suppression. 



\title{
I | Research Chapters
}

\author{
2.1 Research Chapter 1
}

PLANT IDENTITY DRIVES THE EXPRESSION OF BIOCONTROL FACTORS IN A RHIZOSPHERE BACTERIUM ACROSS A PLANT DIVERSITY GRADIENT

Ellen Latz, Nico Eisenhauer, Stefan Scheu and Alexandre Jousset

Functional Ecology, DOI: 10.1111/1365-2435.12417 


\subsubsection{Summary}

Plant performance is influenced by root-associated bacteria that provide important services to the host plant, such as pathogen suppression. Suppression of pathogens is known to be context dependent and to vary between plant species, yet, the significance of plant identity in shaping rhizosphere bacterial functioning in multi-species communities is largely unknown.

We questioned whether the activity of a rhizosphere bacterium in producing biocontrol compounds varies with plant identity in a plant diversity gradient. We set up a gnotobiotic microcosm experiment with the model rhizosphere bacterium Pseudomonas protegens CHAO, an important biocontrol agent, and investigated the effects of plant identity and diversity on its production of biocontrol compounds. Using GFP-based reporter fusions, we assessed gene expression linked to the production of the biocontrol compounds 2,4-diacetylphloroglucinol, pyrrolnitrin, and hydrogen cyanide.

The expression of genes coding for biocontrol compounds was driven to a large extent by plant identity and persisted along the plant species richness gradient for all tested genes. Notably, the effect of certain plant identities varied between the three tested genes, indicating a selective impact of plant species on bacterial gene expression. However, some plant species, such as Lolium perenne, consistently stimulated bacterial gene expression irrespective of the diversity of the plant community.

Our results indicate that the presence of certain plant species within a community disproportionately impact biocontrol traits expressed by rhizosphere bacteria, providing new insight in the patterns driving plant health and productivity. 


\section{1 .2 Introduction}

Plant performance is driven to a large degree by plant-microbe interactions. Soil microorganisms influence plant nutrient acquisition (Chapman et al. 2006; van der Heijden et al. 2008; Bardon et al. 2014), enhance plant immune responses (Pineda et al. 2013) and stress tolerance (Schardl, Leuchtmann \& Spiering 2004), and directly as well as indirectly enhance plant growth (Bais et al. 2006; Raaijmakers et al. 2009). In agriculture, a special group of rhizosphere bacteria has gained particular attention due to their potential to protect plants against soil-borne fungal pathogens (Weller et al. 2002). Fluorescent pseudomonads form a dominant and one of the best characterized groups of bacteria responsible for natural plant protection against pathogens (Haas \& Defago 2005), and are particularly relevant in agricultural systems as well as grasslands (Mendes et al. 2011; Latz et al. 2012). Several strains produce broad spectrum antibiotic compounds, such as 2,4-diacetylphloroglucinol (DAPG), pyrrolnitrin (PRN), and hydrogen cyanide (HCN; Raaijmakers et al. 2002; Haas \& Keel 2003; Haas \& Defago 2005; Weller 2007). However, the expression of the factors that promote plant health are subject to complex regulation, and respond to microbe-microbe interactions, numerous environmental factors, as well as plant-derived cues (Dubuis et al. 2007).

The selectivity of plant species in shaping microbial communities in the rhizosphere has been studied intensively. So far, effects of plants on the efficacy of biocontrol bacteria have been shown to be mediated by 1) plant-induced shifts in the rhizosphere microbial community (Garbeva et al. 2004; Bakker et al. 2012; Mendes et al. 2013) and 2) plant-induced changes in the activity of biocontrol bacteria in producing antifungal compounds (de Werra et al. 2008; Rochat et al. 2010). However, information on plant-microbe interactions is mainly based on plant monocultures, and plant identity effects have rarely been studied in multi-species plant communities.

In grasslands, high plant diversity is associated with increased primary production (Hooper et al. 2005; Cardinale et al. 2012), but the mechanisms underlying this relationship are not yet fully resolved (van der Heijden et al. 2008; Reich et al. 2012; Ebeling et al. 2014). Diverse communities are suggested to be able to capture limiting resources in a complementary and thereby more efficient way (Loreau et al. 2001).

Effects of soil microorganisms on plant growth, such as positive effects through nutrient provisioning or negative effects through pathogen pressure, are suggested to be plant diversity- 
dependent (Schnitzer et al. 2011; Eisenhauer et al. 2012). In case of plant-pathogen interactions, biocontrol bacteria play a crucial role in promoting plant productivity by reducing pathogen pressure, an effect likely to be more pronounced in species rich plant communities (Garbeva et al. 2006; Weller 2007; Latz et al. 2012). Plant diversity has been shown to increase plant root biomas (Craine et al. 2003; Reich et al. 2012; Mueller et al. 2013; Ravenek et al. 2014), and it has been suggested that plant diversity drives microbial density via increasing plant biomass (Spehn et al. 2000; Zak et al. 2003; de Deyn et al. 2011), thereby increasing habitat and resources of root-associated bacteria. Since cell-cell signalling becomes more important at high population densities (Dubuis et al. 2007; Pierson \& Pierson 2007; Lapouge et al. 2008), the production of biocontrol compounds by bacteria is likely to be enhanced in more diverse plant communities. In order to understand the functioning of plant communities and improve intercropping as well as break-cropping strategies (Li et al. 2014), it is essential to link plant community composition and the activity of biocontrol bacteria. However, it has not yet been investigated if the expression of antifungal genes in biocontrol bacteria is modified by the presence of neighbouring plant species in multi-species plant communities.

In addition to plant diversity, the presence of certain functional groups, such as grasses and legumes, has been shown to affect primary productivity in grassland and pasture systems (Spehn et al. 2000; Hedlund et al. 2003; Zak et al. 2003; Milcu et al. 2008). Grasses have highly branched roots with a higher biomass than other plant functional groups (Bessler et al. 2009, 2012; Pérès et al. 2013), thereby providing more habitat for root-associated bacteria (Lange et al. 2014), but also increasing the area for the attack by pathogenic fungi (Sikes, Cottenie \& Klironomos 2009; Kulmatiski et al. 2014). Therefore, grasses are likely to rely heavily on the activity of bacteria antagonistic to fungal pathogens and to benefit from dense bacterial populations protecting their roots. Indeed, in experiments with gnotobiotic systems Pseudomonas spp. reached up to ten times higher densities on the roots of monocots than on those of dicots (Lugtenberg, Dekkers \& Bloemberg 2001). However, whether the expression of genes coding for biocontrol compounds is increased in multi-species plant communities containing grasses remains to be investigated.

We investigated the impact of plant diversity and identity on the expression of genes coding for biocontrol compounds in a root-associated bacterium in a gnotobiotic microcosm experiment. To separate plant diversity and identity effects we set up a full factorial species richness gradient including two grass and two legume species. Plant seedlings were inoculated 
with the representative biocontrol strain Pseudomonas protegens CHAO. Three different GFP reporter fusions were used for measuring the expression of the genes $p h \mid A$, prnA, and $h c n A$, responsible for the production of DAPG, PRN, and HCN, respectively (Baehler et al. 2005; Rochat et al. 2010). Bacterial gene expression was determined via flow cytometry, after three weeks of plant growth. In addition to linear regression analyses, we used structural equation modelling (Grace 2006) to be able to unravel direct and indirect pathways driving the expression of genes coding for bacterial biocontrol compounds.

According to the observations mentioned above, we expected bacterial gene expression to increase with plant diversity. We expected grasses to increase and legumes to decrease the expression of genes coding for biocontrol compounds. Further, we expected plant species to differ in their effects on bacterial gene expression.

\subsubsection{Materials and Methods}

Bacterial strains, plasmids, and culture conditions. By using GFP-based reporter fusions, we integrated bacterial response over the duration of the experiment (de Werra et al. 2008). The expression of DAPG, PRN, and HCN biosynthetic genes has been shown to adequately reflect the production of these biocontrol compounds in P. protegens (Baehler et al. 2005; Rochat et al. 2010). Bacteria and plasmids used in this study are listed in Table 1. All chemicals were purchased from Merck (Darmstadt, Germany), unless noted otherwise. Pseudomonad strain stocks were stored in glycerol at $-80^{\circ} \mathrm{C}$ and pre-grown on Luria Broth (LB) agar plates with the appropriate antibiotics (125 $\mathrm{gg} \mathrm{ml}^{-1}$ tetracycline hydrochloride). Subsequently, bacteria were grown at $22^{\circ} \mathrm{C}$ in $5 \mathrm{ml} 1 / 3$ King's B (KB; BactoTM Protease Peptone No. 3, BD, Le Pont de Claix, France) liquid medium (King, Ward \& Raney 1954; McSpadden Gardener et al. 2001) with agitation for $12 \mathrm{~h}$, harvested by centrifugation ( $4500 \mathrm{~g}, 4^{\circ} \mathrm{C}, 10 \mathrm{~min}$ ) and washed twice in $0.85 \%$ $\mathrm{NaCl}$. We used slowly grown (low temperature) early exponential phase cultures to avoid GFP accumulation in the cells prior to microcosm inoculation (Rochat et al. 2010). $200 \mu \mathrm{l}$ of the overnight culture were grown in $30 \mathrm{ml} \mathrm{KB}$ liquid medium at $25^{\circ} \mathrm{C}$ to an optical density (OD) of 0.1-0.15. Bacterial cells were harvested, washed twice in $0.85 \% \mathrm{NaCl}$ and adjusted to an OD of 0.1 in 1/5 Long Ashton nutrient solution (Hewitt 1966). 
Table 1. Strains and plasmids.

\begin{tabular}{|c|c|c|}
\hline Strain / plasmid & Properties & Reference \\
\hline \multicolumn{3}{|l|}{ Strains } \\
\hline $\begin{array}{l}\text { Pseudomonas } \\
\text { protegens }\end{array}$ & CHAO Wild type, biocontrol strain & Voisard et al. (1994) \\
\hline \multicolumn{3}{|l|}{ Plasmids } \\
\hline pME7100 & $\begin{array}{l}\text { phlA-gfp transcriptional fusion; } \\
\text { reporter for 2,4-diacetylphloroglucinol biosynthetic gene expression; } \mathrm{TC}^{r}\end{array}$ & Baehler et al. (2005) \\
\hline pME7116 & $\begin{array}{l}\text { prnA-gfp transcriptional fusion; } \\
\text { reporter for pyrrolnitrin biosynthetic gene expression; } \mathrm{Tc}^{r}\end{array}$ & Baehler et al. (2005) \\
\hline pME7156 & $\begin{array}{l}\text { hcnA-gfp transcriptional fusion; } \\
\text { reporter for hydrogen cyanide biosynthetic gene expression; } \mathrm{Tc}^{r}\end{array}$ & Rochat et al. (2010) \\
\hline
\end{tabular}

$\mathrm{Tc}^{r}$, tetracycline resistant

Plants. Four plant species, two from each functional group, grasses and legumes, were used. Upscaling the maximum of four plants species per $0.077 \mathrm{~m} \times 0.077 \mathrm{~m}$ equals approximately 60 species per $20 \mathrm{~m} \times 20 \mathrm{~m}$ (according to species area relationships for generalist European grassland species; Krauss et al. 2004), which is the maximum diversity per area in The Jena Experiment (Roscher et al. 2004). Grasses included Lolium perenne L. (Lolium) and Dactylis glomerata L. (Dactylis), and legumes Lotus corniculatus L. (Lotus) and Trifolium repens L. (Trifolium; Appels Wilde Samen GmbH, Darmstadt, Germany). It has been shown that nutrient uptake strategies and other functional traits differ considerably between these species (Roscher et al. 2004).

Grass seeds were incubated in $62 \% \mathrm{H}_{2} \mathrm{SO}_{4}$ on a magnetic stirrer (approximately $250 \mathrm{rpm}$ ) to remove the husks (Lolium: $3.8 \mathrm{~g}$ seeds in $50 \mathrm{ml}$ acid for $35 \mathrm{~min}$; Dactylis: $3 \mathrm{~g}$ seeds in $60 \mathrm{ml}$ acid for $32 \mathrm{~min}$ ), washed in $50 \mathrm{ml}$ distilled water under reduced speed for $15 \mathrm{~min}$ and subsequently sterilized by softly swivelling in $50 \mathrm{ml} 2 \% \mathrm{AgNO}_{3}$ solution on an orbital shaker for $10 \mathrm{~min}$. Silver ions were removed by washing nine times for 10 min alternating sterile distilled water and $1 \%$ $\mathrm{NaCl}$ solution (adapted from Henkes et al. 2008). Legume seeds (2 g each) were shaken in 10 $\mathrm{ml} 70 \%$ ethanol for $2 \mathrm{~min}$, surface sterilized with $10 \mathrm{ml} \mathrm{1 \%} \mathrm{NaClO}$ for $15 \mathrm{~min}$ and washed six times in sterile water by orbital shaking (adapted from Hensel et al. 1990). All seeds were vernalised overnight at $4^{\circ} \mathrm{C}$ and pre-incubated until germination ( $40 \mathrm{~g} \mathrm{liter}^{-1}$ ) on moisturised, $2 \%$ water agar at $25^{\circ} \mathrm{C}$ (grasses up to $30 \mathrm{~h}$; legumes up to $6 \mathrm{~h}$ ). Germinated seeds were stored at $4^{\circ} \mathrm{C}$ until use on the same day. 
Microcosm construction and inoculation. Magenta boxes $(0.077 \times 0.077 \times 0.097 \mathrm{~m})$ were filled with $50 \mathrm{~g}$ of 2-5 mm prewashed expanded clay (FiboExClay Deutschland GmbH, Lamstedt, Germany), watered with $15 \mathrm{ml}$ 1/5 Long Ashton nutrient solution and autoclaved. Plant communities of twelve germinated seeds per microcosm were planted and each seed was inoculated with $50 \mu$ l bacterial suspension.

Experimental setup. We set up a substitutive, full factorial plant species richness gradient ranging from one to four plant species. Two blocks per bacterial treatment (P. protegens inhabiting plasmid pME 7100, pME 7116 and pME 7156, respectively) were set up, each with two replicates per plant species richness level, resulting in four replicates. Additionally, four plant monocultures inoculated with the P. protegens wild-type strain per block served as control (Supplementary Figure 1). The microcosms were incubated at $18-22^{\circ} \mathrm{C}$ with a $12 \mathrm{~h}$ photoperiod (photon flux density: $150 \mu \mathrm{mol} \mathrm{m} \mathrm{m} \mathrm{s}^{-1}$ ) and randomized every 2-3 days over the total experimental time of 20 days.

Sampling. The microcosms were destructively sampled at the end of the experiment. Bacteria were extracted by horizontally shaking total roots in $6 \mathrm{ml}$ of cold phosphate-buffered saline for 30 min (PBS; Sambrook \& Russell 2001) and immediately examined by flow cytometry (see below). Total root biomass (fresh weight) was measured for each microcosm.

Bacterial quantification. Bacterial counts were performed with a C6 flow cytometer (Accuri, Ann Harbor, MI, USA) in $100 \mu \mathrm{l}$ of the root-wash suspension $(25,000$ events in a maximum time of 2 min were recorded; threshold on FSC-H 5,000; threshold on SSC-H 2,000). By gating on the basis of log-scaled fluorescence signals (FL1-A x FL2-A), we measured the density of active bacteria (counted events) and bacterial per capita gene activity (emitted fluorescence per bacterium). In addition to the measured variables, we calculated total bacterial activity as related to the plant communities, but irrespective of the bacterial treatment ( $P$. protegens CHAO with either phIA, prnA, or hcnA gene reporter fusions) by normalizing the measures of the different reporter fusions (from each bacterial per capita gene activity measure we subtracted its mean and divided this by its variance).

Statistical analyses. Data were analysed using the statistical software R (R Core Team 2014) with 
the packages nlme (Pinheiro et al. 2014) and lavaan (Rosseel 2012). To test whether the block had an effect on investigated variables, we used linear models with each measure as explained by plant diversity (continuous) and block (factorial). To measure plant identity effects independent of diversity, we used a sequential statistical approach (Bell et al. 2009). In a first step, we used linear mixed effect models with block as a random effect for analysing the effect of plant diversity on bacterial density $\left[\log _{10}\left(\right.\right.$ active bacteria root $\left.\left.^{-1}\right)\right]$, total bacterial activity $\left[\log _{10}\right.$ (total gene expression $\left.\left.g_{\text {root }}{ }^{-1}\right)\right]$, and $h c n A$ gene activity $\left[\log _{10}\right.$ (gene expression bacterium $\left.\left.{ }^{-1}\right)\right]$. Due to estimated Pearson's product moment correlations between root biomass and bacterial density (cor $=0.33 ; \mathrm{P}<0.001$ ), as well as root biomass and bacterial activity (cor $=0.31 ; \mathrm{P}<$ 0.001), bacterial density and activity were normalized by root biomass. As the block had no effect on gene expression of phIA and prnA [ $\log _{10}$ (gene expression bacterium $\left.\left.{ }^{-1}\right)\right]$, these variables were fitted using linear models. In a second step, the residuals of the first step in the analyses were fitted against the explanatory variables Lolium, Dactylis, Lotus, and Trifolium (presence/absence coded; factorial) using linear models. In a third step, the residuals of the second step were fitted against plant interaction effects. The significance of slopes was determined via t-tests.

To separate plant community effects via root biomass and bacterial density from other mechanisms, we used structural equation modelling, which allows the analysis of variables in a multivariate approach (Grace 2006). We used plant identities (exogenous variables), as well as the explanatory variables root biomass and bacterial density (endogenous variables), as potential indirect pathways affecting bacterial gene activities. Models were performed with the respective residuals of linear models including the explanatory variables as influenced by block. After fitting the full model, the most parsimonious model was derived by removing nonsignificant pathways using Bayesian information criterion (BIC; Burnham \& Anderson 2004) as well as $\chi^{2}$ tests ( $P>0.05$; Grace 2006).

\subsubsection{Results}

Sequential analysis. The density of active bacteria (bacterial density), as well as total bacterial gene expression (bacterial activity), increased with plant diversity (Figure 2 a, b; Table 2); however, the per capita gene expression was not significantly affected by plant diversity (Figure 
2 c-e). The presence of the grass Lolium significantly increased the density of active bacteria, total bacterial gene expression and per capita gene expression of all tested genes (Figure $2 \mathrm{f}-\mathrm{j}$; Table 2). On the other hand, the presence of the grass Dactylis significantly decreased bacterial density, total bacterial gene expression and per capita expression of phIA and prnA and marginally affected the expression of hcnA (Figure $2 \mathrm{f}$-j; Table 2). Fitting Lolium before diversity in the sequential analyses eliminated the marginally significant plant diversity effect on active bacterial density (slope $-0.01, P=0.303$ ) as well as its significant effect on bacterial gene expression (slope-0.03, $\mathrm{P}=0.278$ ), suggesting that the observed plant diversity effects were due to the presence of Lolium and the increased probability of including this species in more diverse communities. The legume Trifolium significantly decreased the density of active bacteria, total bacterial gene expression and per capita expression of all tested genes (Figure 2 $\mathrm{f}$-j; Table 2). The legume Lotus significantly decreased active bacterial density and marginally impacted total bacterial gene expression (Figure $2 \mathrm{f}-\mathrm{g}$; Table 2). As indicated by the third step of the sequential analyses, plant-plant interactions did not significantly affect bacterial gene expression (all $\mathrm{P}>0.1$ ). 

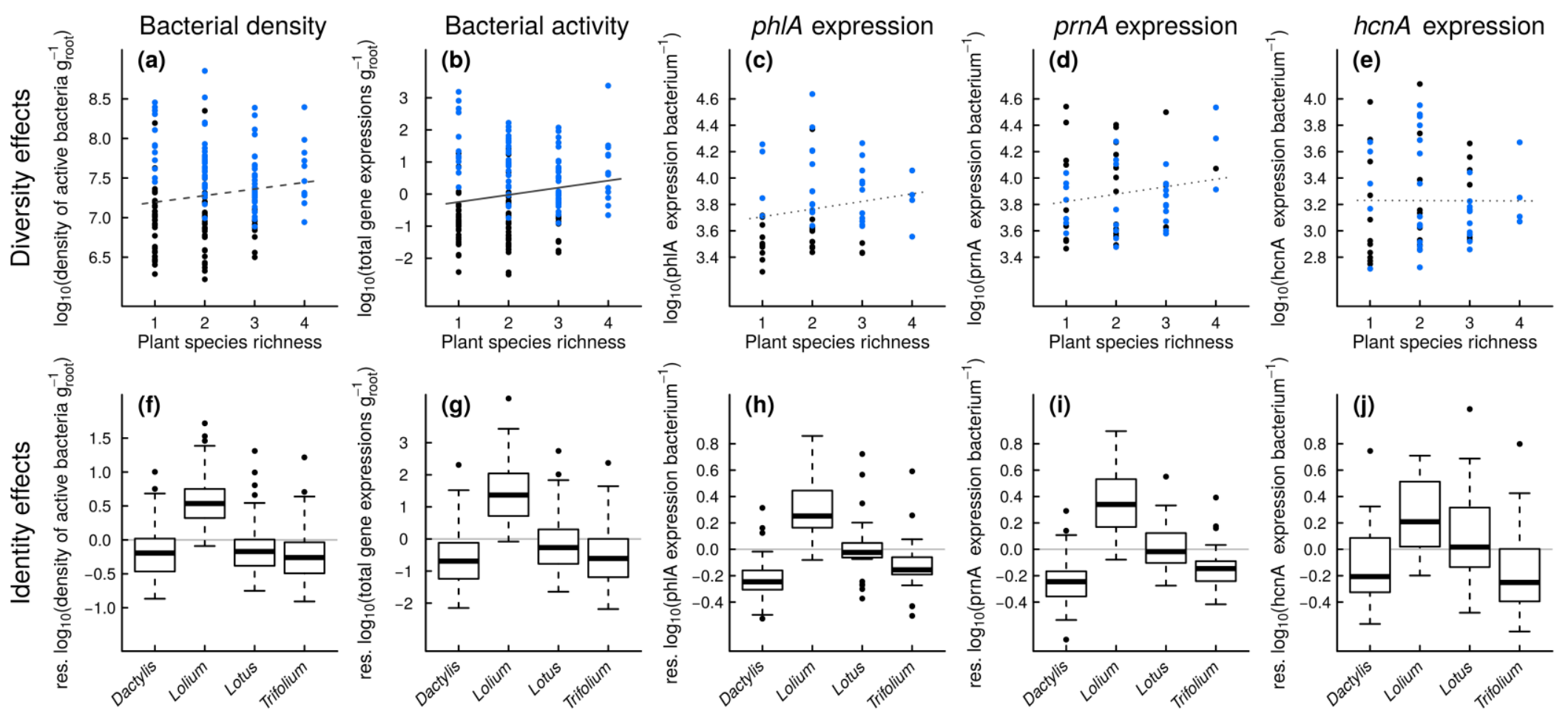

Figure 2. Effect of plant species richness on $\log _{10}$-transformed (a) density of active bacteria per root biomass, (b) total bacterial gene expression per root biomass, (c) ph/A expression per bacterium, (d) prnA expression per bacterium, and (e) hcnA expression per bacterium (upper panel), and the effect of plant identity on log10-transformed (f) density of active bacteria per root biomass, (g) total bacterial gene expression per root biomass, (h) phlA expression per bacterium, (i) prnA expression per bacterium, and (j) hcnA expression per bacterium [lower panel; analysis based on partial residuals (res.) after fitting of species richness]. Solid regression line: $\mathrm{P} \leq 0.05$; dashed regression line: $\mathrm{P}$ $\leq 0.1$; dotted regression line: not significant. Blue dots represent microcosms containing Lolium. 
Table 2. Effects of plant community composition on biocontrol bacteria (Pseudomonas protegens) as indicated by sequential analyses (see text for details).

\begin{tabular}{|c|c|c|c|c|c|c|c|c|c|c|c|c|c|c|c|}
\hline & \multicolumn{3}{|c|}{ Bacterial density } & \multicolumn{3}{|c|}{ Bacterial activity } & \multicolumn{3}{|c|}{ phlA expression } & \multicolumn{3}{|c|}{ prnA expression } & \multicolumn{3}{|c|}{ honA expression } \\
\hline $\begin{array}{l}\text { 1. step } \\
\text { Intercept }\end{array}$ & $\begin{array}{r}\text { Estimate } \\
7.112\end{array}$ & $\begin{array}{l}\text { S.E. } \\
0.22\end{array}$ & $\begin{array}{l}\mathrm{t} \text {-value } \\
31.83 * * *\end{array}$ & $\begin{array}{r}\text { Estimate } \\
-0.467\end{array}$ & $\begin{array}{l}\text { S.E. } \\
0.34\end{array}$ & $\begin{array}{r}\mathrm{t} \text {-value } \\
-1.39\end{array}$ & $\begin{array}{r}\text { Estimate } \\
3.649\end{array}$ & $\begin{array}{l}\text { S.E. } \\
0.10\end{array}$ & $\begin{array}{l}\mathrm{t} \text {-value } \\
36.08 * * *\end{array}$ & $\begin{array}{r}\text { Estimate } \\
3.765\end{array}$ & $\begin{array}{l}\text { S.E. } \\
0.10\end{array}$ & $\begin{array}{l}\mathrm{t} \text {-value } \\
36.07 * * *\end{array}$ & $\begin{array}{r}\text { Estimate } \\
3.231\end{array}$ & $\begin{array}{l}\text { S.E. } \\
0.24\end{array}$ & $\begin{array}{l}\text { t-value } \\
13.74 * * *\end{array}$ \\
\hline $\begin{array}{l}\text { Plant } \\
\text { diversity }\end{array}$ & 0.083 & 0.04 & 1.86 . & 0.222 & 0.10 & $2.16 *$ & 0.058 & 0.04 & 1.32 & 0.056 & 0.05 & 1.23 & -0.001 & 0.05 & -0.02 \\
\hline $\mathrm{DF} / \mathrm{R}^{2}$ & $167 /-$ & & & $167 /-$ & & & $56 / 0.03$ & & & $53 / 0.03$ & & & $58 /-$ & & \\
\hline $\begin{array}{l}\text { 2. step } \\
\text { Lolium }\end{array}$ & 0.582 & 0.05 & $11.62 * * *$ & 1.430 & 0.11 & $13.38 * * *$ & 0.305 & 0.05 & $6.26 * * *$ & 0.367 & 0.05 & $7.65 * * *$ & 0.245 & 0.07 & $3.41 * *$ \\
\hline Dactylis & -0.195 & 0.05 & $-3.91 * * *$ & -0.640 & 0.11 & $-6.02 * * *$ & -0.211 & 0.05 & $-4.37 * * *$ & -0.238 & 0.05 & $-5.05 * * *$ & -0.140 & 0.07 & -1.94 \\
\hline Trifolium & -0.239 & 0.05 & $-4.82 * * *$ & -0.573 & 0.11 & $-5.41 * * *$ & -0.118 & 0.05 & $-2.44 *$ & -0.135 & 0.05 & $-2.89 * *$ & -0.179 & 0.07 & $-2.48 *$ \\
\hline Lotus & -0.144 & 0.05 & $-2.86 * *$ & -0.204 & 0.11 & -1.89 & 0.013 & 0.05 & 0.26 & 0.022 & 0.05 & 0.46 & 0.083 & 0.07 & 1.15 \\
\hline$D F / R^{2}$ & $170 / 0.46$ & & & $170 / 0.54$ & & & $54 / 0.48$ & & & $51 / 0.58$ & & & $57 / 0.25$ & & \\
\hline
\end{tabular}

The tables were generated with the R-function summary(), showing the probability of a variable to be zero (two-tailed t-test). Asterisks denote the level of significance: $\mathrm{P} \leq$ $0.1 ; * \leq 0.05 ; * * \leq 0.01 ; * * * P \leq 0.001$. DF, degrees of freedom; $\mathrm{R}^{2}$, coefficient of determination. 
Structural equation models. The structural equation model explained $49 \%$ of the variance in phIA gene expression. The initial model $(B I C=816.26$; Figure 3 a) could be improved by removing non-significant paths $(\mathrm{BIC}=797.37$; Figure $3 \mathrm{~b})$. The chi-square test indicated that our model adequately represents the data $\left(\chi^{2}{ }_{6}=5.48 ; P=0.484\right)$. Expression of ph/A was directly increased by the presence of Lolium and decreased by the presence of Dactylis, while it was not significantly influenced by bacterial density. Bacterial density increased in presence of Lolium, but was negatively affected by the presence of Trifolium. Root biomass increased significantly in the presence of Lolium and Lotus, respectively, and decreased in the presence of Trifolium (Figure 3 b; Supplementary Table 1).

The structural equation model explained $77 \%$ of the variance in prnA gene expression. The initial model $(\mathrm{BIC}=731.03$; Figure 3 a) could be improved by removing non-significant paths $(B I C=709.51 ;$ Figure $3 \mathrm{c})$. The chi-square test indicated that our model adequately represents the data $\left(\chi^{2} 7=6.53 ; P=0.480\right)$. In the final model, expression of prnA was directly increased by the presence of Lolium and Lotus, but decreased in the presence of Dactylis. In addition, it significantly increased with the density of active bacteria. Active bacterial density was positively related to the presence of Lolium and was significantly driven by root biomass. Root biomass increased in the presence of Lolium and decreased in the presence of Trifolium (Figure 3 c; Supplementary Table 1).

The structural equation model explained $62 \%$ of the variance in $h c n A$ gene expression. The initial model $(\mathrm{BIC}=899.24$; Figure 3 a) could be improved by removing non-significant paths $(B I C=777.14 ;$ Figure $3 \mathrm{~d})$. The chi-square test indicated that our model adequately represents the data $\left(\chi^{2}{ }_{4}=3.02 ; P=0.554\right)$. In contrast to the expression of $p h / A$ and $p r n A$, hcnA expression was only affected by the presence of Lolium, but here the grass decreased gene expression. As in the case of $p r n A$, the expression of honA significantly increased with the density of active bacteria. Active bacterial density increased in the presence of Lolium and decreased in the presence of Trifolium. As in the case of $p h / A$, root biomass significantly increased in the presence of Lolium and Lotus, and decreased in the presence of Trifolium. As Dactylis presence played no appreciable role, it was removed from the model (Figure $3 \mathrm{~d}$; Supplementary Table 1). 

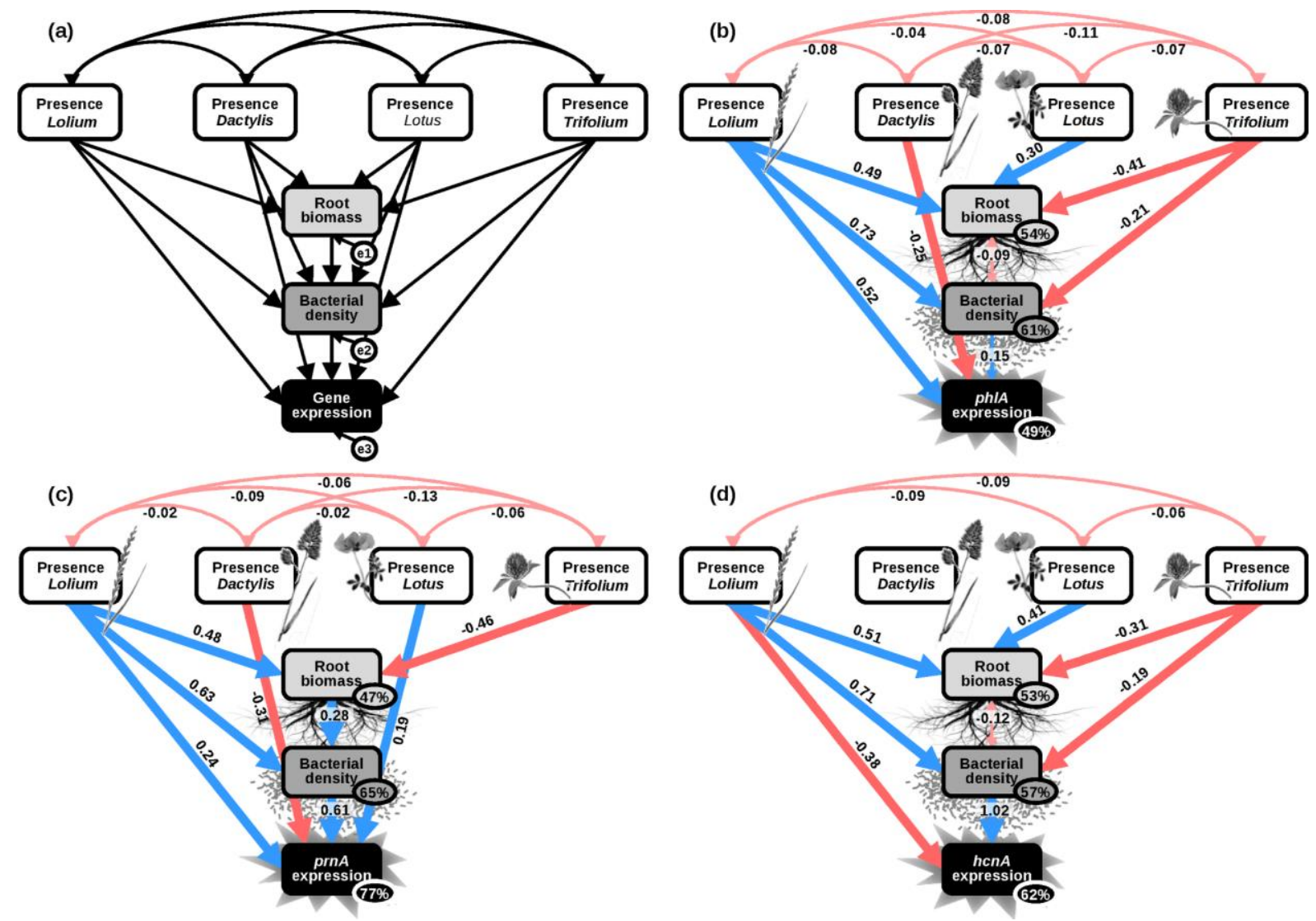

Figure 3. Structural equation models (see (a) for initial model) of direct and indirect (through changes in root biomass and bacterial density) effects of plant identity on (b) phlA expression, (c) prnA expression, and (d) $h c n A$ expression. Exogenous variables (plant identity) are given in white boxes, endogenous, explanatory variables in grey and black boxes. The data did not significantly deviate from the respective models (see main text for model fits). Normal arrows represent causal relationships, and double-headed arrows indicate undirected correlations. Numbers on arrows are standardized path coefficients. Blue arrows indicate positive and red negative estimates; bold arrows indicate significant $(P \leq 0.05)$ and thin arrows non-significant $(P>0.05)$ estimates. Circles in $(a)$ indicate error terms $(\mathrm{e} 1-\mathrm{e} 3)$. Percentages close to endogenous variables indicate the variance explained by the model (R2).

\subsection{5 | Discussion}

Plants rely on their associations with soil microbes, and positive plant-soil microbe interactions are suggested to be more pronounced in species-rich plant communities (Schnitzer et al. 2011; Latz et al. 2012; Eisenhauer et al. 2012). On the other hand, root-associated microbial composition and functioning in diverse plant communities is suggested to be driven by specific plant species within a community (Kowalchuk et al. 2002; Eisenhauer et al. 2010a; de Deyn et al. 2011). Unfortunately, however, the mechanisms involved in the association and facilitation of root-associated bacteria with a specific function like plant growth promotion are virtually unknown in species-rich plant communities. We demonstrate that grassland plant species 
selectively impact the expression of genes coding for biocontrol compounds in $P$. protegens $\mathrm{CHAO}$, and that this effect persists in more diverse plant communities, highlighting the importance of plant species identity for soil microbial functioning. Especially Lolium perenne played a key role by significantly influencing each of the three measured genes coding for important biocontrol compounds. We suggest that the presence of specific plant species within a community may be essential for sustainable and environmentally friendly plant protection, which is one of the today's biggest issues in agricultural management.

Effect of plant diversity. The results showed that increasing plant diversity not only enhanced the density of active bacteria, but further enhanced the expression of genes coding for biocontrol compounds protecting plants from fungal pathogens. This supports reports of higher suppressive abilities against a soil-borne fungal pathogen in species-rich grasslands than in crop monocultures (Garbeva et al. 2006). Interestingly, effects of plant diversity were not pronounced when considering the bacterial genes separately, possibly because of the reduced sample size. However, the results may also indicate that more diverse plant communities are able to support higher activities of multiple genes respectively higher ecosystem multifunctionality (Hector \& Bagchi 2007; Isbell et al. 2011). Nonetheless, the observed diversity effect likely was due mainly to a sampling effect; that is, the greater chance of a species (Lolium) with a disproportionate effect on ecosystem function properties being present at higher diversity levels (Huston 1997). Supporting this conclusion, the diversity effect disappeared when fitting the presence of Lolium before plant diversity, but remained when separately fitting the other species before plant diversity in the sequential analyses. Therefore, this study does not support a general positive effect of plant diversity on gene expression of biocontrol bacteria due to plant-plant interactions. However, it has been suggested that diversity effects are more pronounced in the long-term (Eisenhauer et al. 2012); whether this also applies to bacterial gene expression patterns remains to be investigated.

Effects of plant identity. Generally, our results highlight the importance of plant species identity in eliciting bacterial gene expression. This is in line with studies where soil microbial functioning was attributed to the role of single plant species (Stephan et al. 2000; Eisenhauer et al. 2010a; de Deyn et al. 2011).

The grass Lolium exerted the strongest positive effect, increasing the density of active bacteria 
as well as the total and per capita expression of the three investigated genes as seen in the sequential analyses. Interestingly, although the number of Lolium individuals decreased with increasing plant diversity due to the substitutive design, the positive effect of Lolium remained throughout the diversity gradient. The effect, however, was dampened at higher plant diversity, but it remains unclear to what extend this was driven by the presence of the other species or by a lower number of Lolium individuals.

Structural equation models showed that Lolium increased root biomass as well as the density of active bacteria in each of the models. Notably, in contrast to the other two genes, hcnA was additionally directly negatively affected by Lolium, probably explaining its less pronounced positive effect in the sequential analyses.

In contrast to the overall strong positive effect of Lolium, the presence of the grass Dactylis decreased the density of active bacteria and total gene expression. The observed decrease in the per capita expression of phIA and prnA in the sequential analysis was reflected in the structural equation models, where Dactylis presence directly decreased phIA and prnA expression, but not that of hcnA. The contrasting effects of the two grass species are in line with results from experimental grasslands (Latz et al. 2012), where the presence of grasses in plant communities positively affected PRN producers, but this effect vanished with increasing grass species richness, suggesting that only specific species were responsible for the observed effect.

In the structural equation model, the expression of hcnA was not directly increased by any plant species and down-regulated in the presence of Lolium. It was previously shown that plants upregulate the production of biocontrol compounds in bacteria in the presence of pathogens (Barret et al. 2009; Jousset et al. 2011). Due to the potential phytotoxic side effects of biocontrol compounds, such as DAPG and HCN (Rudrappa et al. 2008; Brazelton et al. 2008), susceptible plants may only benefit from enhancing their production in the presence of pathogens and may therefore suppress their production when pathogens are absent. Future studies are needed to understand how the observed plant community-induced bacterial gene expression patterns are affected by the presence of pathogens or other soil organisms.

The two legume species also had contrasting effects on biocontrol gene expression. In the sequential analyses, the presence of Trifolium decreased all tested parameters, whereas Lotus did not affect the per capita gene expression by the bacteria. In the structural equation models, the presence of Lotus increased root biomass in the models on phIA and hcnA gene expression. 
It remains unclear why Lotus did not significantly influence root biomass in the model on prnA expression, where root biomass directly positively influenced gene expression. The effect of Trifolium was mainly driven by its negative effect on root biomass, in addition to a less pronounced negative effect on the density of active bacteria in the case of the phIA and hcnA model. Interestingly, Trifolium was the only plant species that did not directly affect the expression of any of the studied genes, and future studies should investigate the dependence of this legume species on biocontrol bacteria.

The overall negative effect of legumes on both the density of active bacteria and per capita gene expression matches well with observed decreases in the abundance of DAPG and PRN producers in the presence of legumes in grassland plant communities (Latz et al. 2012). These authors speculated that their results may be due to the production of biocontrol compounds by the plant, such as saponins and coumarin, providing plant-derived defence against root diseases and inhibiting DAPG producers, respectively (Djordjevic et al. 1987; Landa et al. 2002; Bergsma-Vlami, Prins \& Raaijmakers 2005a). Consequently, the general positive effects of legumes on plant community productivity due to $\mathrm{N}$ fixation may be counterbalanced to some extent by a reduction of soil suppressiveness.

Effect of root biomass. In the structural equation models, root biomass increased the density of active bacteria in the case of prnA. Interestingly, in this case, root biomass did not increase in the presence of Lotus. This in turn suggests that an enhanced proportion of Lotus roots that occurred in the models on phIA and honA expression negatively affected the density of active bacteria. This may explain the observed negative effect of the legume on bacterial densities in the sequential analyses (see above). The results support the conclusion that root biomass is an important determinant of the density of active bacteria (Spehn et al. 2000), but they furthermore suggest that the strength and direction of effects depend on the presence of certain plant species.

Effect of active bacterial density. As bacterial gene expression is driven by cell population density-dependent patterns (Lapouge et al. 2008), it is not surprising that the density of active bacteria strongly increased the per capita expression of prnA and honA in the structural equation models. Interestingly, although an auto-inducing function is known for DAPG (Schnider-Keel et al. 2000; Baehler et al. 2005), the density of active bacteria did not increase 
the per capita expression of phIA in our study. Auto-induction of DAPG can be counteracted by bacterial and fungal metabolites (Schnider-Keel et al. 2000), and our results suggest that unknown plant metabolites may also be involved in modifying the expression of biocontrol compounds in bacteria.

Conclusion. This study emphasizes the importance of plant identity for the expression of genes coding for biocontrol compounds in bacteria associated with multi-species plant communities. Expression patterns varied between genes, but some plant species, such as Lolium consistently impacted the expression of biocontrol traits. The results suggest that plants can steer specific microbial activities in the rhizosphere with important consequences for plant health. Similar to legumes improving plant productivity via symbiosis with nitrogen-fixing bacteria, we propose that certain plant species may contribute to community productivity by stimulating biocontrol gene expression in root-associated bacteria. Increased plant biomass production in more diverse communities might therefore in part be due to reduced pathogen load caused by the presence of certain plant species. Further studies are needed to evaluate the magnitude of the effect of single plant species in dampening pathogen pressure on plant communities. We conclude that management systems might benefit from taking the biocontrol-enhancing capabilities of certain plant species within a community into account.

\subsubsection{Acknowledgements}

We thank Joachim Becker, Susanne Böning-Klein and Guido Humpert for their support in conducting the experiment, and Robert Koller for the stimulating discussions. Further, we thank George Kowalchuk and the anonymous referees for constructive comments on the manuscript. Special thanks to Simone Weidner and Björn Rall for their support during the whole working process. This study was funded by the German Science Foundation (JO 935/2-1). Support came from the German Centre for Integrative Biodiversity Research (iDiv) Jena-Halle-Leipzig, funded by the German Science Foundation (FZT 118). 

2.2 Research Chapter 2

ASSESSING PLANT PATHOGEN INFECTION RATES IN NATURAL SOILS: USING bbmle AND deSolve

Björn Christian Rall \& Ellen Latz 


\subsubsection{Summary}

Pathogen infection assays are a standard method for estimating plant resistance to a specific pathogen. In natural soils, however, alternative pathogens might also simultaneously infect plants of the experiment hindering the estimation of the focal pathogen's infection rate. Here we present a method in $\mathrm{R}$ correcting for these unwanted effects by developing a two pathogen monomolecular infection model. We fit the model to data using an integrative approach by combining a numerical simulation of the two pathogen monomolecular infection model and an iterative maximum likelihood fit. Our method will be particularly useful for exploring resistance of natural soils (e.g., biodiversity experiments) from different sites because it allows for different naturally occurring pathogens while estimating comparable infection parameters. 


\subsubsection{Introduction}

Pathogen infection assays (bioassays) are a standard method for estimating plant resistance to pathogens, induced systemic resistance in plants, the effect of artificial or natural plant protectants (e.g., plant beneficial bacteria), and the suppressive potential of soils. Generally, bioassays are performed using just a single point in time (Maurhofer et al. 1994; Pierson \& Weller 1994; Postma et al. 2008) or multiple points in time (Postma et al. 2008; Hanse et al. 2011; Latz et al. 2012). In the latter case, often only one single point in time is chosen for evaluation (e.g., Postma et al. 2008; Hanse et al. 2011; Latz et al. 2012), or the increase from one to the next point in time is evaluated (Kushalappa \& Ludwig 1982). However, disease progression is more precisely described by classical growth curve models (Neher \& Campbell 1992). Out of the plethora of growth models (Paine et al. 2012), the monomolecular model has often been used to describe bioassays with soil-borne pathogens (Stanghellini et al. 2004; Wilson et al. 2008). The monomolecular infection model describes the disease progression (the change of infections over time) with an initial linear increase of infections (the infection rate), followed by a saturation (given by the maximum number of infectable plants, also known as carrying capacity or asymptotic growth).

(a)

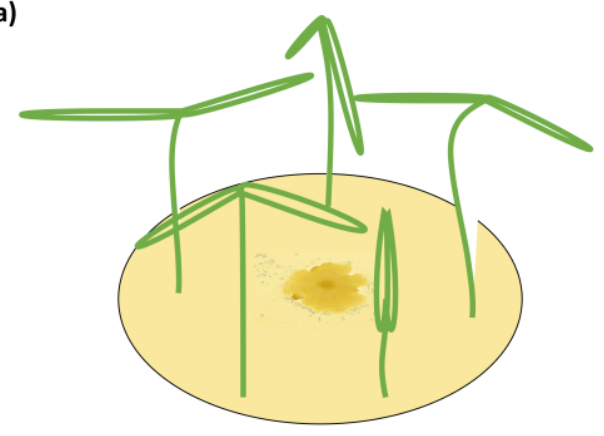

(b)

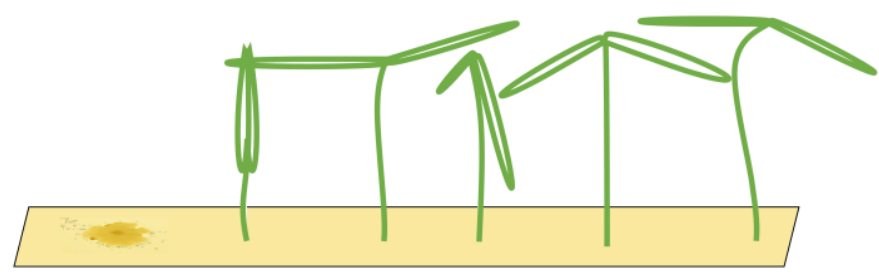

Figure 4. Two different possible setups for infection treatments. The circular setup with a centered pathogen surrounded by plants (a) may lead to a steep linear infection scenario as all plants are probably infected by the source pathogen at more or less the same time. Only the linear spatial assembly (b) allows for a consecutive infection of plants resulting in a linear increase that can be modelled by the monomolecular infection model.

The infection rate seems to be the most important parameter for determining pathogenicity (Raaijmakers et al. 2009). However, when estimating the suppressive potential of soils, the time 
until infections occur (resistance time) might be even more important since pathogen inhibition occurs largely during pathogen growth. Actually, only a few experimental setups allow the investigation of both, infection rate and resistance time. To measure an infection rate it is necessary to use a system with multiple plant individuals (Figure 4) where plants can be infected one after another (i.e. measuring a time-series). In such experiments, the pathogen inoculant can be applied in different ways: (i) equally distributed application, i.e. homogeneously mixed in the soil or growth-substrate, or (ii) single point application (where pathogen spread can be assessed; Figure 4). If a pathogen is homogeneously distributed in the plant growth substrate, it is possible to measure the number of infected plants over time. The measured infection rate, however, would not represent the infection rate per se but rather the resistance variance of the plant community to the pathogen. The same problem occurs if a pathogen is applied to one location in the substrate and plants are planted at equal distances around the inoculum (Figure 4 a). Linear spatial designs (Figure 4 b) have the potential to estimate the correct infection rate in addition to the resistance time, whereas the further mentioned approaches solely allow to estimate the resistance time. Hence, it is important to keep in mind that the design determines the hypothesis that can be tested.

Another difficulty in performing pathogen infection assays occurs if natural field soils are used as substrate (e.g., Mendes et al. 2011; Latz et al. 2012). Here, in addition to the applied pathogen, other unknown pathogens may already exist in the soil and may increase infection in the plants. To cope with this problem, control treatments may be used to reveal the occurrence of natural soil inhabiting pathogens. If controls show infections, (i) these infections might be ignored if they are evaluated as statistically not relevant, (ii) the treatments where the corresponding controls showed infections could be excluded from further analyses, (iii) the treatments may be linearly corrected by simply subtracting the total amount of infectable plants by the infections that occurred in the control, which may lead to erroneous results in non-linear analyses as shown for functional response models (McCoy, Stier \& Osenberg 2012). None of these approaches are desirable as they may lead to a bias in single infection rate measures (due to ignoring or wrongly correcting infections of a naturally occurring pathogen) and the loss of data (exclusion of treatments where the corresponding control was infected). Here, we present an alternative approach that incorporates infections caused by any additional pathogens in the system by using a two-pathogen monomolecular infection model inspired by the competition model for logistic growth (Lotka 1925; Volterra 1926). This two pathogen 
monomolecular model is an ordinary differential equation system with two equations. Systems with two equations are hardly analytically integrable to a single equation describing the progress of infections over time, therewith preventing the use of standard non-linear fitting functions in $\mathrm{R}$, (e.g., $\mathrm{nls}$ ( ) ). To overcome this limitation, we applied a numerical integration routine (Soetaert, Petzoldt \& Setzer 2010) combined with a maximum likelihood optimizer (Bolker \& R Development Core Team 2014) to fit our model to data.

Our method allows for the use of natural soils (i) already contaminated with naturally occurring pathogens, and (ii) from different origins and habitats, while allowing for accurate evaluation of pathogenicity and plant resistance patterns in the field.

\subsubsection{The Model}

The monomolecular infection model (Raaijmakers et al. 2009; Paine et al. 2012) describes the increase of infections in a (plant) community over time, $d l d t^{-1}$, by:

$\frac{d I}{d t}=r\left(I_{\max }-I\right)$

Equation 1

with $r$ [time ${ }^{-1}$ ] being the infection rate and $I_{\max }\left[\right.$ Infected (Plants) Area $\left.{ }^{-1}\right]$ being the maximum number of potentially infectable plants. The infection of the first plant is not necessarily instantaneous, but depends on the resistance of the soil and the plants to the pathogen, leading to a lag phase at the beginning of the experiment. To account for this mechanism, we extend the monotonic infection model by the time to the first infection, to:

$\frac{d I}{d t}=\left\{\begin{aligned} 0, & t<t_{0} \\ r\left(I_{\max }-I\right), & t \geq t_{0}\end{aligned}\right.$

Equation 2

Below to new infections are zero whilst above the occurrence of new infections follows the monomolecular infection model. In experiments using natural soils, alternative pathogens may be responsible for infections in the bioassay. To correct for these "wrong" infections, we extend the monomolecular model, inspired by the two-species competition growth model (Lotka 1925; Volterra 1926), to a two-species monomolecular infection model: 
$\frac{d I_{p}}{d t}=\left\{\begin{aligned} 0, & t<t_{0, p} \\ r_{p}\left(I_{\text {max }}-\left(I_{p}+I_{c}\right)\right), & t \geq t_{0, p} \\ 0, & t<t_{0, c}\end{aligned}\right.$
$\frac{d I_{c}}{d t}=\left\{\begin{aligned} r_{c}\left(I_{\text {max }}-\left(I_{p}+I_{c}\right)\right), & t \geq t_{0, c}\end{aligned}\right.$

Equation 3a

Equation $3 b$

where $I_{p}$ is the number of infected plants due to the pathogen, $I_{c}$ are the number of infected plants in the control; $r_{p}$ and $r_{c}$ are the infection rates of the pathogen and the control treatment, respectively; and $t_{0, p}$ and $t_{0, c}$ are the resistance time of the pathogen and the control treatment, respectively.

\subsubsection{Application}

Before starting the analyses, the packages deSolve (Soetaert et al. 2010) and bbmle (Bolker \& R Development Core Team 2014) must be loaded using library () or require (); the source files (infection.models.r and infection.nll.r) must be loaded using source ( ) .

Parameter estimation. First, the control treatment (Figure 5 a) must be fitted using the monomolecular model including a lag phase (Eqn. 2) using the mle2 () function for general maximum likelihood fits from the package bbmle (Bolker \& R Development Core Team 2014). The mle2() is used to minimize the negative likelihood function mon. inf.lag.1p.nll () from the infection.nll.r source file (see Bolker 2014 for detailed information on using the mle2 () function). We need to supply the arguments start, containing a list of $r$ and to (the start values of the optimization process); data, a list with the headers $\mathrm{nI}$ (the number of infected plants in the experiment), tps (the timepoints from the experiment), and Imax (if the number of total plants differs between experimental units); fixed, a list containing the headers steps (the length of a time step that should be simulated by the integration routine; this is set to 0.1 as default and does not have to be supplied), Imax, (a single value for the maximum of potentially infectable plants in the experiment, only needed if not supplied as data), and tracing (if set to 1 , the trace including the negative likelihood and the parameters is displayed in the console, useful for error checking, default to 0): 


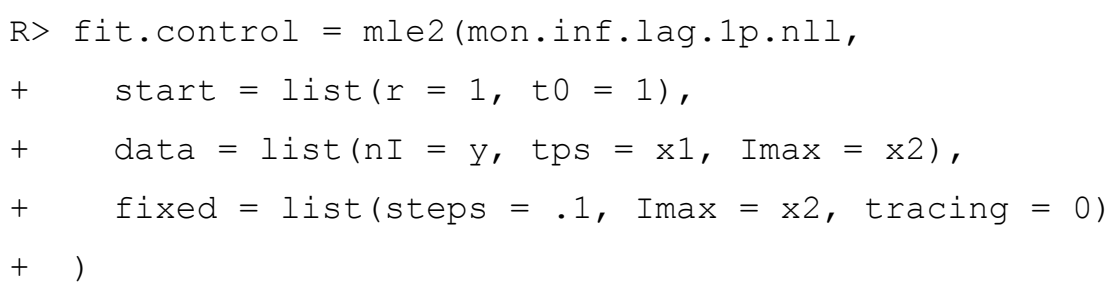

Note that the initial values are just placeholders and might be adapted, but see section Examples for details. Imax must only appear once, either in the data list or in the fixed list in dependence if Imax is only a fixed single value or a set of data of the same length as $y$ and $\mathrm{x} 1$.

Second, after estimating the infection parameters $r$ and t 0 for the control, the two-pathogen monomolecular infection model can be fitted to the data with the experimentally added pathogen (Eqn. 3). Again we use the mle2() function, but now using the mon.inf.lag.2p.nll() function to be minimized. The estimates of the control treatment are assigned to $\mathrm{rc}_{\mathrm{c}}$ and $\mathrm{t} 0 \mathrm{c}$ in the fixed argument list. The target infection parameters are still placed in the start argument but now called $\mathrm{rp}$ and top:

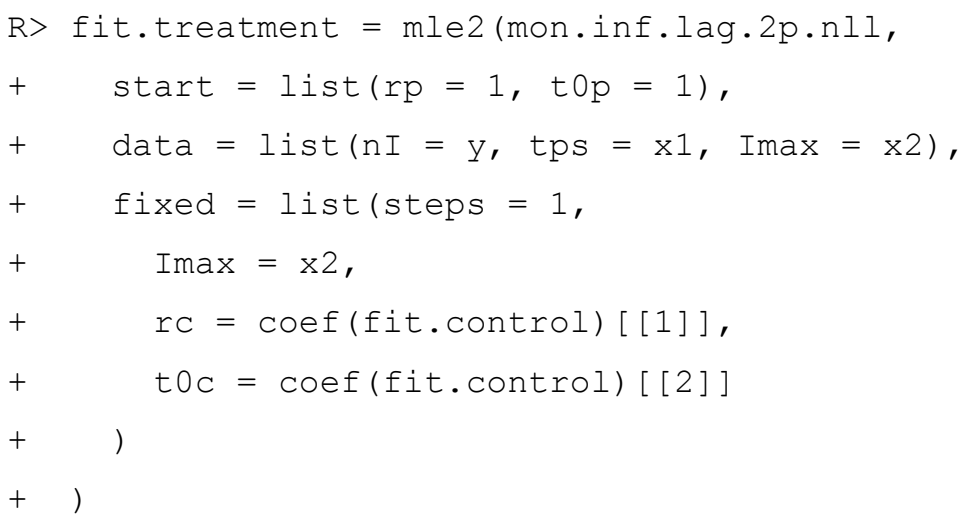

One can investigate the fitting results and statistics using the generic summary ( ) function applied on the object containing fitting results (here: fit. control \& fit.treatment).

\subsubsection{Examples}

$R$ code and data files are provided as supplementary information on $C D$; how to use the $R$ code 
is discussed below.

The files infection.frontend1.r and infection.frontend2.r are the front-end files containing the adaptable examples we will discuss below. These files load the source files, infection.models.r and infection.nll.r, containing all underlying functions. We begin with a detailed description of the front-end files which should be sufficient to apply our fitting method to data. Moreover, we kindly invite you to continue reading the descriptions of the source files later in section Underlying Functions.

Please extract all required files from the zip-folder into one folder and keep the provided folder structure. If you prefer different organization of data and files you have to adapt the paths described below in the code.

Before getting started, use e.g. install.packages () to install the required packages deSolve (Soetaert et al. 2010) and bbmle (Bolker \& R Development Core Team 2014), but see introductory R books and manuals for details (Bolker 2008; Crawley 2012). We first discuss the case of a constant number of plants in the experimental units (infection.frontend1.r).

Required packages and data. First, the required packages, the source files and the data must be loaded:

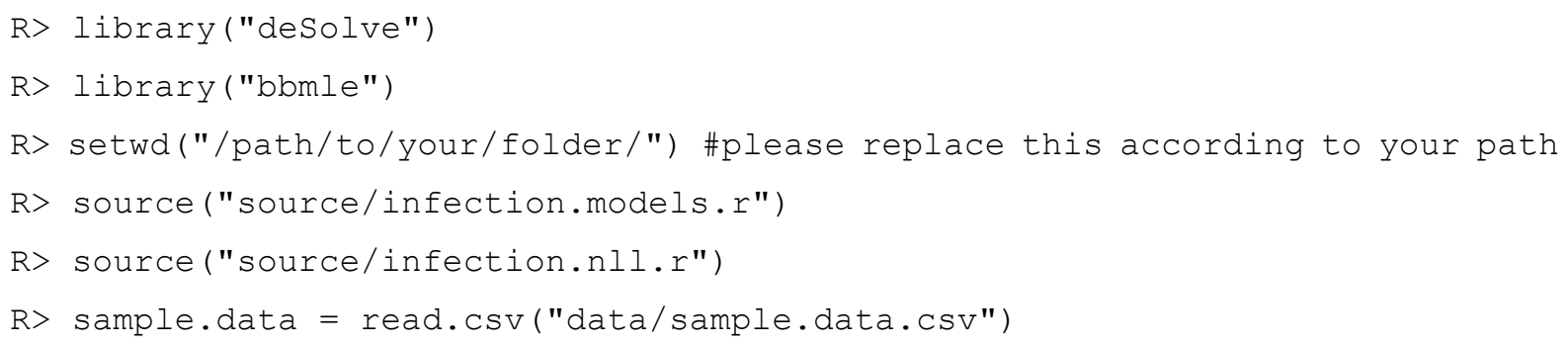

To investigate the data structure we use the generic str () function:

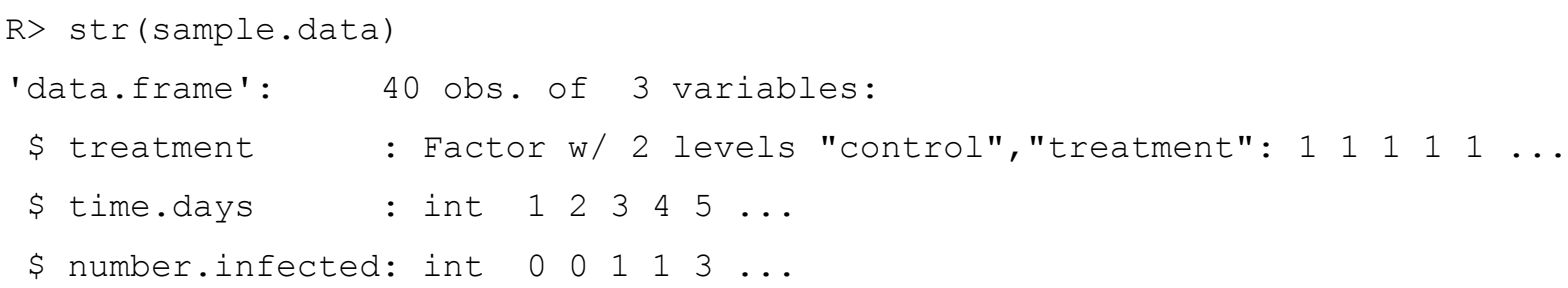

The data comprises three variables, (1) the factorial variable treatment determining if the data 
belongs to the control or the experimental treatment. The variable time. days contains the time of the measurement in days (you can switch the temporal resolution, the unit here determines the unit of the infection rate), and the variable number. infected contains the information of how many plants are infected (note that this must be an integer as we apply a binomial distribution later on; but see [Crawley 2012] and [Bolker 2008] for a detailed description on this topic). The data represents single experimental units (independent replicates, each data point represents the last measurement of a time series). Before continuing, we separate the data into two sub data sets containing just the control or just the treatment data using the subset function.

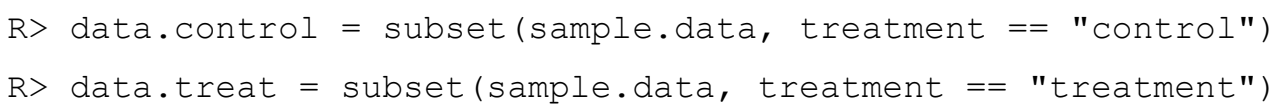

Subsequently, we investigate the data graphically. For a better overview we set the graphical device to display two plotting regions using the par () function (the argument mfrow is set to $c(1,2)$, generating 2 horizontal adjacent plotting regions). Within the plot ( ) functions we fix the $y$-axes ranges to create comparable plots $(y \lim =\mathrm{c}(0,10))$ and display the number of infections (y-axis) depending on the experimental time (x-axis):

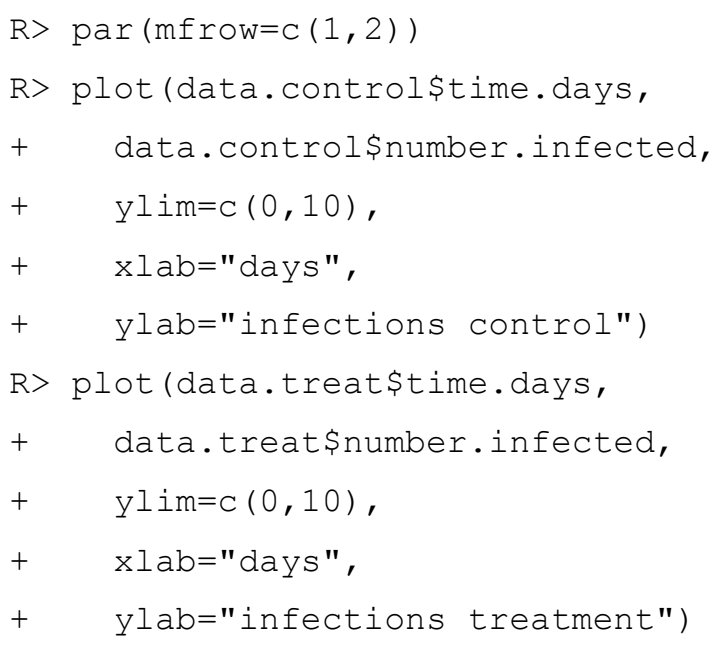

The control without an experimentally added pathogen shows an early increase (day 3) of infected plants over time (Figure $5 \mathrm{a}$ ), but not all plants are infected during the experimental trial. The treatment with the experimentally added pathogen shows the first infections at day 
4, but the increase in new infections is much steeper than in the control, and all plants might be infected (Figure 5 b).
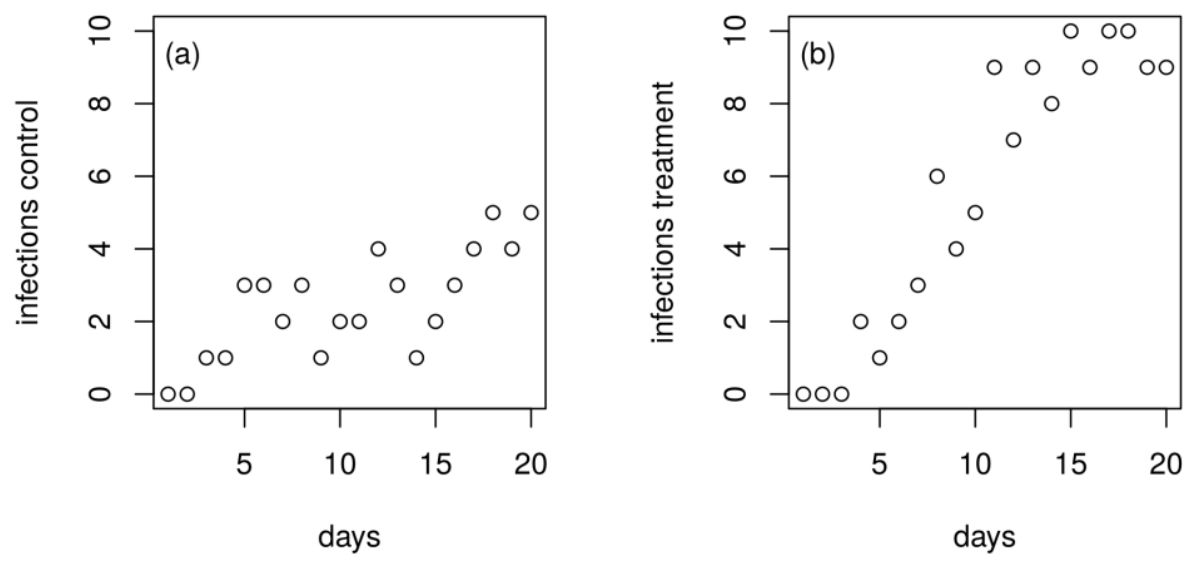

Figure 5. Simulated data of an infection bioassay. The data is simulated based on equations 2 and 3 using the functions mon. inf. lag.1p () and mon. inf.lag.2p(). After simulating the numeric average we applied a random number generator ( $r b$ i nom ( ) ) using Imax as size of the binomial distribution and the floating average of the simulation divided by by Imax as probability. The control data (a) was simulated using $r=0.025, I \max =$ 10 and $t 0=1$ and the experimental treatment $(b)$ was simulated using $r p=0.19, r c=0.025, t 0 p=5.5, t 0 c=$ 1 and $\operatorname{Imax}=10$.

Analysis of the data "wrong" approach. First, we analyse the experimental data using the standard monomolecular growth model (Raaijmakers et al. 2009; Paine et al. 2012). This model ignores the fact that not only the experimentally added pathogen but, in addition, other soil inherent pathogens may infect plant individuals and will be named "wrong method" (fit.treatment.wrong (), note that this method is valid if the medium chosen for the bioassay is sterile or does not contain any alternative pathogens). To fit the model to the data we use the mle2 ( ) function from the bbmle package by Ben Bolker (Bolker 2008; Bolker \& R Development Core Team 2014). The mle2 ( ) function requires (1) a negative log-likelihood function, here the function mon.inf.lag.1p.nll() discussed in section Underlying Functions; (2) a list containing the model parameters that should be estimated (here the infection rate, $r$, and the resistance time, t0); (3) a list containing the data the model should be fitted to, here the first element of the list must be named $\mathrm{nI}$ (the number of infected plants) and the second element must be named tps (timepoints, the time of the experimental data); (4) we also submit a fixed value to mle2 (), again in a list object, containing the maximum 
number of potentially infected plants (all plants in the experimental unit). Note that Imax does not have to be a fixed value but can also be assigned in the data list if the different replicates contain different numbers of plants (see subsection "Analysing data with multiple Imax"). Here, we start the fitting optimization with the initial guessed values of $r=1$ and $t 0=1$ (note that these values are just place-holders and might be adapted by the user, see subsection "What to do if..." below, moreover these values will be changed during the fitting algorithm by the optimizer mle2(); note also that the initial to must be equal or smaller than the experimental resistance time, which according to Figure 5 is at day 4); we set Imax $=10$ (the maximum number of plants in the experiment).

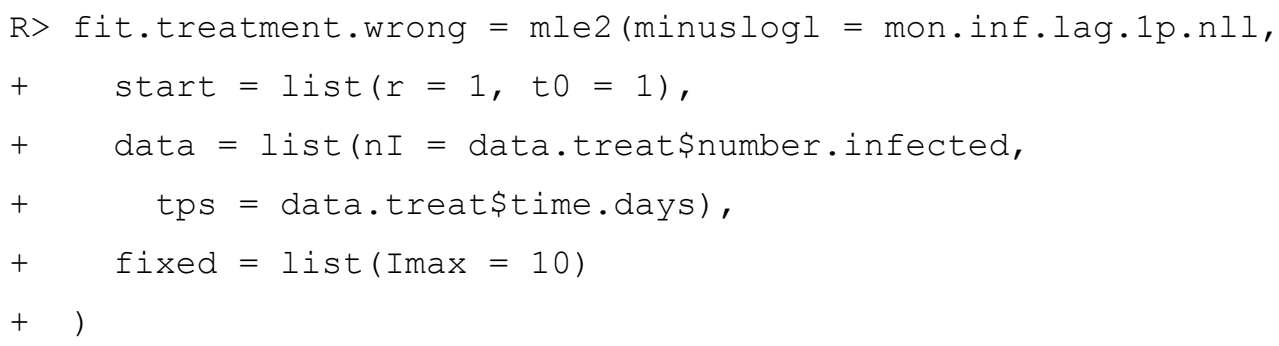

After the fitting procedure, we investigate the data using the generic summary ( ) function:

R> summary(fit.treatment.wrong)

Maximum likelihood estimation

Call:

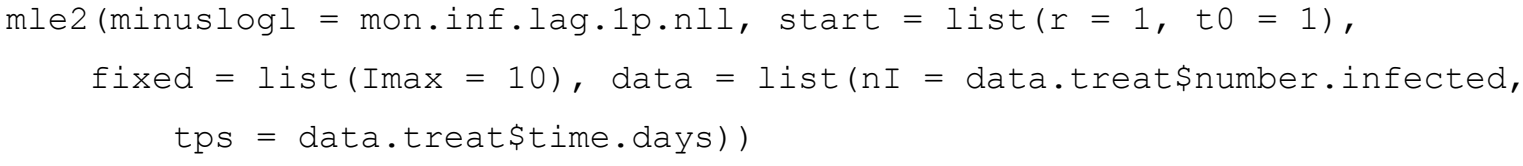


The output provides information on the estimates of the model, as well as statistical indicators such as standard errors and p-values (but see Bolker 2008 for a detailed discussion of the underlying statistics). The infection rate, $r$, is estimated to be $\sim 0.171+/-0.022$ infections per day, and the resistance time, to, is estimated to be $\sim 3.46+/-0.39$ days. These values underestimate both model parameters compared to the simulation parameters $(t)$ simulation $=$ 5.5 days, $r_{\text {simulation }}=0.19$ infections per day).

Analysis of the data-correct approach. Next, we apply the two-pathogen approach to the data, taking the infections of the control treatment into account. In the first step we analyze the control data similarly to the treatment data shown above only with exchanging the data supply from the experimental to the control data and decreasing the starting values for the model parameters (we already saw that the first infections occurred earlier and the slope is less step than for the treatment data).

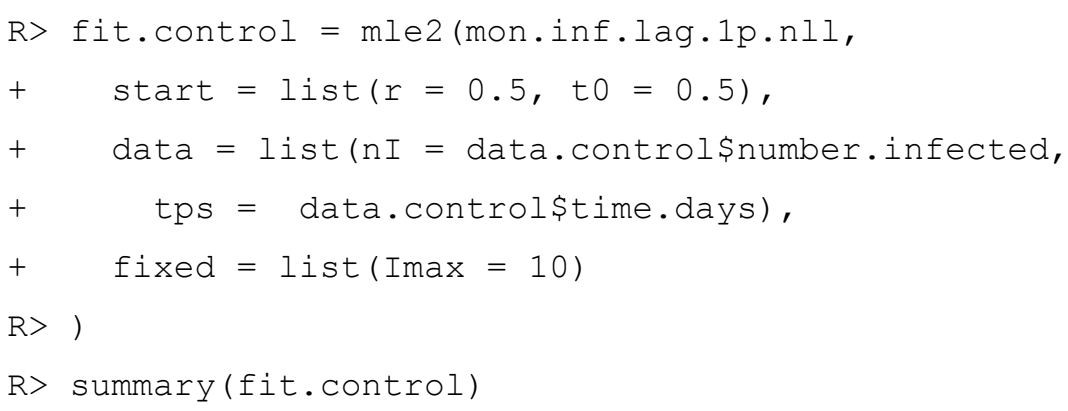


The fitting algorithm revealed that the infection rate, $r$, is $\sim 0.029+/-0.0076$, and the resistance time, $t 0$, is $\sim 0.47+/-2.057$. Both values are not significantly different from the simulated value. We will use the infection rate and the resistance time of the control to parameterize the twopathogen model using the mon.inf.lag.2p.nll() function (see section Underlying Functions for details). Using mon. inf. $\operatorname{lag} .2 \mathrm{p} . \mathrm{nll}$ () requires some reformulation of the code, the infection rate, $r$, and the resistance time, to, for the treatment "pathogen" are now called $\mathrm{rp}$ and t $0 \mathrm{p}$ and both appear in this spelling in the list of starting parameters. In addition to Imax, the list of fixed parameters contains here the infection rate of the control pathogen, $r \mathrm{C}$, and the resistance time of the control, $t 0 \mathrm{c}$. We call this values directly using the coef ( ) function.

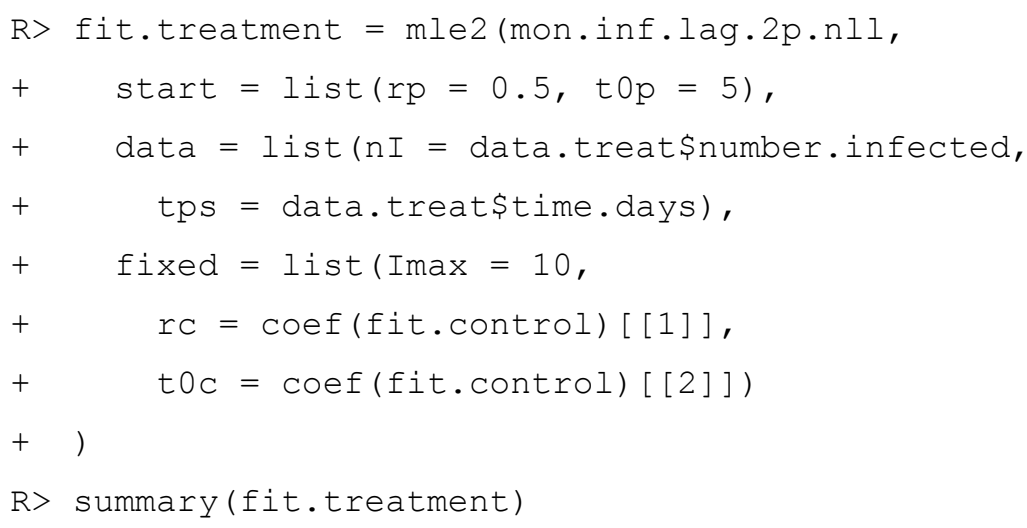




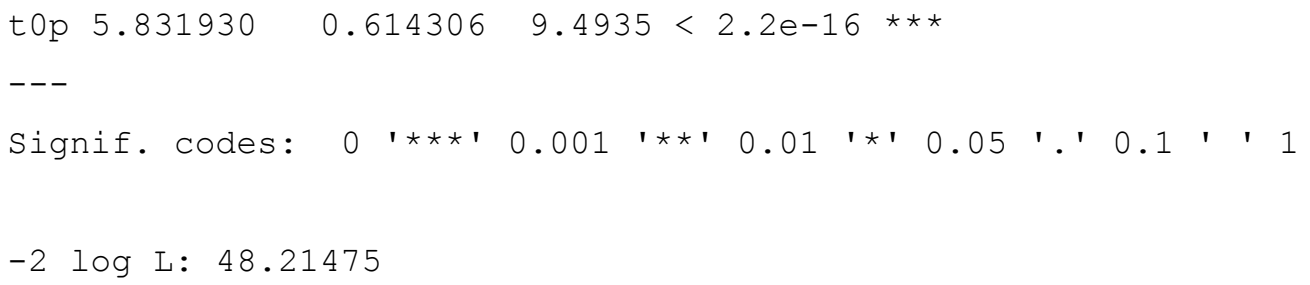

The values estimated by the two pathogen monomolecular model match the simulated values better than the results from the uncorrected fit. The estimated infection rate is measured to be $\sim 0.193+/-0.035\left(r p_{\text {simulation }}=0.19\right)$ and the first infection time is estimated to be $\sim 5.83+/-$ $0.61($ t 0 p simulation $=5.5)$.

Adding lines to the plot. The graphical representation of data and model fits is common practice. Simple linear regressions can be added as line to an existing plot using e.g. the generic abline () function. Our example is slightly more complex, but not much. First we have to create a vector containing values for the $x$-axis (time in days in our case) which will later be used to display a line in the plot. Note that non-linear lines need many values to create a smooth appearance of the line. Here we choose to create $100 x$-values ranging from $t=0$ to $t=20$, the end of our experiment using the seq () function with the third argument set to length = 100 (which creates 100 evenly distributed values ranging from the minimum to the maximum value). To simulate the corresponding y-values we use the lsoda ( ) function from the package deSolve (Soetaert et al. 2010). The Isoda () function builds a complex object including background information on the simulation run not needed for our purpose. To get rid of this information, we save the object created by lsoda () as a data frame by applying the data.frame () function on the lsoda () function. Isoda ( ) requires the starting density of the infected plants as first argument, $\mathrm{y}$, here $\mathrm{c}(\mathrm{I}=0)$; the second argument is the sequence of time points the number of infected plants should be calculated for; the third argument requires the ordinary differential equation model that should be applied (mon. inf. lag.1p (), see below for detailed discussion); and fourth, the parameters of the model must be supplied, here the results of our model fit.

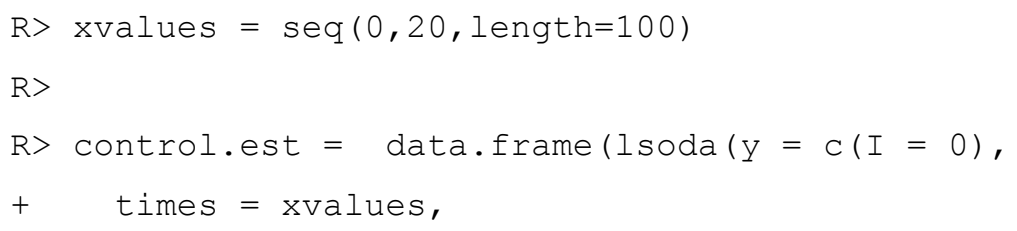




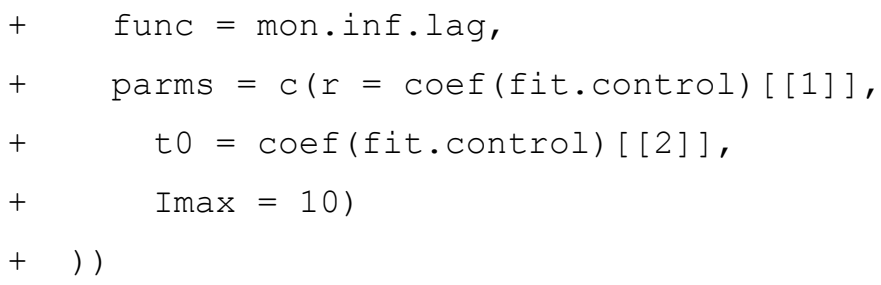

To simulate the regression line for the correct treatment fit, we must extend the code described above to incorporate both the control as well as the treatment pathogen parameters. We again use the lsoda () function, but now call the mon.inf. lag.2p () function that allows to model two pathogens. Also, we have to provide two starting densities for the infected plants (zero infected plants by the treatment pathogen, $I \mathrm{p}=0$, and zero infected plants by the natural occurring (control) pathogens, $I_{C}=0$ ). Moreover, the parameter list must now contain five parameters, both infection rates ( $r p$ and $r c$ ), both resistance times (t $0 p$ and $t 0 \mathrm{c})$ and again the maximum reachable number of infected plants, Imax.
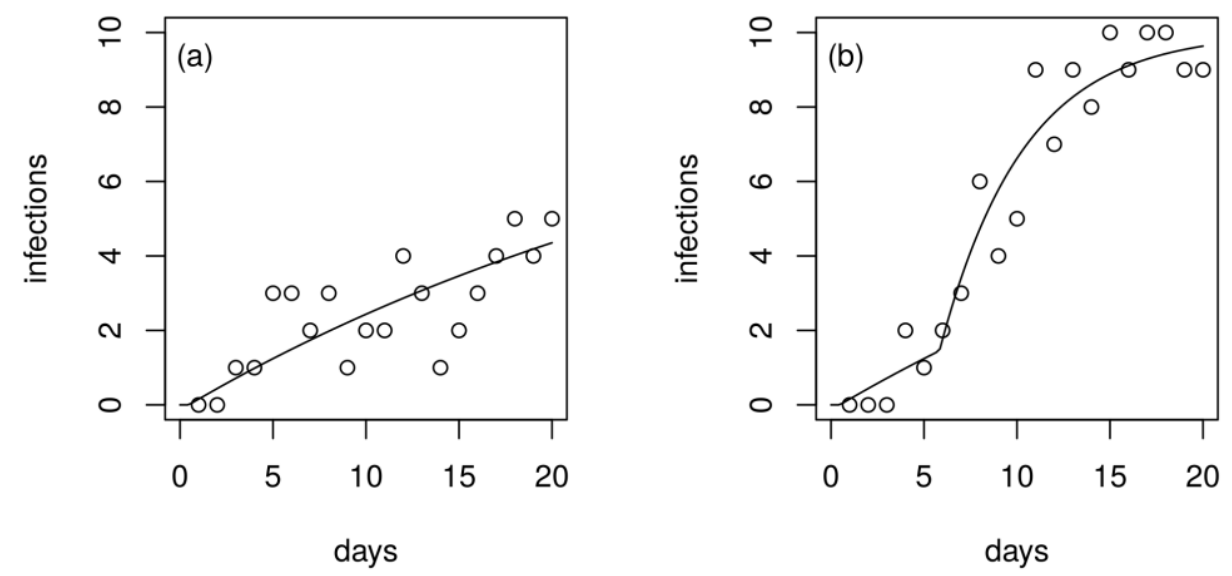

Figure 6. Infection bioassay as in Figure 5. The control (a) shows less infections starting earlier in the time series compared to the treatment with the experimentally added pathogen (b). This leads to a low infection rate combined with a low resistance time visualized by the black line in (a). The early infections in the treatment are due to infections by the natural pathogen, leading to a slight increase of the fitted curve (b), at $t \sim 6$, the treatment pathogen leads to a steep increase of the infection curve.

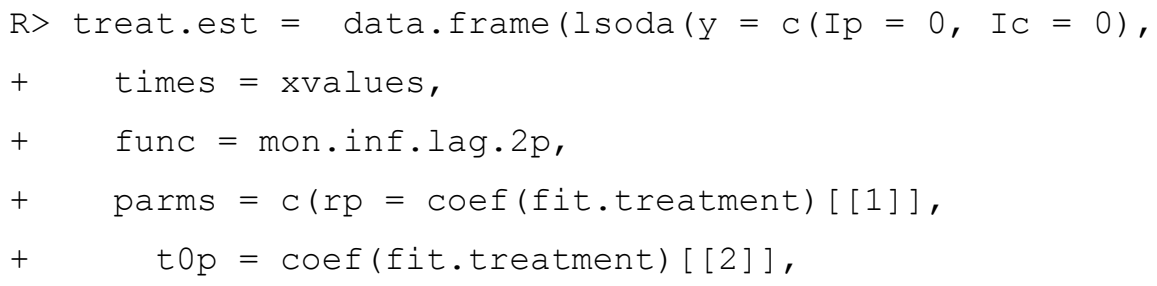




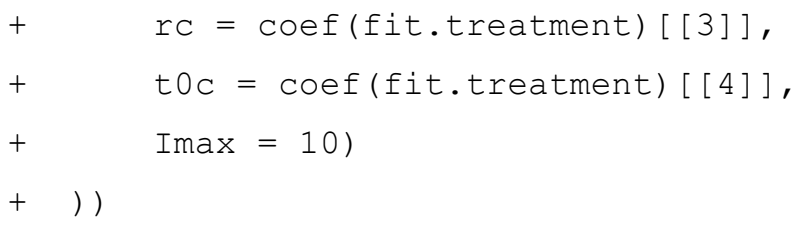

To add the lines to the plot, we again call plot () from above and subsequently lines (). Note that we have to sum both densities of infected plants (due to the treatment pathogen and the natural occurring (control) pathogen) to plot correct line (Figure 6) for the treatment data.

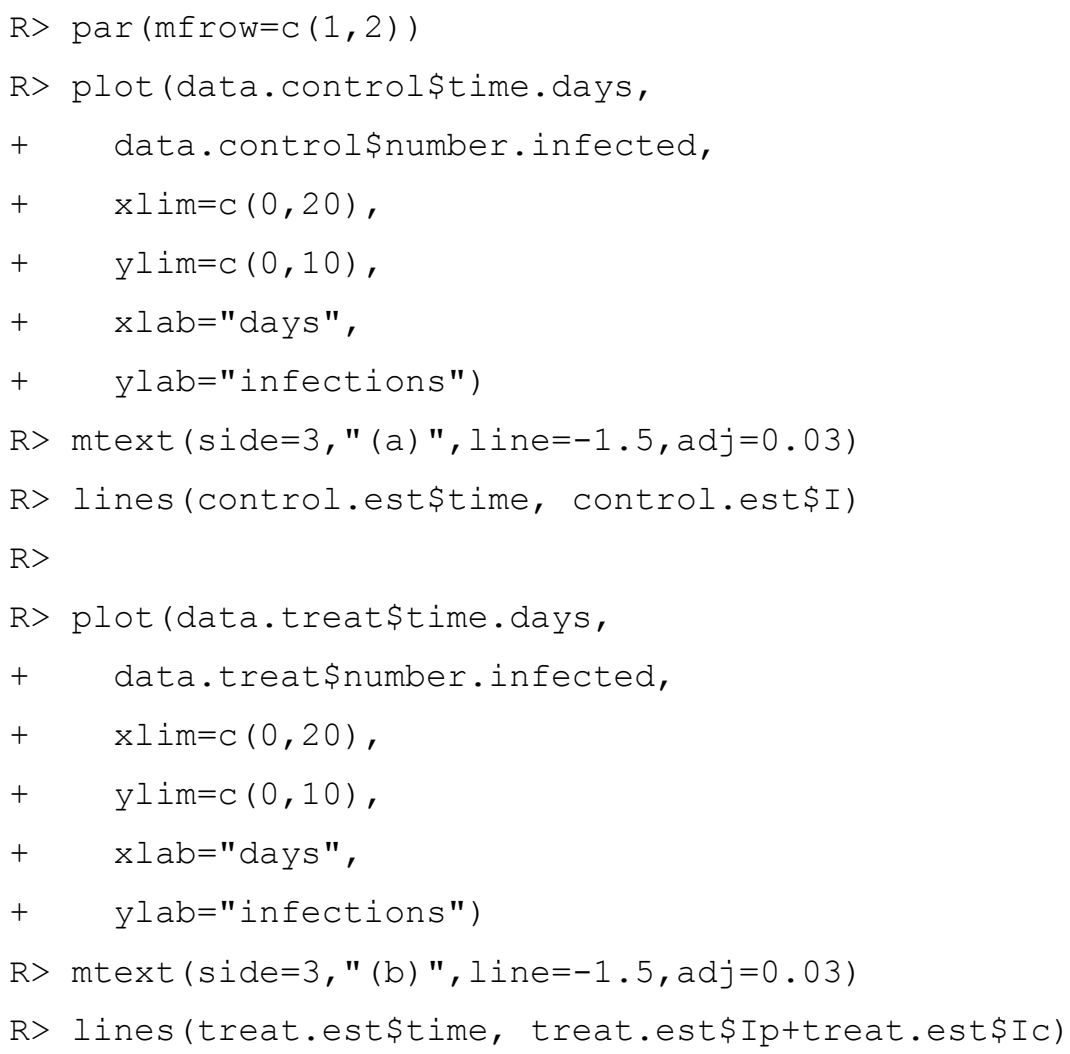

\section{What to do if...}

\section{... / get the}

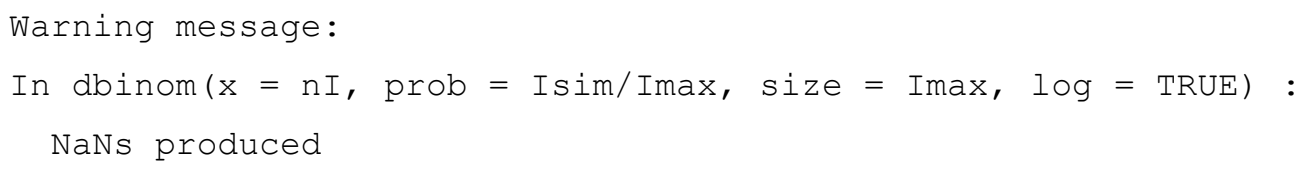

Keep calm, this is just a warning message, not an error and the fitting algorithm still succeeded. 
Let us perform an example using the control treatment from the infection.frontend1.r (line 107 ff). We change the initial infection rate to 3 , a rather high starting value:

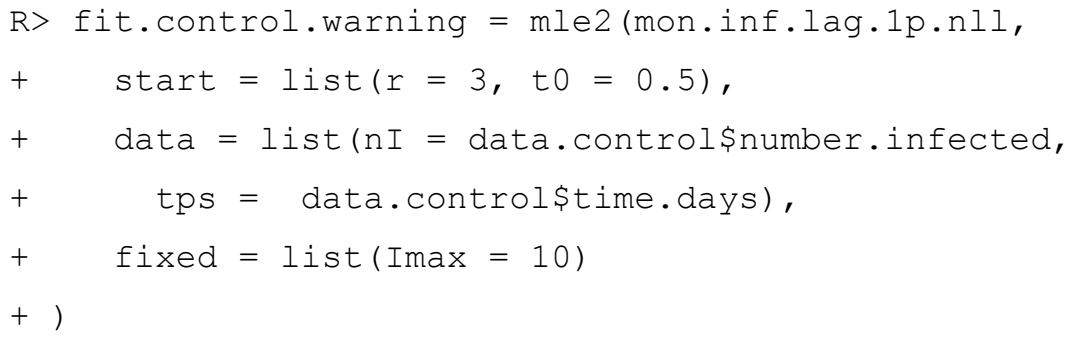

The warning message appears twice, but the fit still succeeded. But we can have a closer look at the problem. To do so, we can have a look at the trace log of the fit. 


\section{... I want to see the trace of the integrative fitting process?}

We continue the example by adding the element tracing to the fixed list. This allows to track the iteration steps in which the NaNs occurred and the values of the infection parameters that have been used in these steps:

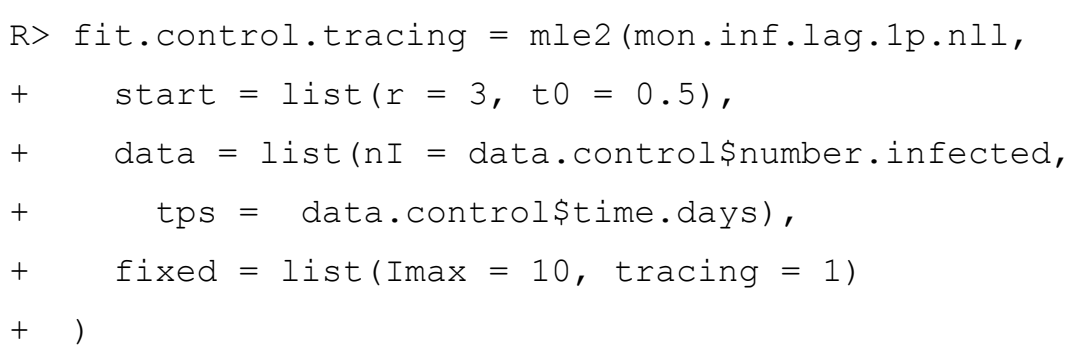

Running this code a list of negative likelihood values and infection parameters appears in the console, getting longer the more the fitting advances (to save space here in the text we truncated the output, you might have to scroll up a little in your console output to see the same):

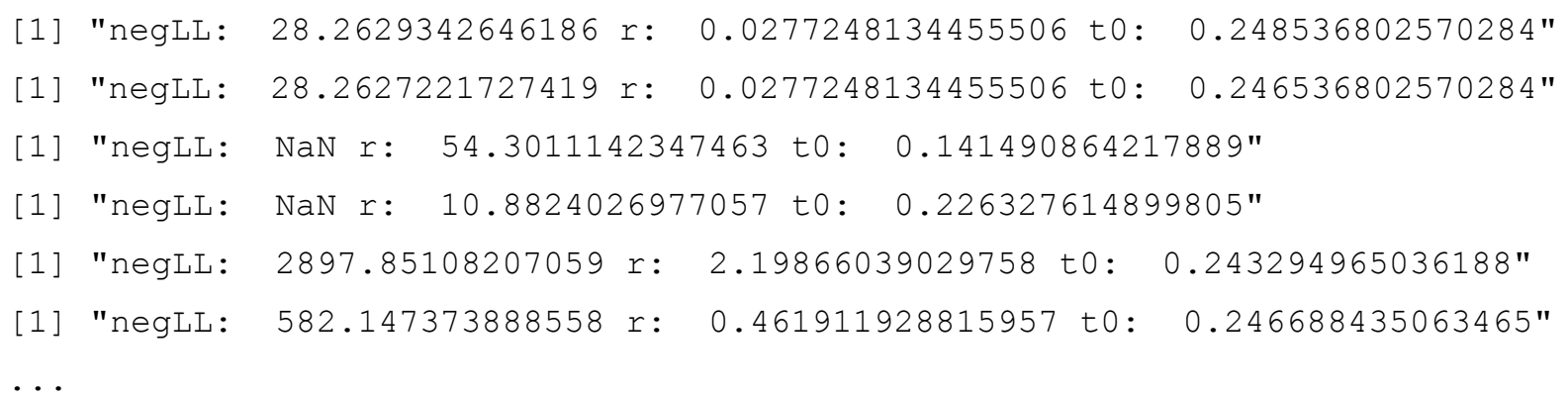

Clearly, the NaNs are produced when extremely high infection rates ( $r \sim 50.3$ and $r \sim 10.88$ ) are tested by the optimization algorithm. This causes the lsoda () to fail as the increase in new infected plants is much larger than the step size of the numeric integration routine (we set the default to 0.1 , which corresponds here to 0.1 days). Therefore (1) the warning message can be ignored as it applies only to unlikely high infection rates; a change in the starting parameters may avoid that the optimization algorithm picks randomly these high rates (the main example did not show any warnings); or the step size of the numerical integration routine can be decreased to increase the temporal resolution of the simulation. 


\section{... I want to change the step size of the numerical integration routine?}

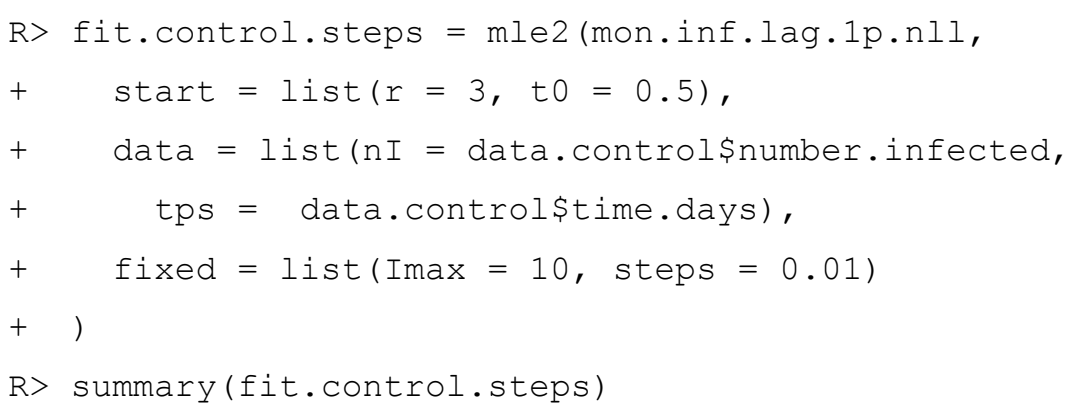

Maximum likelihood estimation

Call:

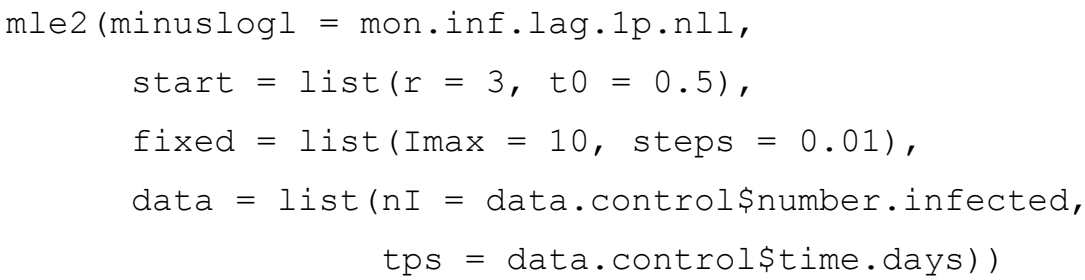

Coefficients:

Estimate Std. Error z value Pr(z)

r $0.02926410 .0076073 \quad 3.84680 .0001197 * * *$

to $0.4656282 \quad 2.0725455 \quad 0.2247 \quad 0.8222400$

Signif. codes: 0 '***' 0.001 '**' 0.01 '*' 0.05 '.'0.1 ' ' 1

$-2 \log \mathrm{L}: 56.46962$

By decreasing the temporal resolution of the underlying integration of the infection model, we got rid of the warning messages, but at the cost of speed (it will take much longer to run the model function with this settings).

Analysing data with multiple Imax. In bioassays using plant seeds instead of plants not all seeds may germinate. This leads to different Imax in the different replicates. You find the example in infection.frontend2.r. As for the above mentioned example, we first have to set the working directory, load the required packages, source files and data: 


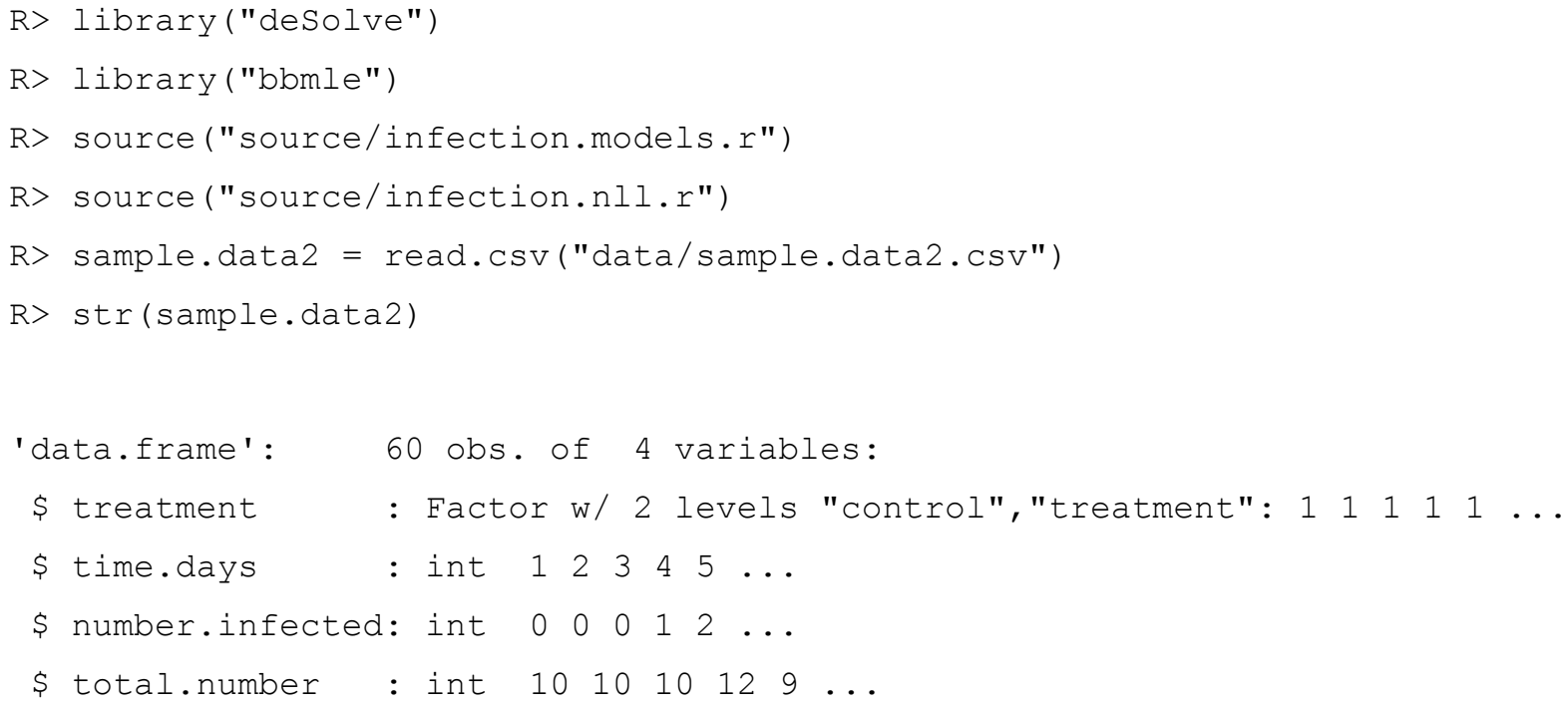

You might notice that the data set now includes the additional variable total number containing the information which experimental unit has which Imax. We continue with separating the data sets as above:

$\mathrm{R}>$ data2. control = subset (sample.data2, treatment == "control")

$\mathrm{R}>$ data2.treat $=$ subset (sample.data2, treatment $==$ "treatment")

As above we begin by fitting the control treatment as discussed above. Additionally we set the step length of the numerical integrator to 0.01 to avoid NaNs:

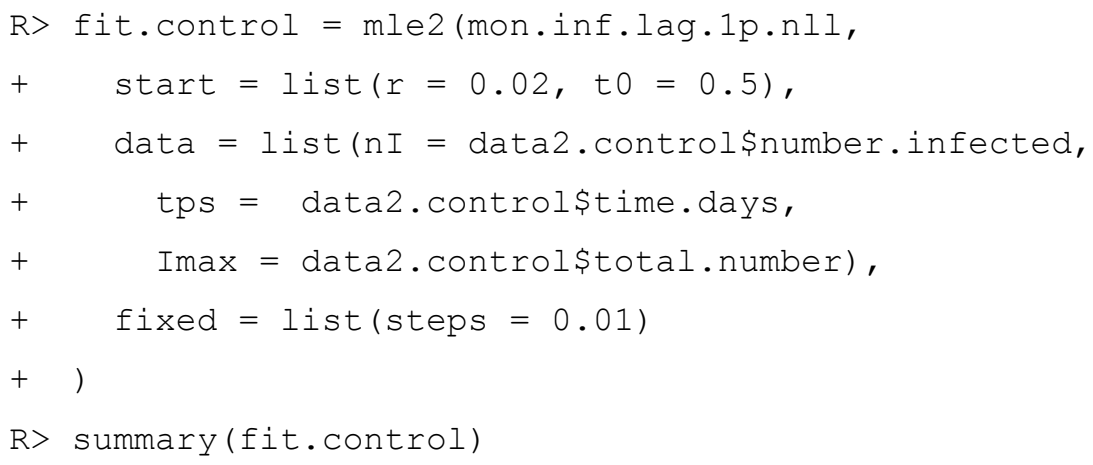

Maximum likelihood estimation

Call:

mle2(minuslogl $=$ mon.inf.lag.1p.nll, start $=$ list $(r=0.02$, t0 $=0.5)$, fixed $=$ list $($ steps $=0.01)$, 


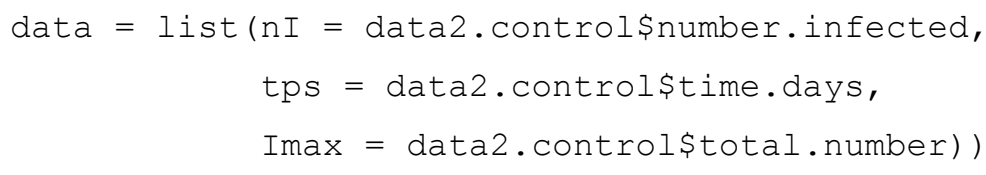

The most important change is that we supply the information for Imax to the data list instead of the fixed list. In total the fit takes longer as in the example above. This is due to the fact that a numerical integration of a time series for each Imax must be calculated which is rather time consuming. We provide more details on this below.

After fitting the controls we follow the procedure explained above and fit the treatments:

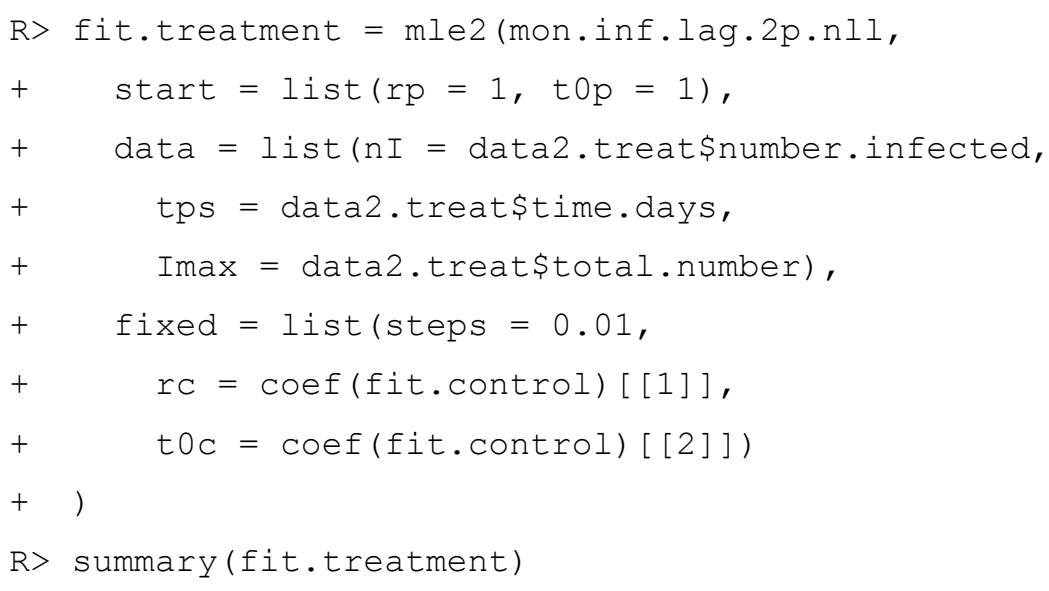


deactivated by default. First the function checks if either $r$ or t 0 are below zero or t 0 is greater than or equal to the minimum time of an infection in the real data. If any of these queries is true, the function returns infinity. Next, the model predictions for each experimentally measured value are simulated using sim.inf.1p() (see subsection "ODE functions"). Finally, the function calculates the negative likelihood using the binomial density function dbinom() and returns it. We choose the binomial distribution as our data is binomially distributed (integer values for infections have a clear defined minimum and maximum number of infections, but see Bolker (2008) for a detailed introduction on this topic).

The two-pathogen variant, mon. inf. $\operatorname{lag} .2 \mathrm{p} . \mathrm{nll}()$, is similar to the above described function and we will only discuss the differences. As this function is created to estimate the negative log-likelihood of a two pathogen system, the model parameters consist of $r p, r c$, top and toc. Moreover, the function sim.inf.2() is used to calculate the number of infections from the model simulation. Also a more complex if-statement is added to ensure that at least one of t $0 \mathrm{p}$ or t $0 \mathrm{c}$ falls below the time the first infection occurred in the experiment (otherwise NaNs may be produced):

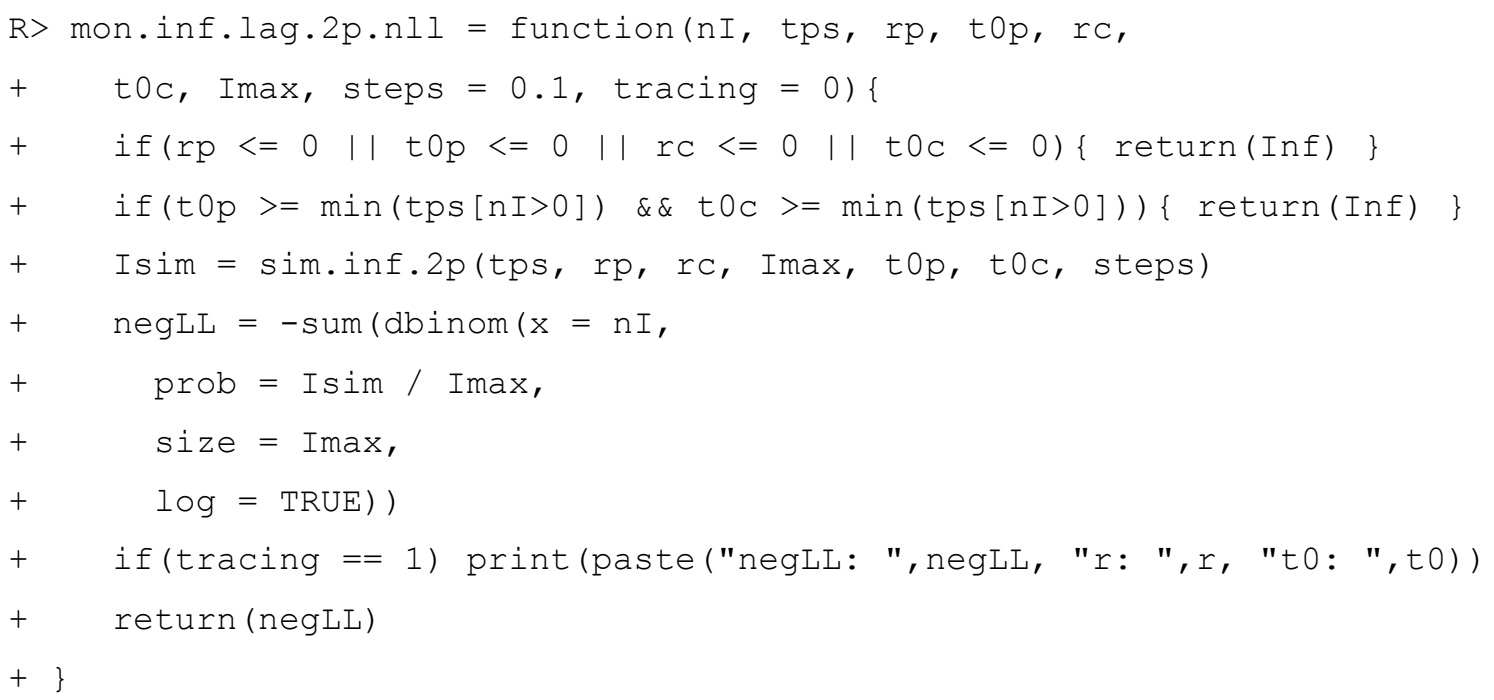

The function sim.inf.1 () first creates an empty numeric vector (Iout) to store the calculated values for infection in. If Imax is only a single value we apply the Isoda ( ) function to simulate a single time series of plant infections according to the assigned parameter values $($ parms $=C(r=r, I m a x=I m a x, t 0=t 0))$ and a starting density of infected plants of unity $(y=C(I=0))$. The numerical simulation of the integration process needs 
a vector of consecutive points in time. This vector consists of a sequence of consecutive values from zero to the maximum time value ( $\operatorname{seq}(0, \max (t p s)$, steps)), and the experimental time values, tps. As no duplicate values should appear in the vector and the time vector should increase consecutively, we first apply the unique ( ) function on the vector to delete duplicates and second sort the vector by the sort ( ) function. The ordinary differential equation system that should be integrated is given by the function mon. inf. $1 \mathrm{ag} \cdot 1 \mathrm{p}()$. Please read into Soetaert and Herman (2008) to get a general introduction into the topic "solving ordinary differential equation systems in R using deSolve". After the integration the number of estimated infections are saved according to their appearance in the experimental time series using a for-loop.

If the experimentally data consist of more than one single value for Imax, the else part of the if/else-statement is activated. First, we create three empty numeric vectors to store the number of infected plants, the time, and the maximum number of infectable plants in (mres.I, mres.time, mres. Imax). Second we use a for-loop to calculate the number of infected plants for each Imax. Third, we save the results to Iout as described above using a for-loop, with additionally separating for each Imax.

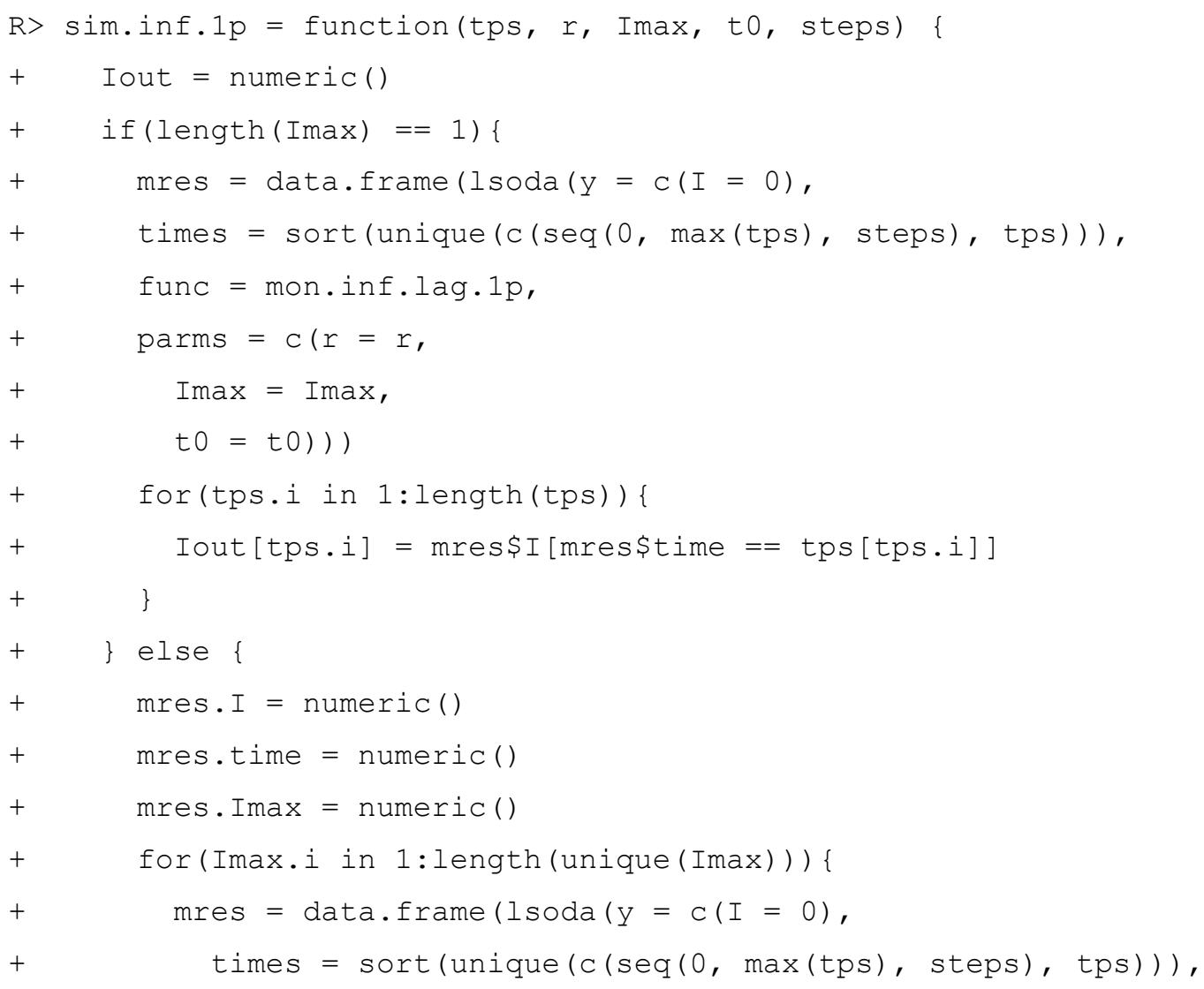




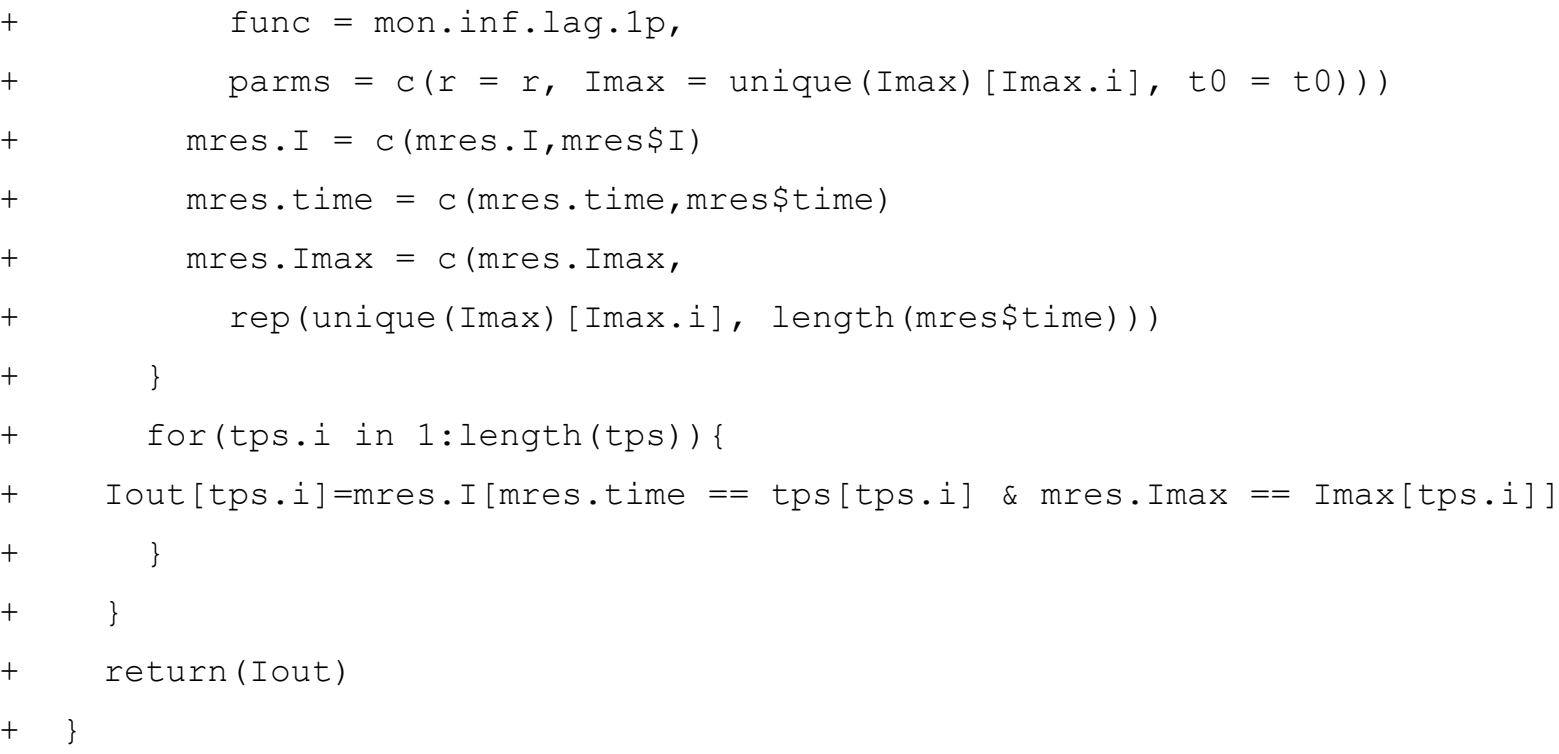

The function sim.inf.2() is similar to the function sim.inf.1() but models the twopathogen system. The differences are: model parameters consist are $r p, r c$, t $0 p$ and toc; Isoda ( ) needs two starting values for infections at time $=0\left(\mathrm{c}\left(\mathrm{IP}=0, I_{\mathrm{c}}=0\right)\right)$; the ordinary differential equation system is given by the function mon.inf. $\operatorname{lag} .2 \mathrm{p}()$. The results for the total infected plants, estimated by the model, are now calculated by (mres\$Ic+mres\$Ip).

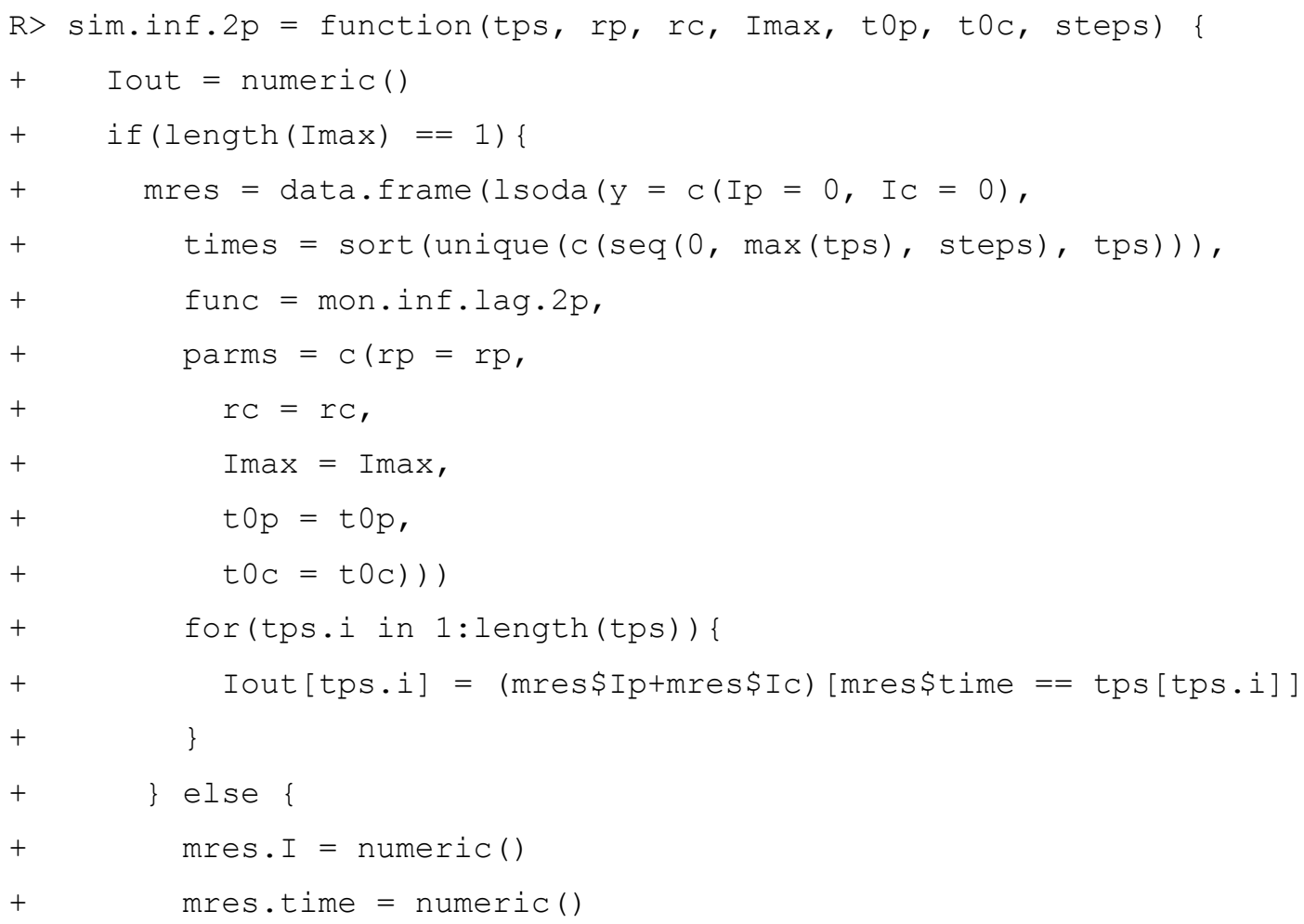




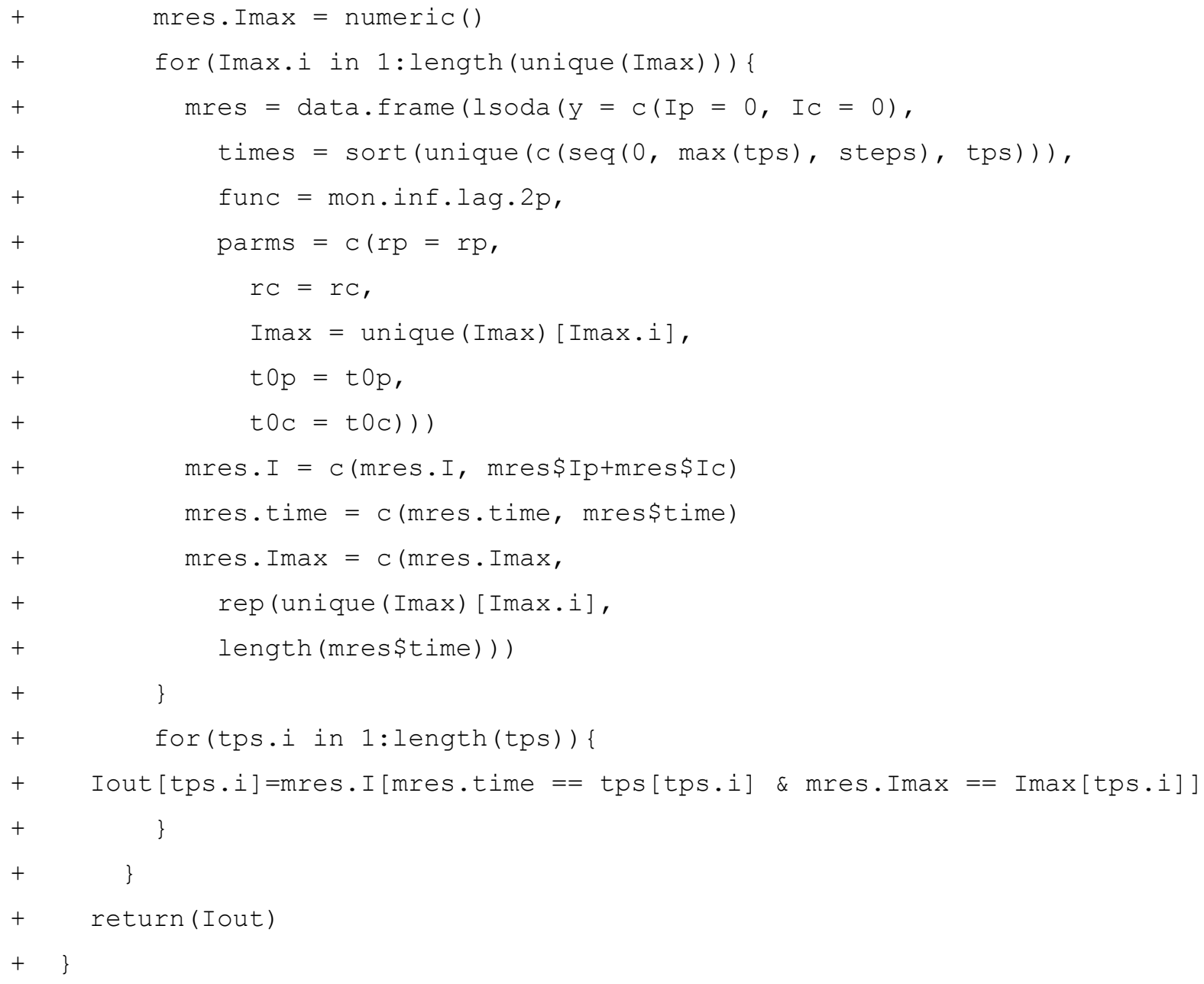

ODE Functions (infection.models.r). The monomolecular infection model (Raaijmakers et al. 2009; Paine et al. 2012) with an additional lag phase can be written as:

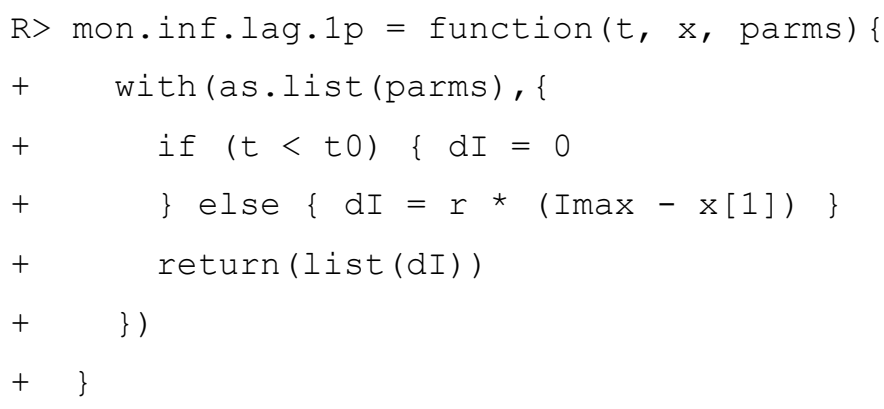

The function contains three arguments, the first argument is the time $t$, the second argument, $\mathrm{x}$, is a list of densities that occur in the differential equation system and the third argument, parms, is a list of constant parameters. We activate the headers of the parms list by using the with() function. Within the with() function the change of infections over time is 
calculated. We use an if/else-statement to discriminate between zero growth (before the first infections occur, $t<t 0)$ and positive new infections above this boundary. Lastly, the function returns a list containing the change of infected plants, $\mathrm{dI}$.

The two pathogen monomolecular infection model can be written as:

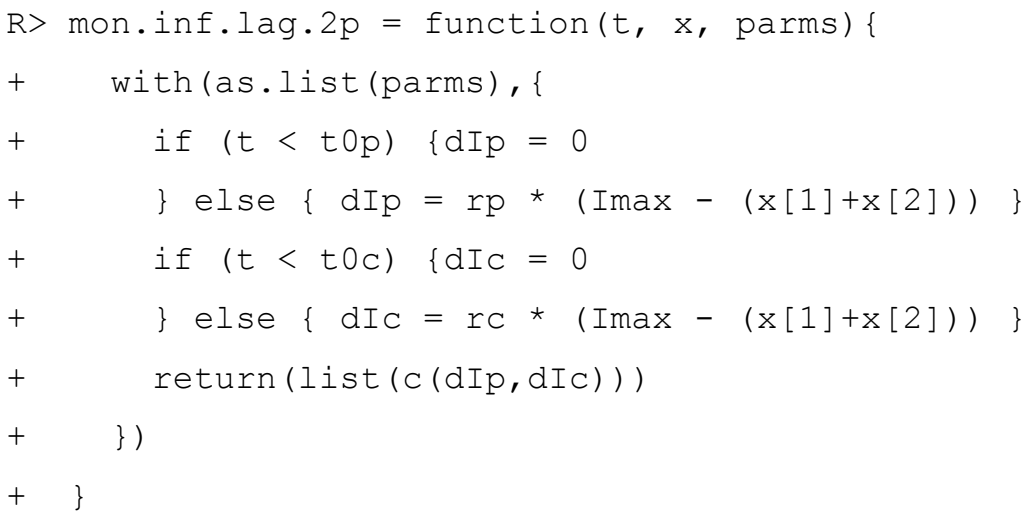

The differences to mon.inf.lag.1p () are: Within the with () function, the change of infections over time is calculated following the two pathogen infection model the function returns a list containing the change in infected plants over time of the experimentally pathogen, $d I p$, and the naturally (control) occurring pathogen, $d I c$.

\subsubsection{Acknowledgements}

We gratefully acknowledge the support of the German Centre for integrative Biodiversity Research (iDiv) Halle-Jena-Leipzig funded by the German Research Foundation (FZT 118). Ellen Latz was funded by the German Research Foundation (JO 935/2-1). We thank Myriam Hirt, Amrei Binzer, Andrew Barnes and Ulrich Brose for proof reading our manuscript and betatesting the R-Code. All R-script files with corresponding data are added as online supporting information. 



\subsection{Research Chapter 3}

\section{MECHANISTIC LINKS BETWEEN PLANT COMMUNITY COMPOSITION AND THE PATHOGEN-SUPPRESSIVE POTENTIAL OF SOILS}

\footnotetext{
Ellen Latz, Nico Eisenhauer, Björn Christian Rall, Stefan Scheu and Alexandre Jousset
} 


\subsubsection{Summary}

Soil-borne plant diseases cause dramatic yield losses worldwide. Current disease control strategies can be deleterious for the environment and human health and foster the need for alternative disease control. Some soils harbour microorganisms that can efficiently suppress pathogens. The main taxa are well characterised, but uncovering mediators driving their functioning in the field still remains challenging.

We set up plant microcosms to experimentally test the Rhizoctonia-suppressive potential of soils in dependence on previous plant community composition. Our results indicate that plant communities shape soil-disease suppression via changes in root biomass, soil $\mathrm{pH}$, and the abundance of the bacterial groups Actinomyces, Bacillus and Pseudomonas, and further stress the significance of plant-plant interactions for the suppressive potential of soils.

Using structural equation modelling, we provide a mechanistic framework showing how the complex interactions between plants, soil and microorganisms jointly shape soil suppressiveness. Our results stress the importance of plant community composition in affecting abiotic and biotic rhizosphere properties, suggesting that plant community composition is an important predictor of the disease suppressive potential of soils. 


\subsubsection{Introduction}

Soil-borne plant pathogens, in particular fungi, cause important yield losses all over the world (Weller et al. 2002; Raaijmakers et al. 2009). An average yield loss of 7-15\% was estimated for the most important crops maize, potato, rice, soybean and wheat (Oerke 2006), and some especially aggressive pathogens such as Fusarium, Pythium and Rhizoctonia can cause losses of up to 20-35\% (Cook 1987; Cook et al. 2002; Smiley et al. 2005). Current control methods are based on heavy pesticide application, which, beside of being highly polluting, provide only partial protection (Weller et al. 2002; Haas \& Defago 2005).

Many soil microorganisms have the potential to suppress diseases to some extent, and pathogen suppression occurring in disease suppressive soils operates through distinct biological mechanisms (Weller et al. 2002). Bacteria of the genera Pseudomonas, Actinomyces and Bacillus are particularly important for the suppressiveness of soils (Weller et al. 2002; Mendes et al. 2011), and their targeted application is offering the opportunity for environmentally friendly control of plant diseases (Weller et al. 2002; Haas \& Defago 2005). However, often disease suppressive bacteria perform poorly when applied to the field (Lugtenberg \& Kamilova 2009; Raaijmakers et al. 2009). Despite of extensive research on the molecular mechanisms involved in disease suppression by bacteria (Mazzola, Funnell \& Raaijmakers 2004; Haas \& Defago 2005; Berg \& Smalla 2009; Mendes et al. 2011), there is still a lack of knowledge on drivers affecting their survival and functioning in the soil (Philippot et al. 2013).

Plant community composition, soil abiotic properties, and pathogen antagonistic microbial communities are linked, and thought to jointly determine the suppressive potential of soils (Garbeva et al. 2004; Berg \& Smalla 2009; Philippot et al. 2013). Soil-moisture is an abiotic component that varies with plant communities and shapes soil microbial communities (Hinsinger et al. 2009). Further, plants specifically impact plant-pathogenic as well as pathogenantagonistic microorganisms via rhizodeposits (Bais et al. 2006; Bardgett \& van der Putten 2014), and their composition shapes nutritional and pH conditions in the rhizosphere (Uren 2007; Hinsinger et al. 2009). However, the importance of abiotic factors is far from being clear, which might be due to their correlative relationships, and the complexity of mechanisms driving soil properties (Janvier et al. 2007).

Plant diversity affects a variety of ecosystem functions and services (Hooper et al. 2005; 
Cardinale et al. 2012), and drives the composition of bacterial communities antagonistic to plant pathogens (Garbeva et al. 2006; Latz et al. 2012). Plant biodiversity further affects the expression of bacterial traits linked to pathogen suppression (Latz et al. 2015). Beside plant diversity, the functional composition of plant communities is important for the structure and functioning of biocontrol bacteria. For instance, legumes and grasses have been shown to affect biocontrol bacteria, and the pathogen suppressive potential of the soil (Latz et al. 2012).

Generally, effects of plant diversity on microbial communities are suggested to be due to increased plant productivity, accompanied by increased resource quantity exudated by plantroots (Spehn et al. 2000; Zak et al. 2003; de Deyn et al. 2011). On the other hand, specific ecosystem functions are suggested to be dependent on resource composition and the quality of specific resources, driven by variation in plant species richness and identity (de Deyn et al. 2011; Latz et al. 2012, 2015). The link between plant diversity and belowground microbial community composition is little studied (Lange et al. 2014), and to our knowledge, studies on mechanisms linking plant community composition with the functionality of soil microbes, such as plant pathogens and plant pathogen antagonists, are lacking entirely.

We hypothesised that abiotic and biotic properties of the rhizosphere jointly shape the pathogen suppressive potential of soils. We assumed changes in the rhizosphere environment (root biomass, soil $\mathrm{C} / \mathrm{N}$ ratio, $\mathrm{pH}$, soil moisture) to vary with plant community composition and in turn affect the abundance and composition of biocontrol bacterial communities, thereby altering pathogen suppression (Supplementary Table 1). We tested this hypotheses by setting up an experimental grassland plant diversity gradient and investigated plant effects on abiotic and biotic soil properties at close to natural conditions. To allow unravelling mechanistic linkages we used a structural equation modelling approach (see Figure 7 and figure legend for details). 

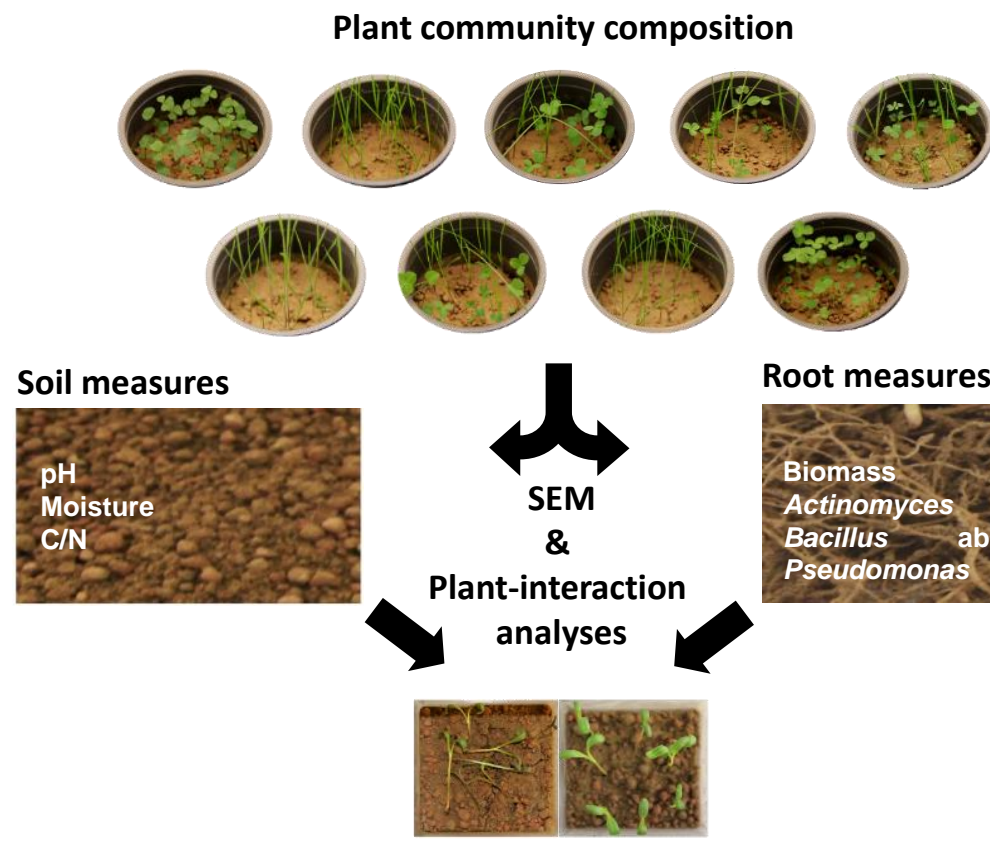

Root measures

Pathogen suppression

Figure 7. Grassland plant communities consisting of one to eight species were set up in a substitutive diversity gradient. To increase plant community effects on soil parameters, plant succession was simulated in growth cycles. After the fifth growth cycle, soil parameters were measured, plant roots were weighed and biocontrol bacteria (Actinomyces, Bacillus and Pseudomonas) enumerated. Subsequently, the soil was planted with sugar beet seedlings and infested with the model pathogen Rhizoctonia solani, and pathogen suppression was assessed. Mechanisms linking plant community composition and pathogen suppression were unravelled via structural equation modelling. In addition, plant-plant interaction effects on pathogen suppression were assessed (see methods for details).

\subsubsection{Materials and Methods}

Plants. We used a total of eight plant species, four from the two functional groups grasses and legumes that are representatives of central European mesophilic grassland Arrhenatherion communities (Roscher et al. 2004). Grasses included Bromus erectus Huds. (Bromus), Dactylis glomerata L. (Dactylis), Festuca pratense Huds. (Festuca), Lolium perenne L. (Lolium), and the legume species were Lotus corniculatus L. (Lotus), Medicago lupulina L. (Medicago), Trifolium pratense L. (Trifolium p.), and Trifolium repens L. (Trifolium r.; Appels Wilde Samen GmbH, Darmstadt, Germany). It has been shown that nutrient uptake strategies and other functional traits differ considerably between these species (Roscher et al. 2004). 
Microcosm construction. Microcosms (PVC tubes; diameter $10 \mathrm{~cm}$, height $18 \mathrm{~cm}$ ) were filled with $680 \mathrm{~g}$ of fresh soil obtained from a bare ground area close to the field site of the Jena Experiment (Roscher et al. 2004). Prior to plantation, the soil was sieved ( $2 \mathrm{~mm}$ ) to remove macrofauna, roots, and stones. Subsequently, the soil was mixed with $170 \mathrm{~g} 2-5 \mathrm{~mm}$ expanded clay; $20 \%$ of total volume (Fibo ExClay Deutschland $\mathrm{GmbH}$, Lamstedt, Germany) to ensure constant humidity. Upscaling the maximum of 8 plants species per $0.00785 \mathrm{~m}^{2}$ equals approximately 60 species per $20 \mathrm{~m} \times 20 \mathrm{~m}$ (according to species area relationships for generalist European grassland species; Krauss et al. 2004), which is the maximum diversity per area in the Jena Experiment (Roscher et al. 2004). For each plant to be established three seeds were placed per sowing-spot; superfluous plant seedlings were removed after emergence.

Experimental setup. Plant diversity was varied independently of functional group affiliation in a substitutive gradient ranging from one to eight species by using the random partitions design (Bell et al. 2009). Every species was drawn at random from the species pool without replacement, such that each species was selected once at each level of diversity. Drawing was replicated three times resulting in three partitions, each containing of eight plant monocultures, eight two-species mixtures, four four-species mixtures, and one eight-species mixture. One microcosm without plants per experimental block served as control (Supplementary Figure 2). We used a well-established accelerated cycle design, in which plants were harvested and the microcosms planted again with the same plant communities in a three week cycle with five cycles in total. This design allowed simulating plant succession cycles in reduced time course, and has been used to investigate the effect of plants on the structure of bacterial communities before (Landa et al. 2003; Mazzola et al. 2004; Bergsma-Vlami et al. $2005 b)$. Plant communities were grown in a climatic chamber $\left(18-22^{\circ} \mathrm{C}\right.$; photoperiod $12 \mathrm{~h} ; 150$ $\mu \mathrm{mol} \mathrm{m}^{-2} \mathrm{~s}^{-1}$ photon flux density), and watered and randomized twice a week.

Sampling and measurements. Plant communities were harvested after the completion of the fifth growth cycle. Roots of plant communities were weighed and the soil was homogenized and stored at $4^{\circ} \mathrm{C}$ until further use. To quantify cultivable bacteria with biocontrol function, total bacteria were recovered from the root systems by horizontally shaking in $20 \mathrm{ml}$ cold 1/10 phosphate-buffered saline for 0.5 h (PBS; Sambrook \& Russell 2001). We focused on the bacterial genera Actinomyces, Bacillus, and Pseudomonas, known to have high suppressive 
potential against the chosen model pathogen Rhizoctonia solani (Garbeva et al. 2006; Mendes et al. 2011). Starch Casein Agar (SCA) containing $100 \mu \mathrm{g} \mathrm{ml} \mathrm{m}^{-1}$ cycloheximide (Hirsch \& Christensen 1983) was used for the enumeration of actinomycetes in diluted rhizosphere-soil suspensions $\left(2 \times 10^{4}-2 \times 10^{6}\right.$-fold). Bacillus spp. were isolated by incubating the rhizospheresoil suspension at $85^{\circ} \mathrm{C}$ for $0.5 \mathrm{~h}$, and dilutions $\left(2 \times 10^{3}-2 \times 10^{4}\right.$-fold $)$ were plated on $1 / 10$ Tryptic Soy Agar (TSA; Stevenson \& Segner 1992). Pseudomonads were isolated by dilutionplating $\left(2 \times 10^{4}-2 \times 10^{6}\right.$-fold) on 1/3 King's B agar containing $40 \mu \mathrm{g} \mathrm{ml}^{-1}$ ampicillin, $13 \mu \mathrm{g} \mathrm{ml}{ }^{-1}$ chloramphenicol, and $100 \mathrm{mg} \mathrm{ml}^{-1}$ cycloheximide (Simon \& Ridge 1974; McSpadden Gardener et al. 2001). Bacterial colonies were counted after four and additional colonies after six days (Actinomyces), two and three days (Bacillus), and three and four days (Pseudomonas) of growth at $20^{\circ} \mathrm{C}$. For further analyses plate counts from soil dilutions resulting in $50-500$ bacterial colonies per plate were chosen.

The $\mathrm{pH}$ of $2 \mathrm{~g}$ soil was determined in a $1: 10$ dilution with $0.01 \mathrm{M} \mathrm{CaCl}_{2}$. The gravimetric water contend was measured by drying soil at $65^{\circ} \mathrm{C}$ for three days. Thereafter, dried soil samples were ball-milled (MM 400; Retsch GmbH, Haan, Germany) for analysis of total carbon (C) and nitrogen $(\mathrm{N})$ concentrations in an element analyser (Vario EL III, Elementar, Hanau, Germany).

Soil suppressiveness assay. In order to analyse the effects of previous plant community composition on pathogen suppression in the following crop, we carried out a standardized infection assay with sugar beet seedlings (Beta vulgaris L.; variety BELINDA, Rhizoctonia susceptible, KWS SAAT AG, Einbeck, Germany) and the model pathogen Rhizoctonia solani Kühn (AG 2-2 IIIB; IfZ, Göttingen, Germany), as described elsewhere (Postma et al. 2008; Mendes et al. 2011; Latz et al. 2012). Briefly, four Magenta boxes per experimental plot $(7.7 \times 7.7 \times 9.7$ cm; Sigma-Aldrich, St. Louis, MO, USA) were filled each with $100 \mathrm{~g}$ of sieved soil. One barley corn infested with $R$. solani was placed in the centre of three boxes, the fourth box remained inoculum as control. Eight sugar beet seeds (germination rate 93\%) were added to each box about $0.5 \mathrm{~cm}$ below soil surface. The jars were incubated at $21^{\circ} \mathrm{C}$ and $12 \mathrm{~h}$ photoperiod (photon flux density: $120 \mu \mathrm{mol} \mathrm{m} \mathrm{m}^{-2} \mathrm{~s}^{-1}$ ) and randomised every two days over a total experimental time of ten days. Dead seedlings were counted at day 2, 4, 6, and 10, and pathogen suppression was calculated as the time span until the first infection of sugar beet seedlings occurred (see statistical analyses for details). 
Statistical analyses. To estimate the disease suppressive potential of the soils after being exposed to different plant community compositions, we analysed every experimental unit separately using a monomolecular infection model (Raaijmakers et al. 2009; Paine et al. 2012 Rall \& Latz, in prep.) describing the change of infected plants $(d l)$ over time $(d t)$ by an infection rate, $r$, and first infection occurrence, $t_{0}$ :

$\frac{d I}{d t}=\left\{\begin{array}{r}0, t<t_{0} \\ r\left(I_{\max }-I\right), \quad t \geq t_{0}\end{array}\right.$

Equation 4

If controls were not infected by any pathogen being present in the soil, we estimated infection parameters according to the classic monomolecular model (Eqn. 4). Whereas, to correct for the occurrence of pathogens whose presence was detected in the control, we fitted the monomolecular model (Eqn. 4) to the control data, and subsequently used the results of this fitting for parameterization of a two pathogen monomolecular infection model (Rall \& Latz, in prep.):

$\frac{d I_{p}}{d t}=\left\{\begin{aligned} 0, & t<t_{0, p} \\ r_{p}\left(I_{\text {max }}-\left(I_{p}+I_{c}\right)\right), & t \geq t_{0, p} \\ 0, & t<t_{0, c}\end{aligned}\right.$
$\frac{d I_{c}}{d t}=\left\{\begin{aligned} r_{c}\left(I_{\text {max }}-\left(I_{p}+I_{c}\right)\right), & t \geq t_{0, c}\end{aligned}\right.$ Equation 5a Equation $5 b$

The differential equation includes two types of infected plants, plants infected by the experimentally added pathogen, $p$, and plants infected by pathogens in the control treatment, $c$ (Eqn. 5).

The models were fitted to the data by using a numerical integration routine (lsoda () from the deSolve package in $\mathrm{R}$ [Soetaert et al. 2010; R Core Team 2014]) combined with the maximum likelihood optimizer mle2() from the package bbmle (Bolker \& R Development Core Team 2014). To ensure the estimation of high infection rates, we chose a step size for the numerical integration routine ( 1 soda ( ) ) of 0.025 (default is 0.1 ) and allowed the maximum likelihood optimizer (mle2()) to try at maximum 10,000 iteration steps (control= list (maxit=10000); default is 100). Integrative maximum likelihood estimations of nonlinear models may result in local optima that lead to biased results or, in dependence of the starting parameters, fail completely (Bolker 2008). To cope with this problem, we repeated each 
analyses 100 times with starting parameters randomly sampled out of a uniform distribution with: $0.0001 \leq r \leq 3 ; 0.0001 \leq t_{0} \leq 0.8 \times \min \left(t_{\text {Infectedcontrol }>0}\right) ; 0.01 \leq r_{p} \leq 15 ; 0.001 \leq t_{0 p} \leq 0.8$ $x \min \left(t_{\text {Infectedtreatment }>0}\right)$.

We checked for the quality of the fitted parameters in each experimental unit by (1) selecting all model fits out of the hundred fittings where the $\triangle \mathrm{AIC}$ was below 2, and (2) we calculated the coefficient of variation for to of the remaining model fits. Only if the coefficient of variation was below 0.05, we rated the fit as trustful. Subsequently, we chose the value for to of the fit with the lowest AIC for further analyses.

Subsequent analyses were performed using the statistical software R (R Core Team 2014) using the packages car (Fox \& Weisberg 2011), lavaan (Rosseel 2012) and semTools (Pornprasertmanit et al. 2014).

In order to unravel mechanisms responsible for plant community effects on soil suppression, we used structural equation modelling, which allows the analyses of variables in a multivariate approach (Grace 2006). All variables were continuously coded. The initial model contained the exogenous variables plant diversity, presence of grasses, and presence of legumes in addition to the endogenous variables root biomass (g fresh weight; $\log _{10}$-transformed), the abiotic factors $\mathrm{pH}$, total $\mathrm{C}$ and $\mathrm{N}$ content, and soil moisture (\% data; logit-transformed) as well as the abundance of Actinomyces, Bacillus, and Pseudomonas (colony forming units [cfu] per root system; $\log _{10}$-transformed) as potential variables explaining soil suppression against $R$. solani (initial infection occurrence (to); $\log _{10}$-transformed;

Supplementary Table 2; Figure 8 a). This model was improved by: (i) separately analysing each endogenous variable and its dependencies in a linear regression and selecting the most parsimonious models via using the stepAICc() function (Scherber 2009), respectively. Subsequently, each of those separately predefined paths were used to create a second SEM. (ii) checking model modification indices for potential additional paths and undirected correlations that might not have been considered in the second model (iii) deriving the most parsimonious model by removing non-significant pathways. Model selection was conducted by comparative fitting (Eisenhauer et al. 2015) and using corrected Akaike's Information Criterion (AICc; Akaike 1974; Burnham \& Anderson 2004) and absolute goodness of fit was determined by using $\chi^{2}$ tests ( $P>0.05$; Grace 2006). 
To account for additional plant effects, we performed a linear model with the residuals of the SEM fit (after fitting of abundance of Actinomyces, Bacillus, and Pseudomonas, pH, plant diversity and legume presence) as being dependent on the presence and $2^{\text {nd }}$ order interactions of the plant species. We selected the most parsimonious model via AICc. Significance of slopes were determined via t-tests.

\subsubsection{Results}

Structural equation model (SEM). Structural equation modelling revealed pathogen suppression to be affected by multiple mechanisms that are shaped by plant community composition. The initial model $\left(\chi^{2} 11=65.30 ; P<0.001\right.$; Figure 8 a; Supplementary Table 2$)$ could be improved by (i) using linear models to separately predefine each endogenous variable and its main dependencies to set up a second SEM (AICC $\left.=-1640.10 ; \chi^{2} 22=27.64 ; P=0.130\right)$, (ii) checking model modification indices, and (iii) removing non-significant pathways (AICC $=-1649.73 ; \chi^{2} 21$ $=17.22 ; \mathrm{P}=0.698)$. The final model explained $32 \%$ of the variance in pathogen suppression Figure 8 b; Supplementary Table 3).

Plant diversity increased root biomass production as well as soil $\mathrm{pH}$, thereby indirectly increasing the abundance of Bacillus and thereby increasing pathogen suppression (although the effect being small). In addition, the abundance of Bacillus increased in presence of grasses, while grasses slightly decreased root biomass. Root biomass, in turn, indirectly decreased the abundance of Bacillus via decreasing soil moisture. Further, soil pH decreased pathogen suppression. Despite the identified indirect pathways, a direct positive effect of plant diversity on pathogen suppression remained in the final model. The presence of legumes increased the abundances of Pseudomonas and Actinomyces and furthermore, directly decreased pathogen suppression. While being positively correlated, the abundance of Pseudomonas and Actinomyces decreased with root biomass and in presence of grasses. Pathogen suppression increased with increasing abundance of Actinomyces, whereas it marginally decreased with increasing abundance of Pseudomonas (Figure 8 b, Supplementary Table 3). 

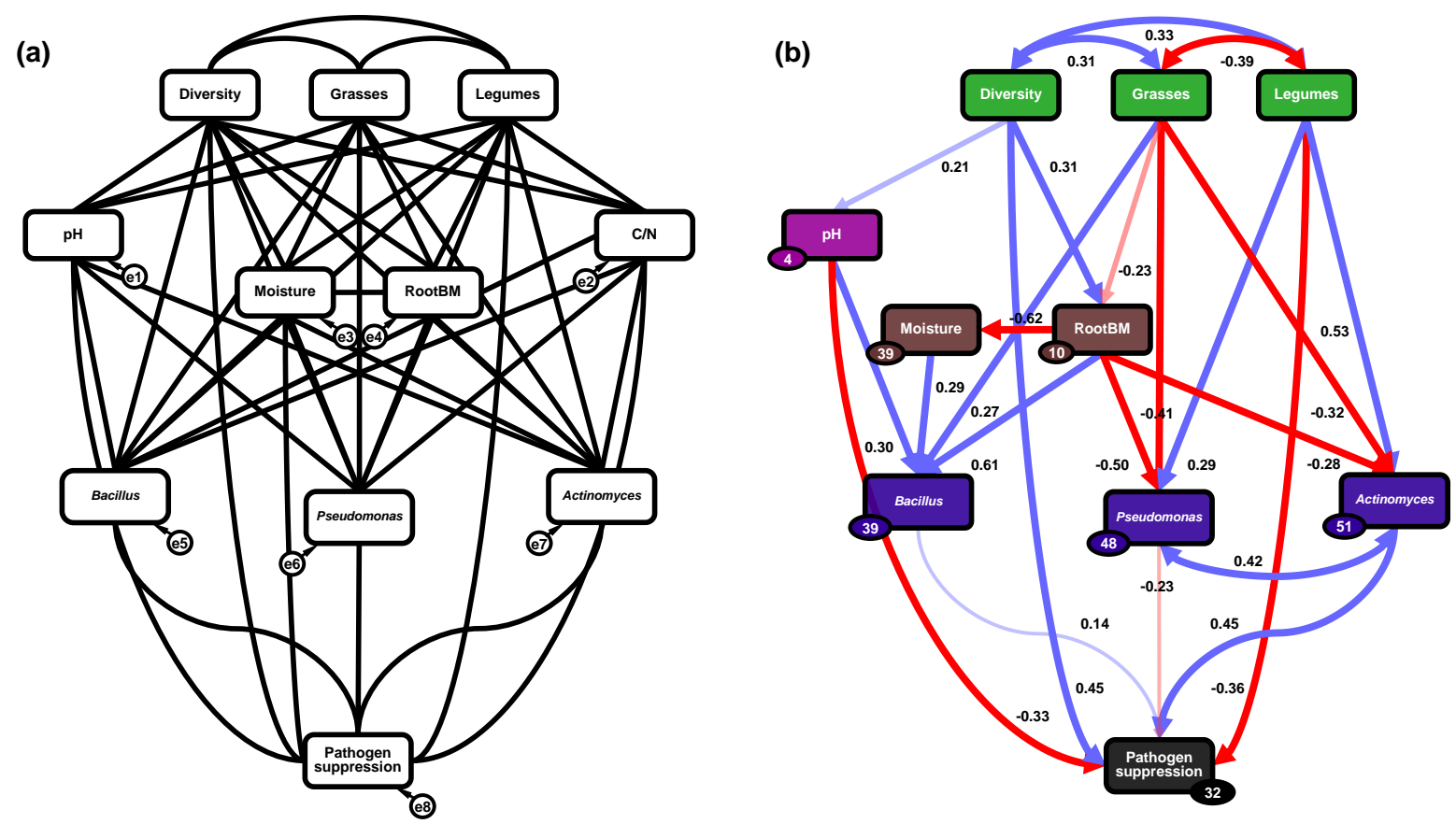

Figure 8. Structural equation model (see (a) for initial model) of (b) direct and indirect (through changes in soil pH, root biomass, soil moisture, and bacterial abundances) effects of plant community composition on pathogen suppression. Exogenous variables (plant diversity and functional group affiliation) are given on top, endogenous variables below. The data did not significantly deviate from the respective models (see main text for model fits). Single-headed arrows represent causal relationships and double-headed arrows indicate undirected correlations. Numbers on arrows give standardized path coefficients. Blue arrows indicate positive and red negative relationships; bold arrows indicate significant $(P \leq 0.05)$, medium size arrows indicate marginally significant $(P \leq$ $0.1)$, and thin arrows non-significant $(P>0.1)$ estimates. Circles indicate error terms $(e 1-e 8)$. Numbers close to endogenous variables indicate the variables variance explained by the model ( $R^{2}$; percent).

Plant-plant interaction analyses. Analysing the residuals of the final SEM fit revealed that beyond plant diversity and legume presence, specific plant-plant interactions play an important role in influencing the pathogen suppressive potential of soil (Figure 9). Here, the most parsimonious model included the species pairs Medicago-Lolium and Dactylis-Festuca that increased pathogen suppression (Figure 9 a, d), and Medicago-Dactylis and Lolium-Festuca that decreased pathogen suppression (Figure 9 b, c). Further, the species pair Festuca-Trifolium $r$. remained in the most parsimonious model and slightly decreased pathogen suppression (Figure 9 e). Interestingly, the positive effect of Medicago-Lolium and Dactylis-Festuca was most obvious at plant diversity level 2, whereas the negative effect of the species pair Festuca-Lolium and Festuca-Trifolium r. was most pronounced at diversity level 4 (Figure 9 f). Interactions explained additional 32\% of the remaining variance (after fitting the SEM) in pathogen suppression, resulting in $64 \%$ explained variance in total. 

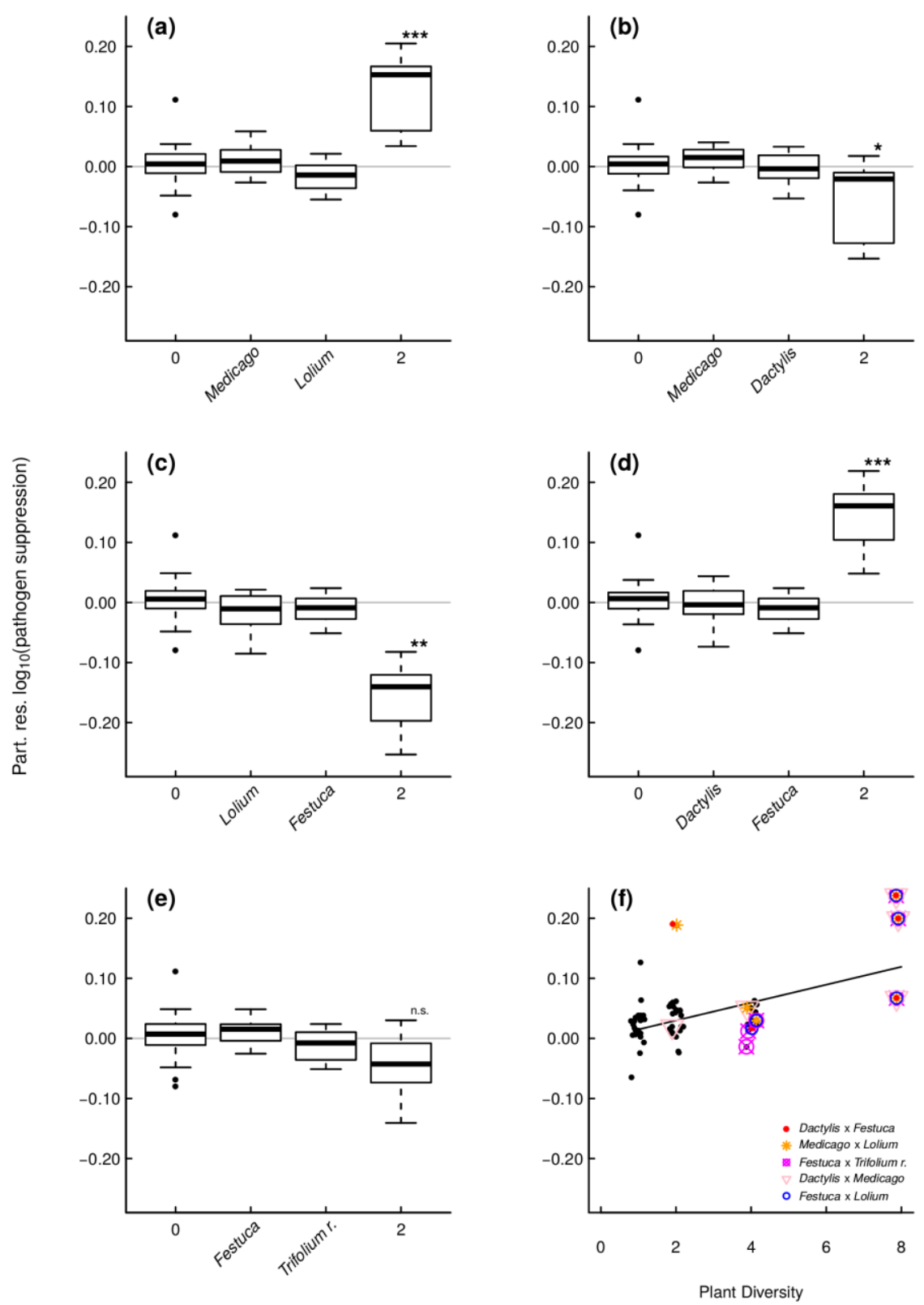

Figure 9. Partial residuals of $\log _{10}$-transformed pathogen suppression (according to the most parsimonious model of the interaction analyses) as affected by (a) Medicago and Lolium, (b) Medicago and Dactylis, (c) Lolium and Festuca, (d) Dactylis and Festuca, (e) Festuca and Trifolium r.. First box per graph indicates both plant species being absent " 0 "; second and third box indicate named plant species being present and the other being absent; fourth box indicates both plant species being present "2" (left to right). Interaction effects were tested against zero (twotailed t-test). Asterisks denote the level of significance: ${ }^{*} p \leq 0.05, * * P \leq 0.01, * * * p<0.001$. (f) Partial residuals of $\log _{10}$-transformed pathogen suppression (according to the most parsimonious SEM fit) as affected by plant diversity.

Additional analyses. Interestingly, when investigating whether the plant diversity effect was due to the presence of single species (sampling-effect; Aarssen 1997; Tilman et al. 1997; Huston 1997) by fitting the presence of Bromus, Dactylis, Festuca, Lolium, Lotus, Medicago, Trifolium 
$p$. and Trifolium $r$. separately in a linear regression and fitted the residuals of the respective analyses against plant diversity (Latz et al. 2015; Weidner et al. 2015), the plant diversity effect only remained when fitted after the presence of some legume species (Supplementary Table 4). Further, the diversity effect disappeared when fitted after both the number of legume and the number of grass species (Supplementary Table 4).

\subsection{5 | Discussion}

Sustainable agriculture aims at optimizing crop yield while minimizing deleterious impacts on the environment and human health. Microbial communities that inhibit plant pathogens represent a promising tool to achieve this goal (Mendes et al. 2013; Philippot et al. 2013). Soil microbial consortia are driven by soil properties and plant community composition (Garbeva et al. 2004; Berg \& Smalla 2009; Philippot et al. 2013). However, so far research neglected the complex linkages taking place in the rhizosphere when predicting or manipulating the suppressive potential of soils. In the present study we provide a mechanistic framework showing how the complex interactions between plants, soil and microorganisms jointly shape soil suppressiveness.

In the present study, pathogen suppression is influenced by a complex set of abiotic as well as biotic rhizosphere properties that are in turn linked, directly or indirectly, to plant community composition. Plant community composition affected $\mathrm{pH}$ and the abundance of Actinomyces (positively correlated with Pseudomonas abundance), that both significantly affected the suppression against $R$. solani. Further, certain interactions between plant species explained a large proportion of pathogen suppression in addition to the presence of plant functional groups and plant diversity per se. This suggests that plant community effects on soil abiotic and biotic properties alter microbial consortia in the rhizosphere and interactions therein, which need to be taken into account for predicting and manipulating the disease suppressive potential of soils.

Effects of plant diversity. Generally, our results underline the importance of plant diversity as an important driver of soil suppression. This is supported by studies showing (1) soil suppressiveness to rapidly vanish during the conversion of grasslands to monocultures, which was ascribed to biocontrol microbes being associated to diverse grasslands (Garbeva et al. 
2006); (2) soils from species-rich grasslands to host high abundances of bacteria associated with pathogen suppression, which in turn improved disease suppression (Latz et al. 2012), and (3) diverse plant communities supporting higher abundances of bacteria being active in producing antifungal compounds (Latz et al. 2015).

The SEM approach revealed that part of the plant diversity effect on the community structure and functioning of biocontrol bacteria was mediated by increased root biomass and soil $\mathrm{pH}$. This is in line with a recent field study on experimental grassland, showing that plant diversity increases root biomass and soil pH, and thereby microbial biomass in soil (Eisenhauer et al. 2013).

Effects of plant functional groups. The presence of functional groups (grasses and legumes) also predicted suppressiveness and again the effects were partly mediated by changes in root biomass and microbial communities. Generally, plant functional groups inconsistently affected the three groups of biocontrol bacteria. While grasses increased the abundance of Bacillus, they decreased the abundance of Pseudomonas and Actinomyces. Interestingly, via decreasing root biomass the presence of grasses in parallel also increased the abundance of Pseudomonas and Actinomyces. In addition, the abundance of Pseudomonas and Actinomyces was increased in presence of legumes. In an earlier study legumes and grasses also shaped biocontrol Pseudomonas communities, but legumes detrimentally and grasses beneficially affected their abundance (Latz et al. 2012). However, effects of legumes and grasses also have been shown to be species specific (Latz et al. 2015), and functional group effects on biocontrol bacteria therefore might be dependent on the respective species pool.

Effects of root biomass associated by effects of soil moisture. Root biomass increased the abundance of Bacillus but decreased that of Pseudomonas and Actinomyces. Root morphology differs considerably between plant species and shapes rhizosphere microbial communities (Berg \& Smalla 2009). In accordance, inconsistent results of root biomass effects on bacterial abundances in diverse grassland communities were recently suggested to be driven by species identity (Latz et al. 2015). Species-specific analyses showed strong effects of the presence of Medicago on root biomass (data not shown), suggesting that a higher proportion of Medicago roots might foster Bacillus while decreasing the abundance of Pseudomonas and Actinomyces. Further, via decreasing soil moisture root biomass also decreased the abundance of Bacillus, 
but this neither affected the abundance of Pseudomonas and Actinomyces nor soil suppression. Generally, soil moisture is an important driver for soil microbial communities (Eisenhauer et al. 2013; Lange et al. 2014), and our results show that different microbial groups differ in their sensitivity to soil moisture.

Effect of soil pH. Soil pH significantly increased the abundance of Bacillus and further directly decreased pathogen suppression. The lack of effects of soil $\mathrm{pH}$ on the abundances of Actinomyces and Pseudomonas is not surprising since variations in $\mathrm{pH}$ were small (7.60- 7.85) and close to the optimum of most bacterial consortia (Rousk et al. 2010). However, the increased abundance at higher $\mathrm{pH}$ suggests that Bacillus has a slightly higher $\mathrm{pH}$ optimum then the other two bacterial groups. The decreasing effect of $\mathrm{pH}$ with higher $\mathrm{pH}$ levels on pathogen suppression might have been due to the low pH optimum of $R$. solani AG3 (Ritchie, Bain \& McQuilken 2009).

Effects of biocontrol bacterial communities. Bacillus abundance only marginally increased pathogen suppression. This supports the observation that Bacillus diversity rather than their abundance drives suppression against $R$. solani (Garbeva et al. 2006). Nevertheless, other pathogens than $R$. solani might have been affected by Bacillus abundance, and therefore the importance of this path in driving pathogen suppression should not be underestimated.

Interestingly, Pseudomonas and Actinomyces were positively correlated, and Actinomyces were the only bacterial group significantly increasing pathogen suppression. In a study on crop management effects on soil bacterial populations of Actinomyces, Pseudomonas and Bacillus, pseudomonads and Bacillus turned out to be the most important biocontrol agents associated with Rhizoctonia-suppressive soil (Garbeva et al. 2006). Further, another study identified Pseudomonas as main drivers of suppression, but other taxa, such as Actinomyces, were also associated to disease suppressiveness against R. solani (Mendes et al. 2011). These findings underline that soil pathogen suppression likely is not only due to the presence of certain antagonistic bacterial groups, but to facilitative interactions among bacterial groups or taxa (Mendes et al. 2011). This is also supported by the observation that bacterial strains can gain antagonism against pathogens when growing in bacterial consortia (Garbeva et al. 2011).

Effects of plant-plant interactions. In addition to the SEM approach, we evaluated the role of 
plant species interactions as drivers of pathogen suppression. Identified plant interactions explained additional $32 \%$ of the remaining variance (after fitting the SEM) in pathogen suppression, showing that pathogen suppression is strongly influenced by plant-plant interactive effects. Further, sequential analyses suggest that the direct positive diversity and the negative legume effect on pathogen suppression, we observed in the SEM, were driven by those plant-plant interactions (Supplementary Figure 3). In presence of competitors plants increase root exudation and alter exudate composition, thereby affecting rhizosphere microbial communities (Bais et al. 2006; Semchenko et al. 2007). In addition, different plant species are suggested to use resources in a complementary way, thereby contributing to ecosystem functioning (Loreau et al. 2001; Eisenhauer 2012). Signaling adaptations in plants to pathogens results in differential responses in root-associated bacteria (de Werra et al. 2008), and may require adequate resource availability. Therefore, an importance of resource complementarity in plant community resistance to pathogens is likely. However, whether the observed plantplant interaction effects on pathogen suppression were due to complementary resource acquisition, or plant competition driven changes in root exudation, will need further evaluation. Remarkably, in the sequential approach, we observed high pathogen suppressiveness at diversity levels 2 and 8 . Interestingly, these positive effects likely were due to synergistic effects of plant species being in close proximity, i.e. were arranged side by side. Further, in each of the 4 species treatments and in one 8 species treatment positive interacting plant individuals were either not arranged side by side or accompanied by negatively interacting species, which might explain their low pathogen suppression (Supplementary Figure 2). Unfortunately, due to designlimitations we were not able to directly test for $3^{\text {rd }}$ order interactions. Microbial communities generally are suggested to respond with a time lag to plant community changes (Eisenhauer et al. 2010a). Our design, in which each plant community composition was harvested and the same plant community planted again (but differentially spatially arranged), might have uncovered that plant-plant interaction effects on specific soil functions, such as soil suppression, are rather short-term effects. Further studies are needed to disentangle spatial and temporal effects of plant communities on the rhizosphere-environment and their implications for specific microbial functions.

Conclusion. Results of our study support the assumption that plant community composition, soil abiotic properties, and microbial communities being antagonistic to soil pathogens are 
linked and interactively shape the suppressive potential of soils (Garbeva et al. 2004; Berg \& Smalla 2009; Philippot et al. 2013). In addition to plant community induced changes in soil pH, root biomass, and abundances of biocontrol bacteria, plant-plant interactions were of major importance in driving the disease suppressive potential of soils. Therefore, to mechanistically understand the functioning of microbial communities involved in pathogen suppression and enabling to predict and manipulate the suppressive potential of soils, it is necessary to take the environment shaping potential of a plant community into account. The results represent an important step in understanding the complexity of mechanisms linking plant community composition and plant disease suppression.

\subsubsection{Acknowledgements}

We thank Paul Goetsch, Simone Weidner, Anna Hille, Ingrid Kleinhans, Susanne Böning-Klein and Guido Humpert for support in conducting the experiment. Further, we thank M. Varrelmann (IfZ, Göttingen, Germany) for kindly advising Rhizoctonia inoculum preparation. This study was funded by the German Science Foundation (JO 935/2-1). Support came from the German Centre for Integrative Biodiversity Research (iDiv) Jena-Halle-Leipzig, funded by the German Science Foundation (FZT 118). 

2.4 Research Chapter 4

\section{INTERCROPPING AND SOIL PROTOZOA INTERACTIVELY SHAPE SOIL FUNCTION AND CROP YIELD}

Ellen Latz, Simone Weidner, Patricio Sobrero, Juan Galantini, Santiago Lorenzatti, Alexandre Jousset and Claudio Valverde 


\subsubsection{Summary}

Intercropping systems, in which different crop species are sown together in the same field, are increasingly being investigated as a sustainable, high yield agricultural practice. A better understanding of soil processes linked to higher productivity of mixed cultures is an important tool to apply intercropping in an efficient way.

We used a soybean-maize intercropping system and scrutinized the links between crop richness, soil enzymatic profiles and yield. We gave a special attention to protozoa, a group of microbial predators exerting a strong control on the structure and function of bacterial communities but often overlooked in agricultural research.

We observed that mixing soybean and maize increased crop yield. Further, we provide first evidences that cropping regime interactively with soil protozoa shapes soil functioning by essentially influencing soil enzyme activities and thereby influences yield.

We suggest that resident key soil biota (protozoa) that regulate important soil functions should be taken into account in order to predict the effect of agricultural practices on soil fertility and plant yield. 


\section{4 .2 Introduction}

The growing human population and dwindling resources call for new strategies to secure agricultural yields while reducing fertilizer input and thereby minimizing negative impacts on the environment (Tilman et al. 2002). Current agricultural systems usually rely on monocultures, with or without crop rotation. While optimizing the use of mechanized management strategies, monocultures tend to be vulnerable to diseases and require high fertilizer input to reach a given yield (Tilman et al. 2002). The use of intercropping, in which multiple crop plants are sown on the same field, appears as a promising method to sustainably increase yields (Li et al. 2014). Mixed plant communities often show a higher yield than monocultures, an effect that might be due to promotion of beneficial soil (Eisenhauer et al., 2012).

Intercropping cereal fields with legumes that, due to their association with rhizobia increase nitrogen supply, results in an increased cereal yield (Chu, Shen \& Cao 2004). Monocots on their side enhance global yield by supporting beneficial bacteria, such as biocontrol pseudomonads, which suppress phytopathogens (Mazzola 2007; Latz et al. 2012). Further, some grasses, support aerial fungal endophytes that protect neighboring legumes from aphid herbivory (García Parisi, Grimoldi \& Omacini 2014). Thus, setting up appropriate plant mixtures promoting the activity of beneficial soil organisms may help to reach high agricultural yields while reducing agrochemical input.

Soybean and maize are two of the most relevant crops in temperate and subtropical areas. In Argentina, a total of 25 million hectares have been devoted to soybean and maize crops in the 2012/2013 campaign (SIIA 2014). The productivity of maize and soybean together reached 81 million of tons in 2013, with 32 million of tons of maize and 49 million of tons of soybean (SIIA 2014). Interestingly, first studies on maize and soybean intercropping reported to increase yields in terms of land-use efficiency (Verdelli, Acciaresi \& Leguizamon 2012; Ariel et al. 2013) and enhanced soil-quality (Regehr 2014). However, the short-term impact of maize-soybean intercropping on soil biota and microbial functionality as well as their impact on yield have not yet been explored.

In this study, we followed the effect of intercropping soybean and maize on soil functioning and crop yield. We measured enzymatic activity patterns to estimate microbial traits involved in nitrogen, carbon and phosphorus cycling as well as suppression of soil borne pathogens. Soil 
enzymes are important bioindicators of soil health (Burns \& Strauss 2012) as they reflect the ability of soil microorganisms to transform nutrients from the soil organic material into forms available for uptake by plants. In addition, lytic exoenzymes such as chitinase or proteases play an important role in pathogen suppression (Haas \& Defago 2005; Kielak et al. 2013). In addition, we measured the abundance of protozoa, a key soil taxon that structures soil microbial community composition and functioning (Rosenberg et al. 2009; Jousset 2012), particularly in relation to nutrient cycling and pathogen suppression (Bonkowski 2004; Müller et al. 2013). We expected intercropping to increase protozoa abundance and improve enzymatic activity either by a sampling effect, that is, increasing the chance that at least one of the species will be particularly supportive to a given function (Huston 1997). Alternatively, interaction between the two sown plant species may result in a higher belowground population growth and activity (Eisenhauer et al. 2010a, 2013), which may positively affect fertility. Interplay between plant composition, soil communities and subsequent soil fertility are often difficult to separate (Eisenhauer et al. 2010b). Thus, we used a structural equation modelling approach (Grace 2006) that enables to unravel direct and indirect pathways driving the effect of intercropping on soil functioning and yield.

\subsubsection{Materials and Methods}

Field site. The field site is located near the city of Monte Buey (Córdoba province, Argentina). The climate in the region is characterised as Pampean Temperate (subhumid), with an average temperature of $23^{\circ} \mathrm{C}$ and a total of $445 \mathrm{~mm}$ of rainfall during the period of the experiment (13 November 2012 to 16 May 2013). Soil is characterized as a Typic Argiudoll of silt loam texture. Prior to the experiment, maize has been grown at the whole field site. Soybean (DM3810) and maize (DK692RR) seeds were sown in November 2012. Planting was done mechanically using a John Deere 1740 planter. Triplicate plots of $65 \times 18 \mathrm{~m}$ each were sown with soybean alone (40 seeds per $\mathrm{m}^{2}$ ), with maize alone (7.6 seeds per $\mathrm{m}^{2}$ ), or with soybean and maize as alternating individual sowing lines (20 seeds per $\mathrm{m}^{2}$ for soybean and 3.8 seeds per $\mathrm{m}^{2}$ for maize). In all plots, the distance between rows was $52 \mathrm{~cm}$. Maize was fertilized at the moment of sowing with $90 \mathrm{~kg} / \mathrm{ha}$ of mono ammonium phosphate and re-fertilized with $235 \mathrm{~kg} / \mathrm{ha}$ ureaammonium nitrate ( $32 \%$ of $\mathrm{N}$ ) at the V5 stage. Soybean seeds were coated with a commercial 
inoculant containing Bradyrhizobium japonicum in addition to fungicides (thiram and carbendazim) according to the instructions of the supplier (Rhizopack 101; Rizobacter Argentina S.A.)

Sampling. Soil samples were taken in March 2013. At each plot, three sites (subplots) were randomly chosen excluding each the outer 2 meters to prevent border effects of neighboring fields. At each site we sampled three soil cores to a depth of $5 \mathrm{~cm}$ using a metal corer (inner diameter $7 \mathrm{~cm}$ ) within one row, within the neighboring row, and in-between the two rows (resulting in three positions per subplot), respectively. The three cores per position were pooled, homogenized and sieved $(2 \mathrm{~mm})$ to remove macrofauna, roots and stones and stored at $4^{\circ} \mathrm{C}$ until analyses.

Harvest. Plants were harvested mechanically in May 2013 with John Deere 9650 harvest equipment. In intercropping plots, maize was harvested in a first pass at $50 \mathrm{~cm}$ height, and then soybean was harvested in a second pass at $3 \mathrm{~cm}$ height. As this procedure leads to soybean grain loss due to machine trampling, the observed yield is lower than the real one. Thus, soybean yield from intercropping plots was corrected by multiplying by 1.33 , a correction factor previously determined by comparison to manual harvesting (Romagnoli, J.; pers. comm.). Yield was calculated as g applied seed ${ }^{-1}$.

Enzyme tests. Extracellular chitinase, ß-glucosidase and phosphatase were measured in a microplate reader (BMG LABTECH POLARstar Omega; Ortenberg, Germany) via fluorogenic assays (Marx, Wood \& Jarvis 2001), using the software associated with the equipment (BMG LABTECH MARS data analysis). For each sample, $0.1 \mathrm{~g}$ of soil (fresh weight) were dissolved in $10 \mathrm{ml}$ 0.1 M MES buffer (2-[N-Morpholino]ethanesulfonic acid, pH 6.1) and homogenized with a IKA Ultra Turrax Tube Drive (Staufen im Breisgau, Germany). Enzyme activity was measured at a substrate concentration of $40 \mu \mathrm{M}$, corrected for quenching effects of soil particles on the fluorescence intensity of MUB and calculated as enzyme activity $\min ^{-1} \mathrm{~g}_{\text {soil }}{ }^{-1}$.

Protozoan abundance. Numbers of protozoa were determined by the most-probable-number (MPN) method based on an established protocol (Rønn, Ekelund \& Christensen 1995). Briefly, $0.2 \mathrm{~g}$ of air-dried soil were dissolved in 20 volumes of autoclaved distilled water, and then 
shaken vigorously at room temperature for $20 \mathrm{~min}$ in a 15-ml Falcon tube containing 3 stainlesssteel beads ( $4 \mathrm{~mm}$ of diameter), to liberate the protozoa from soil particles. The soil samples were distributed in 96-well microtiter plates (four samples per plate; Cellstar ${ }^{\circledR}$, Greiner BioOne, Frickenhausen, Germany) by using four replicates and six threefold dilutions in modified Neff's amoeba saline (Page, 1988) supplemented with $0.3 \mathrm{~g} \mathrm{~L}^{-1}$ tryptic soy broth (Oxoid, Basingstoke, UK). Plates were incubated at $22^{\circ} \mathrm{C}$ in the dark and examined for the presence of protozoa (flagellates, amoebae and ciliates) after 8 days using an inverted microscope (200x magnification, phase contrast). A freely distributed Excel sheet (Jarvis, Wilrich \& Wilrich 2010) was used to convert the microtiter plate patterns to the MPN of fast-growing flagellates and total protozoa (individuals $\mathrm{g}^{-1}$ soil).

Statistical analyses. Data were analyzed using the statistical software R (R Core Team 2014) with the packages nlme (Pinheiro et al. 2014) and lavaan (Rosseel 2012). To be able to compare soybean and maize yields, both were normalized by dividing each measure by the respective treatments mean (norm. yield). The effect of treatment on norm. yield was analysed in pairwise comparisons by using Tukey's Honest Significance Difference (Tukey's HSD). In order to unravel the linkages between crop richness, protozoa, soil enzymatic profiles and yield we used structural equation modelling (SEM), which allows analysing variables in a multivariate approach (Grace 2006). In the initial model we used the exogenous variable crop richness as potential variable explaining norm. yield, presence of amoeba and ciliates, abundance of flagellates as well as chitinase, phosphatase and ß-glucosidase activity. The endogenous variables presence of amoeba and ciliates and abundance of flagellates were used as variables potentially explaining chitinase, phosphatase and ß-glucosidase activity. Further, the endogenous variables presence of amoeba and ciliates, abundance of flagellates as well as chitinase, phosphatase and ß-glucosidase activity were used as variables potentially explaining yield (continuous data were $\log _{10}$-transformed). Model modification indices were checked for potential additional paths that initially have not been considered in the model. Subsequently, model selection was conducted via using Bayesian information criterion (BIC; Burnham \& Anderson 2004) as well as $\chi^{2}$ tests ( $P>0.05$; Grace 2006).

We completed this approach by using linear mixed effect models fitted by restricted maximum likelihood (REML) with subplot and position (factorial) as random effects to account for spatial differences between samples. Here, we estimated effects of protozoa, namely flagellate 
abundance (continuous, $\log _{10}$ (individuals $\mathrm{g}^{-1}$ soil)), amoeba presence (factorial) and ciliates presence (factorial), on chitinase, phosphatase and ß-glucosidase activity ( $\log _{10}$ (enzyme activity $\left.\min ^{-1} g_{\text {soil }}{ }^{-1}\right)$ ) crop independently, in soybean, and maize monocropping-rows and in interrows (here, only subplot was used as random effect), where we expected plant root interactions to take place.

\subsubsection{Results}

Tukey's HSD indicates that intercropping maize with soybean increases maize yield up to $50 \%$, whereas soybean yield was not significantly affected by intercropping (Figure 10). The clear-cut stimulation of maize yield in intercropping with soybean compared with maize alone was not accompanied by overall significant changes in a set of chemical soil indicators, such as total nitrogen content, extractable phosphorus content, total organic carbon content, soluble carbohydrate and total carbohydrate content (Supplementary Table 5).
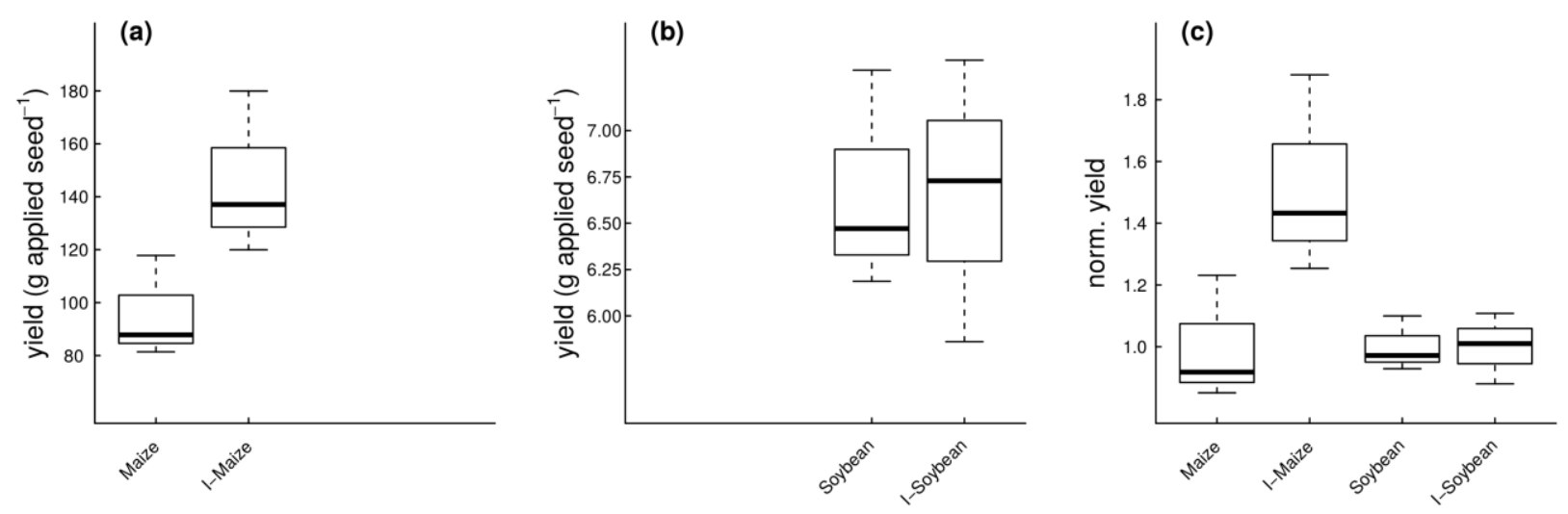

Figure 10. Yield (g applied seed $^{-1}$ ) of (a) maize and (b) soybean in monoculture (Maize, Soybean) and in intercropped fields (I-Maize, I-Soybean); (c) normalized yield, which is the respective yield divided by the treatments mean. *yield in I-Maize is significantly higher than in Maize (Tukey's HSD; P < 0.05).

Structural equation modelling (SEM) revealed that yield is affected by multiple mechanisms, including crop richness and enzymes activities that in turn were influenced by protozoa. The initial model $\left(B I C=-215.24 ; \chi^{2}{ }_{6}=19.99 ; P=0.003\right)$ could be improved by removing non- 
significant paths $\left(\mathrm{BIC}=-242.81 ; \chi^{2}{ }_{14}=9.82 ; \mathrm{P}=0.775 ;\right.$ Figure 11$)$. The final model explained $76 \%$ of the variance in yield.

Crop richness increased the activity of ß-glucosidase and directly increased yield, while protozoa weren't affected. ß-glucosidase activity and phosphatase activity decreased in presence of ciliates, but increased with increasing flagellate abundance. By contrast, chitinase activity, which also increased with flagellate abundance, was decreased in presence of amoeba. Further, amoeba and ciliate presence were correlated and amoeba presence was also correlated to flagellate abundance. In addition, amoeba directly increased yield. Chitinase activity decreased yield as so did ß-glucosidase activity that, although its effect was not significant, remained in the final model. While being marginally significant, phosphatase activity was the only enzyme activity having a positive effect on yield.

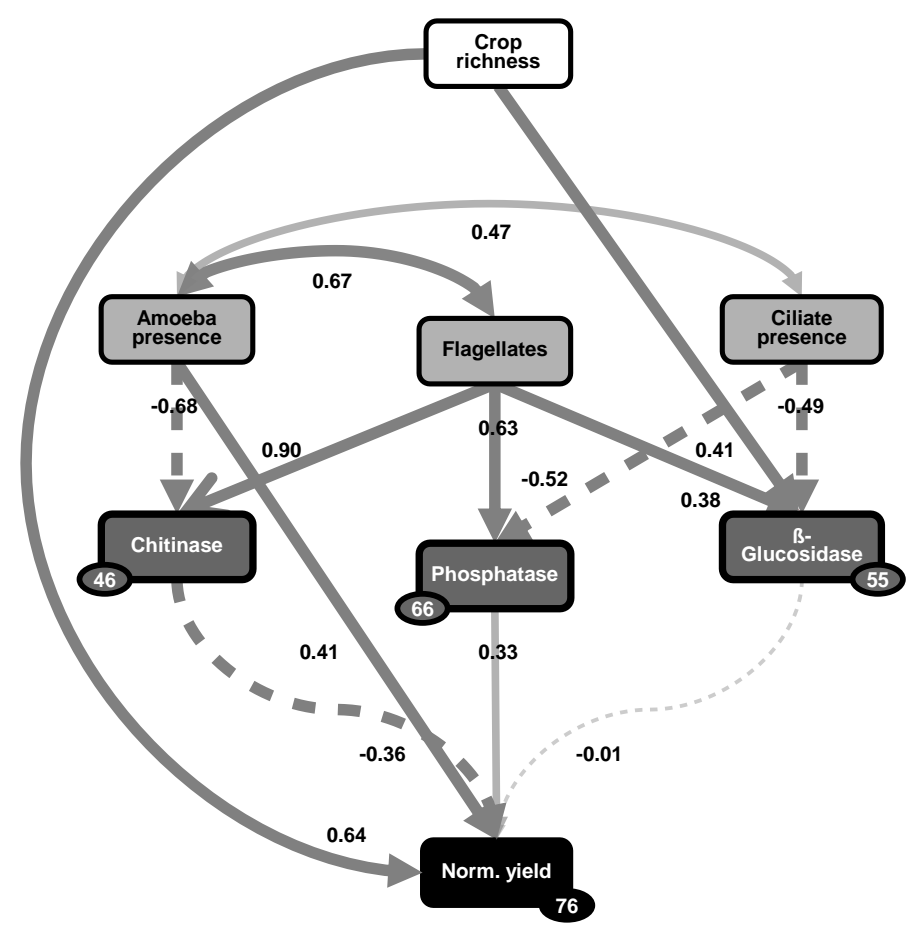

Figure 11. Final structural equation model showing effects of crop richness, protozoa abundance/presence and enzyme activities on normalized yield (see main text for model fit). Normal arrows indicate directed regressions and double-headed arrows indicate undirected correlations. Numbers on arrows indicate standardized path coefficients. Solid arrows indicate positive and dashed negative estimates; bold arrows indicate significant $(P \leq$ $0.05)$ thinner arrows marginally significant $(P \leq 0.1)$ and thinnest arrows non-significant $(P>0.1)$ estimates. Percentages close to endogenous variables indicate the variance explained by the model $\left(R^{2}\right)$. 
Generally, SEM results could only partially be rediscovered in the mixed effect models (Table 3). While we couldn't underline the observed positive effects of flagellates on enzyme activities, we could observe negative effects of amoeba on chitinase activity $\left(P_{F}=0.030\right)$ and ciliate presence on phosphatase activity $\left(P_{F}=0.032\right)$ that were independent of the cropping-regime in the mixed effect models. Further, ciliates decreased chitinase activity, an effect we only observed in maize-rows $\left(\mathrm{P}_{\mathrm{F}}=0.047\right.$; Table 3$)$. 
Table 3. Effects of Flagellate abundance, Amoeba presence and Ciliate presence on chitinase, B-glucosidase and phosphatase activities as indicated by Mixed Effects Models.

Chitinase activity

\begin{tabular}{|c|c|c|c|c|c|c|c|c|c|c|c|c|c|c|c|c|c|c|c|}
\hline & \multicolumn{5}{|c|}{ crop independently } & \multicolumn{5}{|c|}{ in maize-rows } & \multicolumn{5}{|c|}{ in soybean-rows } & \multicolumn{4}{|c|}{ in inter-rows } \\
\hline & DF & Estimate & S.E. & t-value & & DF & Estimate & S.E. & t-value & & DF & Estimate & S.E. & t-value & & DF & Estimate & S.E. & t-value \\
\hline Intercept & 36 & 0.418 & 0.09 & 4.59 & $* * *$ & 17 & 0.620 & 0.31 & 2.01 & & 17 & 0.423 & 0.09 & 4.50 & $* * *$ & 25 & 0.343 & 0.29 & 1.19 \\
\hline $\begin{array}{l}\text { Flagellate } \\
\text { abundance }\end{array}$ & 17 & 0.009 & 0.01 & 0.86 & & 8 & -0.015 & 0.04 & -0.39 & & 8 & 0.009 & 0.01 & 0.80 & & 25 & 0.018 & 0.04 & 0.51 \\
\hline & DF & $\begin{array}{l}\text { Mean } \\
\text { absent }\end{array}$ & $\begin{array}{c}\text { Mean } \\
\text { present }\end{array}$ & $\begin{array}{c}\text { F- } \\
\text { value }\end{array}$ & & DF & $\begin{array}{l}\text { Mean } \\
\text { absent }\end{array}$ & $\begin{array}{c}\text { Mean } \\
\text { present }\end{array}$ & F-value & & DF & $\begin{array}{l}\text { Mean } \\
\text { absent }\end{array}$ & $\begin{array}{l}\text { Mean } \\
\text { present }\end{array}$ & F-value & & DF & $\begin{array}{l}\text { Mean } \\
\text { absent }\end{array}$ & $\begin{array}{c}\text { Mean } \\
\text { present }\end{array}$ & F-value \\
\hline Ciliates & 17 & 0.510 & 0.474 & 1.78 & & 8 & 0.539 & 0.436 & 5.52 & $*$ & 8 & 0.488 & 0.506 & 0.18 & & 25 & 0.503 & 0.468 & 0.42 \\
\hline Amoeba & 17 & 0.510 & 0.432 & 5.65 & $*$ & 8 & 0.522 & 0.440 & 2.85 & & 8 & 0.500 & 0.463 & 0.33 & & 25 & 0.507 & 0.409 & 2.25 \\
\hline
\end{tabular}

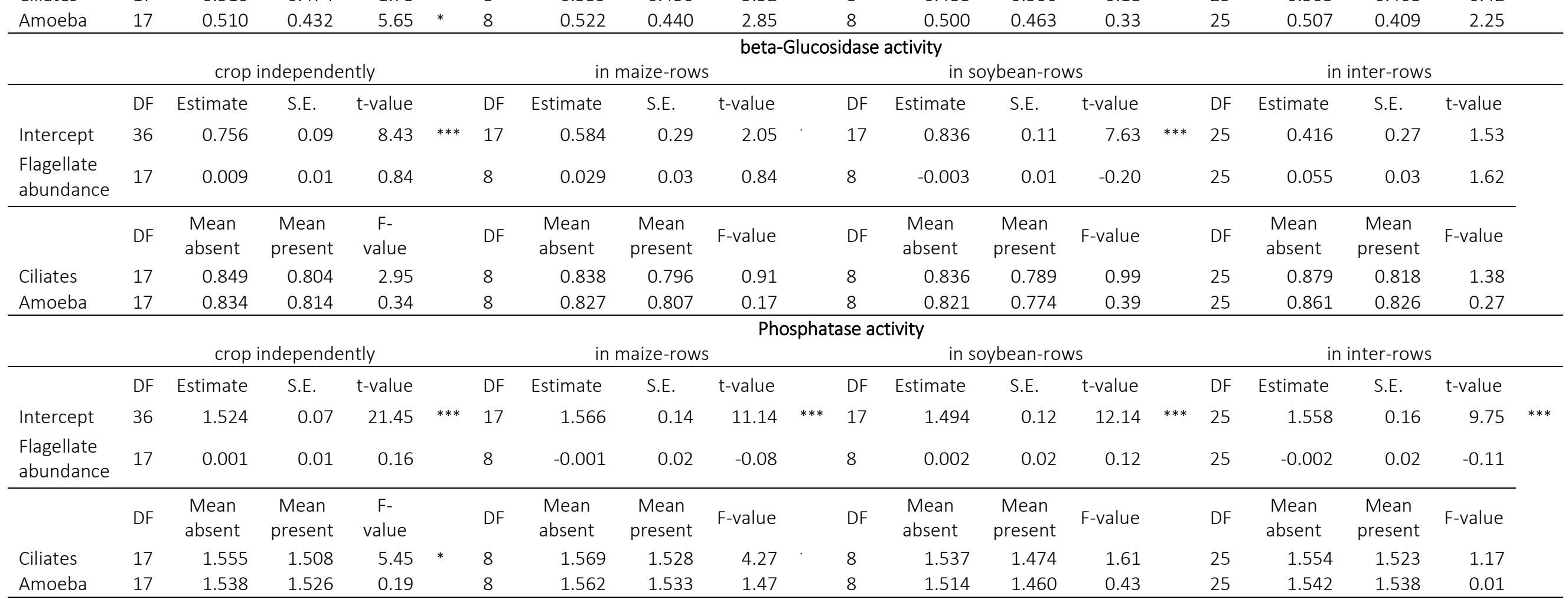

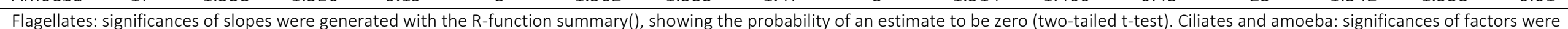
determined via analyses of variance (ANOVA). Asterisks denote the level of significance: $P \leq 0.1 ;{ }^{*} P \leq 0.05 ;{ }^{* * P} \leq 0.01 ;{ }^{* * *} P \leq 0.001$. DF: degrees of freedom. 


\subsection{5 $\quad$ Discussion}

While intercropping strategies are receiving increasing interest, it remains a challenge to unravel the pathways linking cropping treatment to yield. By using the structural equation modelling approach, we were able to separate direct effects of crop richness, different soil protozoa and soil inherent enzyme activities from indirect pathways connecting the investigated variables to crop yield. Protozoa are considered to be a keystone soil taxon regarding plant growth. As predators of bacterial communities, they select for species and functional genes responsible for plant growth (Bonkowski \& Brandt 2002; Müller et al. 2013) and enhance nutrient cycling (Uikman, Jansen \& van Veen 1991; Bonkowski 2004). Here, we provide first evidences that cropping strategy interactively with soil protozoa shapes soil functioning and thereby influences yield.

In the present study, crop richness had an important positive effect on normalized yield, which was mainly driven by an enhanced yield of maize in intercropping treatments (Figure 10 and Figure 11). We suggest that the maize plants benefitted of the nitrogen fixing property of rhizobia in their association with the legume, which is in line with other experiments where intercropping with legumes increased yields (Chu et al. 2004). In addition, different plant species can exploit different soil fractions and have different affinities for nutrients allowing for complementarity between species (Loreau et al. 2001; Eisenhauer 2012), an affect already suggested to improve yields in intercropping regimes (Bedoussac et al. 2015).

The SEM approach revealed that intercropping further directly increased ß-glucosidase activity, an enzyme linked to carbon cycling (Marx et al. 2001). We could, however, not connect the activity of this enzyme to plant yield, suggesting that this enzyme may have more long-term effects on plants.

Our approach revealed that protozoa may play a central role in linking plant diversity to soil fertility, and that the effect may be functional group-specific. Flagellates, ciliates and amoeba, which represent the three main functional types of protozoa in agricultural soils, (Ekelund \& Rønn 1994), responded differently to the cropping regime, had contrasting effects on enzymatic activity and plant yield. According to the mixed effect model, amoebae decrease chitinase activity independently of the crop diversity. By contrast, the negative effects of ciliates on chitinase and phosphatase observed in the SEM, might have been driven by the presence of maize as indicated by the mixed effect models and might be powered by specific compounds 
exuded by maize roots. Root exudates are suggested to play an important role in driving plantspecific effects on soil microbial communities (Bais et al. 2006; Berg \& Smalla 2009).

Amoeba, affected both enzymatic activity and directly promoted crop yield, indicating that they may affect plant yield via other mechanisms independent from enzymatic activity. Amoeba are known to support plant-growth-promotion by bacteria (Bonkowski \& Brandt 2002), an effect that might also have played a role in the present study.

Flagellates appeared as the functional group with the strongest effect on enzyme activity, stimulating the activity of all tested enzymes. The discrepancies between the SEM and the mixed effect model might be at least partially explained by the correlation effects between the three protozoan groups that we could not account for in the mixed effect models. However, by using mixed effect models in addition to the SEM we were able to account for differences between crop identities that we were not able to address in the SEM (due to the small sample size accompanied by limiting degrees of freedom).

With this study, we provide first evidence that agricultural treatment and soil biota may interactively explain the increased plant yield in intercropping systems. In this study we focused on a restricted number of organisms and functions. Due to the large number of soil organisms shaping soil fertility and plant health, we propose that our approach could be refined by including more functional groups, from bacteria to macrofauna across a higher number of sites to achieve a sufficient explanatory power. We suggest that combining those studies with the SEM approach will enable to disentangle the complex biotic interactions linking cropping regime to soil functioning and yield and may help developing agricultural practices that enhance soil fertility and yield sustainably.

\subsubsection{Acknowledgements}

We thank Jorge Romagnoli (La Lucía S.A. - Grupo Romagnoli) for providing access to the field site, and Daniel Peruzzi (La Lucía S.A. - Grupo Romagnoli) for managing the field experiment. Further, we thank Betina Agaras, Luciano Gabbarini, Luis Gabriel Wall and all other people in the laboratory for kind support throughout the study. This work was supported by grants PUNQ 1009/11 (Universidad Nacional de Quilmes, Argentina), DFG 935/2-1, BMBF 01DN13009, PIP 2008-801 (CONICET, Argentina), and AL-12-14 (Ministerio de Ciencia, Tecnología e Innovación 
Productiva, Argentina). Patricio Sobrero, Juan Galantini and Claudio Valverde are members of CONICET. 



\section{III | General Discussion}

Microbial communities producing antifungal compounds are crucial drivers of naturally occurring disease suppression in soil (Weller et al. 2002; Haas \& Defago 2005), and soil microbial consortia are interactively driven b y soil properties and plant community composition (Garbeva et al. 2004; Berg \& Smalla 2009; Philippot et al. 2013). However, there are still significant gaps in our understanding of the mediators that structure rhizosphere microbial functioning that prevent successfully improving plant growth and health (Bakker et al. 2012; Mendes et al. 2013).

This thesis demonstrated that (1) plant species within a diverse community exert a strong impact on antifungal traits of bacteria, (2) plant community composition affects soil abiotic and biotic properties and thereby drives the suppressive potential of soils, (3) plant-plant interactions exert a strong impact on disease suppression, and (4) cropping regime interactively with soil protozoa shapes soil microbial functioning.

The results underline that the abundance, activity and diversity of root-associated bacteria is affected by biotic and abiotic properties of the rhizosphere environment (Berg \& Smalla 2009). Therefore, to mechanistically understand the functioning of microbial communities involved in pathogen suppression and enabling to predict and manipulate the suppressive potential of soils, it is necessary to consider the potential of plant communities to shape microbial communities in soil.

\subsection{Effects of plant species diversity}

In the experiments presented in Chapters 2.1 and 2.3 plant species richness significantly affected soil microbial functioning. This is in line with studies identifying plant diversity as important driver of the diversity, abundance and activity of soil microorganisms (Stephan et al. 2000; Zak et al. 2003; Liu et al. 2008; Eisenhauer et al. 2010a). Further, the importance of plant diversity in driving microbial communities involved in pathogen suppression is highlighted (Garbeva et al. 2006; Weller 2007; Latz et al. 2012). 
Bacterial population density turned out to be a distinct mediator of plant diversity effects on bacterial gene activities (Chapter 2.1; Latz et al. 2015). Effects of plant diversity on microbial density were observed in several studies (Chapter 2.3; Garbeva et al. 2006; Weller 2007; Latz et al. 2012), and density dependent gene activity was also observed previously (Rochat et al. 2010). Further, soil pH and plant root biomass mediated plant diversity effects on a plant pathogen and on groups of bacteria antagonistic to plant pathogens (Chapter 2.1 [root biomass], Chapter 2.3 [root biomass and $\mathrm{pH}$ ]), underlining their role in mediating plant diversity effects on microbial communities (Eisenhauer et al. 2013).

However, the observed diversity effects turned out to be mainly driven either by the presence of specific plant species (Chapter 2.1) or specific plant species interactions (Chapter 2.3). Therefore, although species richness measures often cover significant plant community effects on ecosystem functions, they might be not adequate to mechanistically understand plant community driven effects on given ecosystem functions (Loreau et al. 2001; Ebeling et al. 2014).

\subsection{Effects of plant functional groups}

Effects of plant functional groups on microbial abundances and functioning were nonconsistent throughout the experiments of this thesis. Grasses and legumes were previously suggested as key plant functional groups for soil microbial communities (Spehn et al. 2000; Milcu et al. 2008; Eisenhauer et al. 2010a), and also turned out to shape Pseudomonas communities producing antifungal compounds (Latz et al. 2012). In the experiment presented in Chapter 2.3, grasses mediated effects on pathogen suppression mainly via increasing the abundance of Bacillus, and decreasing abundances of Pseudomonas and Actinomyces. Interestingly, the presence of grasses also partly increased the abundance of the latter two bacterial groups by decreasing root biomass. In addition, legumes mediated effects on pathogen suppression via increasing the abundance of Pseudomonas and Actinomyces. These results were unexpected, since legumes have been shown to decrease and grasses to increase Pseudomonas communities (Latz et al. 2012). In the experiment reported in Chapter 2.1, however, effects of the two grass respectively the two legumes species contrasted each other,

with one species increasing and the other decreasing Pseudomonas density and/or gene expression patterns (Latz et al. 2015). Here, plant species identity turned out to be the most 
important driver of Pseudomonas functioning, suggesting that functional group effects on biocontrol bacteria depend on the respective species pool. Understanding differences in functional properties of plant species may be essential for understanding diversity-ecosystem functioning relationships, but the importance of specific species traits may differ depending on a given ecosystem function (Cadotte, Albert \& Walker 2013). Results of this thesis underline that important species differences are not adequately covered by traditional functional group assignments (Ebeling et al. 2014), at least regarding differences in drivers of biocontrol microbial functioning.

\subsection{Effects of plant species identity}

Results of the experiment presented in Chapter 2.1 support the role of plant species identity in eliciting bacterial gene expression. This is in line with studies where the production of antifungal compounds by bacteria has been shown to be plant species and also plant cultivar specific (de Werra et al. 2008; Rochat et al. 2010). As shown by Rochat et al. (2010), the expression of genes coding for DAPG and $\mathrm{HCN}$ is associated with higher numbers of $P$. protegens CHAO (prior known as $P$. fluorescens $\mathrm{CHAO}$ ) colonizing the roots. Results of the experiment presented in Chapter 2.1, however, unraveled that bacterial density is not the only driving force in shaping bacterial gene expression, but unknown plant mediators (e.g., specific exudates) drove bacterial density and/or gene expression (Latz et al. 2015). Interestingly, not higher biomass of plant roots per se, which was suggested to increase habitat and resource availability (Spehn et al. 2000; Zak et al. 2003; de Deyn et al. 2011), but an enhanced root-biomass of specific species mediated plant effects on bacterial abundances (Chapter 2.1; Latz et al. 2015). This species-specific plant root biomass effect was supported by results of the experiment presented in Chapter 2.3. Here, Medicago was primarily accountable for increased root biomass (data not shown) that in turn increased the abundance of Bacillus, while it decreased that of Pseudomonas and Actinomyces. The importance of plant species identity for the community composition of rhizosphere bacteria was also supported by results of the study on intercropping, where ciliates decreased the activity of chitinase in presence of maize plants (an enzyme involved in the suppression of fungal pathogens; Loper et al. 2012; Chapter 2.4).

Remarkably, Lolium perenne that enhanced bacterial densities and activities in the gnotobiotic 
system (where only $P$. protegens CHAO was present) turned out to non-specifically foster microbial densities in natural soil, as indicated by increased colony forming units on nonselective media in presence of that grass species (Chapter 2.3; data not shown). Since gene activities have been shown to be partly density dependent (Rochat et al. 2010; Latz et al. 2015), this suggests that observations regarding bacterial gene activities in gnotobiotic systems may not be transferable to natural soil systems and have to be interpreted with care. Gene activities could not be measured in the experiment presented in Chapter 2.3, and possibly specific species drove gene activities. However, the presence of specific species had no important effect at least on the investigated host-pathogen system.

\subsection{Plant-plant interaction effects}

In the experiment presented in Chapter 2.3, direct effects of specific plant-plant interactions rather than plant species identity effects turned out to be essential drivers of pathogen suppression. It was shown that plant-plant competition increases the amount of exudates released by plant roots, an effect likely influencing microbial communities (Bais et al. 2006). Enhanced root exudation might also explain the increased enzymatic activity of the ßglucosidase (which is involved in sugar degredation; Marx et al. 2001) in response to intercropping (Chapter 2.4). In the same experiment, crop species richness increased crop yield, presumably due to a positive effect of soybean on maize. Maize plants likely benefitted from the nitrogen fixing property of rhizobia in association with legumes, which is in line with other experiments where intercropping with legumes increased crop yields (Chu et al., 2004). In addition, different plant species can exploit different soil fractions and have different affinities for nutrients allowing for species complementarity (Loreau et al. 2001; Eisenhauer 2012), an effect suggested to improve crop yields in intercropping systems (Bedoussac et al. 2015). Signaling adaptations in plants to pathogens, that results in differential responses in root-associated bacteria (de Werra et al. 2008), may require adequate resource availability. Therefore, resource complementarity of plant species is likely to play a role in plant community resistance to pathogens. However, the experiment presented in Chapter 2.3 was rather shorttermed and effects of complementary resource use or facilitative resource acquisition generally increase with time (Eisenhauer 2012). Whether the effect of plant-plant interactions on 
pathogen suppression, observed in the experiment presented in Chapter 2.3, was due to complementary resource acquisition or plant competition driven changes in root exudation needs further investigation.

\subsection{Conclusion}

The use of microbes for biological control of plant diseases represents an environmentally friendly and promising approach. Biocontrol bacteria are natural antagonists to pathogens and act on a local scale, thereby alleviating environmental pollution that is a problem of artificial, chemical pathogen control (Lugtenberg \& Kamilova 2009). However, for developing effective biocontrol agents, bacteria not only need to produce antibiotics in sufficient amounts, but also successfully compete for nutrients and niches on the root surface, and escape predation (Lugtenberg \& Kamilova 2009). Soil conditions and plant communities essentially impact the composition, dynamics and functions of rhizosphere microbial communities (Garbeva et al. 2004, 2006; Berg \& Smalla 2009). However, the extent to which each mediator impacts rhizosphere microbial functioning is not fully understood (Bakker et al. 2012; Mendes et al. 2013). Further, since many of the driving forces involved in disease suppression are interwoven, disentangling the mechanisms driving rhizosphere microbial functioning is essential (Philippot et al. 2013).

Despite underlining the role of plant diversity in driving soil disease suppression (Garbeva et al. 2006; Latz et al. 2012, 2015), results of this thesis show that plant diversity (and functional group) effects likely are mediated by specific plant identity and plant-plant interaction effects. Further, results of this thesis proved plant community induced changes in soil pH, root biomass and abundances of biocontrol bacteria to be important determinants of pathogen suppression. The results underline the assumption that plant community composition, soil abiotic properties and microbial communities being antagonistic to soil pathogens are linked and interactively shape the suppressive potential of soils (Garbeva et al. 2004; Berg \& Smalla 2009; Philippot et al. 2013). Choosing specific plant communities may enable to manipulate rhizosphere environmental conditions, thereby fostering microbial establishment in the rhizosphere and increase the disease suppressive potential of soils.

Overall, results of this thesis represent an important step in unravelling the complexity of 
mechanisms linking plant community composition and plant disease suppression.

\subsection{Perspectives}

Although having identified distinct mechanisms and unravelled indirect effects of plant community composition as drivers of the pathogen suppressive potential of soils, there is the need to investigate the rhizosphere system in more detail. In addition to abiotic soil conditions, plant protective bacteria and protozoa, the role of other (micro-) organisms need to be considered.

New methodologies, such as next-generation sequencing or non-invasive two-dimensional imaging, allow the assessment of the roles of organisms within communities thereby uncovering unknown microorganisms and genes and their functioning in rhizosphere interactions (Mendes et al. 2013; Philippot et al. 2013). This may enable to identify (micro-) organisms needed to fulfil specific ecosystem functions (Mendes et al. 2013). However, more important than knowing which microbial consortia are needed to fulfil specific functions might be knowledge on how their functioning can be maintained.

Plants essentially shape the rhizosphere environment (Raaijmakers et al. 2009), and the use of specific (sets of) plant traits as promising predictors of plant community effects on soil functions has been proven (Duffy 2008; Ebeling et al. 2014). However, the set of traits being important predictors may differ depending on the respective ecosystem function (Cadotte et al. 2013), probably explaining why previously used morphological, physiological and phenological traits failed in adequately predicting abundances of biocontrol bacteria (Latz et al. 2012). Identifying distinct plant traits is essential in order to predict and manipulate ecosystem functions mediated by plant effects on microbiota.

Root exudates are primarily discussed in mediating plant effects on microbiota in the rhizosphere (Bardgett \& van der Putten 2014). Therefore, understanding differences in plant exudation properties, and being able to relate them to environmental conditions, cropping regimes and plant traits is crucial to be able to successfully promote plant growth and health (Philippot et al. 2013).

The results of this thesis suggest that setting up plant communities selected for traits that support specific microbial communities in the rhizosphere can be used, in order to prepare the 
soil for subsequent crops. This would allow both the promotion of specific functions of microbial communities as well as induction of multifunctionality (since in managed systems multiple functions and services may be of primary importance; Duffy 2008).

I suggest that (1) additional (micro-) organisms involved in pathogen suppression and their drivers need to be identified, and (2) knowledge on plant traits that predict and maintain community functioning is needed, in order to improve environmentally friendly plant protection strategies and ensure the long term stability of crop yield. 



\section{IV | References}

Aarssen, L.W. (1997) High productivity in grassland ecosystems: effected by species diversity or productive species? , 80, 183-184.

Akaike, H. (1974) A new look at the statistical model identification. IEEE Transactions on Automatic Control, 19, 716-723.

Ariel, C.E., Eduardo, O.A., Benito, G.E. \& Lidia, G. (2013) Effects of two plant arrangements in corn (Zea Mays L.) and soybean (Glycine Max L. Merrill) intercropping on soil nitrogen and phosphorus status and growth of component crops at an Argentinean Argiudoll. American Journal of Agriculture and Forestry, 1, 22-31.

Baehler, E., Bottiglieri, M., Pechy-Tarr, M., Maurhofer, M. \& Keel, C. (2005) Use of green fluorescent protein-based reporters to monitor balanced production of antifungal compounds in the biocontrol agent Pseudomonas fluorescens CHAO. Journal of Applied Microbiology, 99, 24-38.

Baird, R.E., Watson, C.E. \& Scruggs, M. (2003) Relative longevity of Macrophomina phaseolina and associated mycobiota on residual soybean roots in soil. Plant Disease, 87, 563-566.

Bais, H.P., Weir, T.L., Perry, L.G., Gilroy, S. \& Vivanco, J.M. (2006) The role of root exudates in rhizosphere interactions with plants and other organisms. Annual Review of Plant Biology, 57, 233-266.

Baker, K.F. \& Cook, R.J. (1974) Biological Control of Plant Pathogens. Freeman, San Francisco, USA.

Bakker, M.G., Manter, D.K., Sheflin, A.M., Weir, T.L. \& Vivanco, J.M. (2012) Harnessing the rhizosphere microbiome through plant breeding and agricultural management. Plant and Soil, 360, 1-13.

Bandick, A.K. \& Dick, R.P. (1999) Field management effects on soil enzyme activities. Soil Biology and Biochemistry, 31, 1471-1479.

Bardgett, R.D. \& van der Putten, W.H. (2014) Belowground biodiversity and ecosystem functioning. Nature, 515, 505-511.

Bardon, C., Piola, F., Bellvert, F., Haichar, F. el Z., Comte, G., Meiffren, G., Pommier, T., Puijalon, S., Tsafack, N. \& Poly, F. (2014) Evidence for biological denitrification inhibition (BDI) by plant secondary metabolites. New Phytologist, 204, 620-630.

Barret, M., Frey-Klett, P., Guillerm-Erckelboudt, A.-Y., Boutin, M., Guernec, G. \& Sarniguet, A. (2009) Effect of wheat roots infected with the pathogenic fungus Gaeumannomyces graminis var. tritici on gene expression of the biocontrol bacterium Pseudomonas 
fluorescens Pf29Arp. Molecular Plant-Microbe Interactions, 22, 1611-1623.

Bedoussac, L., Journet, E.-P., Hauggaard-Nielsen, H., Naudin, C., Corre-Hellou, G., Jensen, E.S., Prieur, L. \& Justes, E. (2015) Ecological principles underlying the increase of productivity achieved by cereal-grain legume intercrops in organic farming. A review. Agronomy for Sustainable Development, in press.

Bell, T., Lilley, A.K., Hector, A., Schmid, B., King, L. \& Newman, J.A. (2009) A linear model method for biodiversity-ecosystem functioning experiments. The American Naturalist, 174, 836-849.

Berg, G. \& Smalla, K. (2009) Plant species and soil type cooperatively shape the structure and function of microbial communities in the rhizosphere. FEMS Microbiology Ecology, 68, $1-13$.

Bergsma-Vlami, M., Prins, M.E. \& Raaijmakers, J.M. (2005a) Influence of plant species on population dynamics, genotypic diversity and antibiotic production in the rhizosphere by indigenous Pseudomonas spp. FEMS Microbiology Ecology, 52, 59-69.

Bergsma-Vlami, M., Prins, M.E., Staats, M. \& Raaijmakers, J.M. (2005b) Assessment of genotypic diversity of antibiotic-producing Pseudomonas species in the rhizosphere by denaturing gradient gel electrophoresis. Applied and Environmental Microbiology, 71, 993-1003.

Bessler, H., Oelmann, Y., Roscher, C., Buchmann, N., Scherer-Lorenzen, M., Schulze, E.-D., Temperton, V.M., Wilcke, W. \& Engels, C. (2012) Nitrogen uptake by grassland communities: contribution of $\mathrm{N}_{2}$ fixation, facilitation, complementarity, and species dominance. Plant and Soil, 358, 301-322.

Bessler, H., Temperton, V.M., Roscher, C., Buchmann, N., Schmid, B., Schulze, E.-D., Weisser, W.W. \& Engels, C. (2009) Aboveground overyielding in grassland mixtures is associated with reduced biomass partitioning to belowground organs. Ecology, 90, 1520-1530.

Bolker, B.M. (2008) Ecological Models and Data in R. Princeton University Press, Princeton, USA.

Bolker, B. \& R Development Core Team. (2014) Bbmle: Tools for General Maximum Likelihood Estimation. R Package Version 1.0.17.

Bonkowski, M. (2004) Protozoa and plant growth: the microbial loop in soil revisited. New Phytologist, 162, 617-631.

Bonkowski, M. \& Brandt, F. (2002) Do soil protozoa enhance plant growth by hormonal effects? Soil Biology \& Biochemistry, 34, 1709-1715.

Brazelton, J.N., Pfeufer, E.E., Sweat, T.A., Gardener, B.B.M. \& Coenen, C. (2008) 2,4diacetylphloroglucinol alters plant root development. Molecular Plant-Microbe Interactions, 21, 1349-1358.

Bressan, M., Roncato, M.-A., Bellvert, F., Comte, G., Haichar, F.Z., Achouak, W. \& Berge, O. (2009) 
Exogenous glucosinolate produced by Arabidopsis thaliana has an impact on microbes in the rhizosphere and plant roots. The ISME Journal, 3, 1243-1257.

Burnham, K.P. \& Anderson, D.R. (2004) Multimodel inference understanding AIC and BIC in model selection. Sociological Methods \& Research, 33, 261-304.

Burns, J.H. \& Strauss, S.Y. (2012) Effects of competition on phylogenetic signal and phenotypic plasticity in plant functional traits. Ecology, 93, 126-137.

Cadotte, M., Albert, C.H. \& Walker, S.C. (2013) The ecology of differences: assessing community assembly with trait and evolutionary distances. Ecology Letters, 16, 1234-1244.

Cardinale, B.J., Duffy, J.E., Gonzalez, A., Hooper, D.U., Perrings, C., Venail, P., Narwani, A., Mace, G.M., Tilman, D., Wardle, D.A., Kinzig, A.P., Daily, G.C., Loreau, M., Grace, J.B., Larigauderie, A., Srivastava, D.S. \& Naeem, S. (2012) Biodiversity loss and its impact on humanity. Nature, 486, 59-67.

Cardinale, B.J., Wright, J.P., Cadotte, M.W., Carroll, I.T., Hector, A., Srivastava, D.S., Loreau, M. \& Weis, J.J. (2007) Impacts of plant diversity on biomass production increase through time because of species complementarity. Proceedings of the National Academy of Sciences, 104, 18123-18128.

Chapman, S.K., Langley, J.A., Hart, S.C. \& Koch, G.W. (2006) Plants actively control nitrogen cycling: uncorking the microbial bottleneck. New Phytologist, 169, 27-34.

Chu, G.X., Shen, Q.R. \& Cao, J.L. (2004) Nitrogen fixation and N transfer from peanut to rice cultivated in aerobic soil in an intercropping system and its effect on soil $\mathrm{N}$ fertility. Plant and Soil, 263, 17-27.

Cook, R.J. (1987) Influence of soil treatments on growth and yield of wheat and implications for control of Pythium root rot. Phytopathology, 77, 1192.

Cook, R.J., Schillinger, W.F. \& Christensen, N.W. (2002) Rhizoctonia root rot and take-all of wheat in diverse direct-seed spring cropping systems. Canadian Journal of Plant Pathology, 24, 349-358.

Craine, J.M., Reich, P.B., David Tilman, G., Ellsworth, D., Fargione, J., Knops, J. \& Naeem, S. (2003) The role of plant species in biomass production and response to elevated $\mathrm{CO}_{2}$ and N. Ecology Letters, 6, 623-625.

Crawley, M.J. (2012) The R Book, 2nd ed. John Wiley \& Sons, Ltd, Chichester, U.K.

Czaban, J., Gajda, A. \& Wroblewska, B. (2007) The motility of bacteria from rhizosphere and different zones of winter wheat roots. Polish Journal of Environmental Studies, 16, 301308.

Dakora, F.D. \& Phillips, D.A. (2002) Root exudates as mediators of mineral acquisition in lownutrient environments. Plant and Soil, 245, 35-47.

De Deyn, G.B., Quirk, H. \& Bardgett, R.D. (2011) Plant species richness, identity and productivity 
differentially influence key groups of microbes in grassland soils of contrasting fertility. Biology Letters, 7, 75-78.

Djordjevic, M.A., Redmond, J.W., Batley, M. \& Rolfe, B.G. (1987) Clovers secrete specific phenolic compounds which either stimulate or repress nod gene expression in Rhizobium trifolii. The EMBO Journal, 6, 1173-1179.

Dong, Y.H. \& Zhang, L.H. (2005) Quorum sensing and quorum-quenching enzymes. Journal of Microbiology, 43, 101-109.

Dubuis, C., Keel, C. \& Haas, D. (2007) Dialogues of root-colonizing biocontrol pseudomonads. European Journal of Plant Pathology, 119, 311-328.

Duffy, J.E. (2008) Why biodiversity is important to the functioning of real-world ecosystems. Frontiers in Ecology and the Environment, 7, 437-444.

Duval, M.E., Galantini, J.A., Iglesias, J.O., Canelo, S., Martinez, J.M. \& Wall, L. (2013) Analysis of organic fractions as indicators of soil quality under natural and cultivated systems. Soil and Tillage Research, 131, 11-19.

Ebeling, A., Pompe, S., Baade, J., Eisenhauer, N., Hillebrand, H., Proulx, R., Roscher, C., Schmid, B., Wirth, C. \& Weisser, W.W. (2014) A trait-based experimental approach to understand the mechanisms underlying biodiversity-ecosystem functioning relationships. Basic and Applied Ecology, 15, 229-240.

Eisenhauer, N. (2012) Aboveground-belowground interactions as a source of complementarity effects in biodiversity experiments. Plant and Soil, 351, 1-22.

Eisenhauer, N., Beßler, H., Engels, C., Gleixner, G., Habekost, M., Milcu, A., Partsch, S., Sabais, A.C.W., Scherber, C., Steinbeiss, S., Weigelt, A., Weisser, W.W. \& Scheu, S. (2010a) Plant diversity effects on soil microorganisms support the singular hypothesis. Ecology, 91, 485-496.

Eisenhauer, N., Bowker, M.A., Grace, J.B. \& Powell, J.R. (2015) From patterns to causal understanding: Structural equation modeling (SEM) in soil ecology. Pedobiologia, in press.

Eisenhauer, N., Dobies, T., Cesarz, S., Hobbie, S.E., Meyer, R.J., Worm, K. \& Reich, P.B. (2013) Plant diversity effects on soil food webs are stronger than those of elevated $\mathrm{CO}_{2}$ and $\mathrm{N}$ deposition in a long-term grassland experiment. Proceedings of the National Academy of Sciences, 110, 6889-6894.

Eisenhauer, N., Hörsch, V., Moeser, J. \& Scheu, S. (2010b) Synergistic effects of microbial and animal decomposers on plant and herbivore performance. Basic and Applied Ecology, $11,23-34$.

Eisenhauer, N., Reich, P.B. \& Scheu, S. (2012) Increasing plant diversity effects on productivity with time due to delayed soil biota effects on plants. Basic and Applied Ecology, 13, 571-578. 
Ekelund, F. \& Rønn, R. (1994) Notes on protozoa in agricultural soil with emphasis on heterotrophic flagellates and naked amoebae and their ecology. FEMS Microbiology Reviews, 15, 321-353.

Foissner, W. (1999) Soil protozoa as bioindicators: pros and cons, methods, diversity, representative examples. Agriculture, Ecosystems and Environment, 74, 95-112.

Fox, J. \& Weisberg, S. (2011) An R Companion to Applied Regression, 2nd ed (ed HS Weisberg). Sage Publication Inc, Thousand Oaks, USA.

Garbeva, P., Postma, J., van Veen, J.A. \& van Elsas, J.D. (2006) Effect of above-ground plant species on soil microbial community structure and its impact on suppression of Rhizoctonia solani AG3. Environmental Microbiology, 8, 233-246.

Garbeva, P., Silby, M.W., Raaijmakers, J.M., Levy, S.B. \& Boer, W. de. (2011) Transcriptional and antagonistic responses of Pseudomonas fluorescens Pf0-1 to phylogenetically different bacterial competitors. The ISME Journal, 5, 973-985.

Garbeva, P., van Veen, J.A. \& van Elsas, J.D. (2004) Microbial diversity in soil: selection of microbial populations by plant and soil type and implications for disease suppressiveness. Annual Review of Phytopathology, 42, 243-270.

García Parisi, P.A., Grimoldi, A.A. \& Omacini, M. (2014) Endophytic fungi of grasses protect other plants from aphid herbivory. Fungal Ecology, 9, 61-64.

Grace, J.B. (2006) Structural Equation Modeling and Natural Systems. Cambridge University Press, Cambridge, USA.

Haas, D. \& Defago, G. (2005) Biological control of soil-borne pathogens by fluorescent pseudomonads. Nature Reviews Microbiology, 3, 307-319.

Haas, D. \& Keel, C. (2003) Regulation of antibiotic production in root-colonizing Pseudomonas spp. and relevance for biological control of plant disease. Annual Review of Phytopathology, 41, 117-153.

Hanse, B., Schneider, J.H.M., Termorshuizen, A.J. \& Varrelmann, M. (2011) Pests and diseases contribute to sugar beet yield difference between top and averagely managed farms. Crop Protection, 30, 671-678.

Hector, A. \& Bagchi, R. (2007) Biodiversity and ecosystem multifunctionality. Nature, 448, 188190.

Hedlund, K., Santa Regina, I., van der Putten, W.H., Lepš, J., Díaz, T., Korthals, G.W., Lavorel, S., Brown, V.K., Gormsen, D., Mortimer, S.R., Rodríguez Barrueco, C., Roy, J., Smilauer, P., Smilauerová, M. \& Van Dijk, C. (2003) Plant species diversity, plant biomass and responses of the soil community on abandoned land across Europe: idiosyncracy or above-belowground time lags. Oikos, 103, 45-58.

Van der Heijden, M.G.A., Bardgett, R.D. \& van Straalen, N.M. (2008) The unseen majority: soil 
microbes as drivers of plant diversity and productivity in terrestrial ecosystems. Ecology Letters, 11, 296-310.

Henkes, G.J., Thorpe, M.R., Minchin, P.E.H., Schurr, U. \& Röse, U.S.R. (2008) Jasmonic acid treatment to part of the root system is consistent with simulated leaf herbivory, diverting recently assimilated carbon towards untreated roots within an hour. Plant, cell \& environment, 31, 1229-1236.

Hensel, M., Bieleit, G., Meyer, R. \& Jagnow, G. (1990) A reliable method for the selection of axenic seedlings. Biology and Fertility of Soils, 9, 281-282.

Hewitt, E.J. (1966) Sand and Water Culture Methods Used in the Study of Plant Nutrition. Commonwealth Agricultural Bureaux, Farnham, U.K.

Hiltner, L. (1904) Über neuere Erfahrungen und Probleme auf dem Gebiete der Bodenbakteriologie unter besonderer Berücksichtigung der Gründüngung und Brache. Arbeiten der Deutschen Landwirtschaftlichen Gesellschaft, 98, 59-78.

Hinsinger, P., Bengough, A.G., Vetterlein, D. \& Young, I.M. (2009) Rhizosphere: biophysics, biogeochemistry and ecological relevance. Plant and Soil, 321, 117-152.

Hirsch, C.F. \& Christensen, D.L. (1983) Novel method for selective isolation of actinomycetes. Applied and Environmental Microbiology, 46, 925-929.

Hooper, D.U., Chapin, F.S., Ewel, J.J., Hector, A., Inchausti, P., Lavorel, S., Lawton, J.H., Lodge, D.M., Loreau, M., Naeem, S., Schmid, B., Setälä, H., Symstad, A.J., Vandermeer, J. \& Wardle, D.A. (2005) Effects of biodiversity on ecosystem functioning: a consensus of current knowledge. Ecological Monographs, 75, 3-35.

Huston, M.A. (1997) Hidden treatments in ecological experiments: re-evaluating the ecosystem function of biodiversity. Oecologia, 110, 449-460.

lavicoli, A., Boutet, E., Buchala, A. \& Metraux, J.P. (2003) Induced systemic resistance in Arabidopsis thaliana in response to root inoculation with Pseudomonas fluorescens CHAO. Molecular Plant-Microbe Interactions, 16, 851-858.

Isbell, F., Calcagno, V., Hector, A., Connolly, J., Harpole, W.S., Reich, P.B., Scherer-Lorenzen, M., Schmid, B., Tilman, D., van Ruijven, J., Weigelt, A., Wilsey, B.J., Zavaleta, E.S. \& Loreau, M. (2011) High plant diversity is needed to maintain ecosystem services. Nature, 477, 199-202.

Janvier, C., Villeneuve, F., Alabouvette, C., Edel-Hermann, V., Mateille, T. \& Steinberg, C. (2007) Soil health through soil disease suppression: Which strategy from descriptors to indicators? Soil Biology and Biochemistry, 39, 1-23.

Jarvis, B., Wilrich, C. \& Wilrich, P.-T. (2010) Reconsideration of the derivation of Most Probable Numbers, their standard deviations, confidence bounds and rarity values. Journal of Applied Microbiology, 109, 1660-1667. 
Jousset, A. (2012) Ecological and evolutive implications of bacterial defences against predators. Environmental Microbiology, 14, 1830-1843.

Jousset, A., Rochat, L., Lanoue, A., Bonkowski, M., Keel, C. \& Scheu, S. (2011) Plants respond to pathogen infection by enhancing the antifungal gene expression of root-associated bacteria. Molecular Plant-Microbe Interactions, 24, 352-358.

Jousset, A., Rochat, L., Pechy-Tarr, M., Keel, C., Scheu, S. \& Bonkowski, M. (2009) Predators promote defence of rhizosphere bacterial populations by selective feeding on non-toxic cheaters. The ISME Journal, 3, 666-674.

Kielak, A.M., Cretoiu, M.S., Semenov, A.V., Sørensen, S.J. \& van Elsas, J.D. (2013) Bacterial chitinolytic communities respond to chitin and $\mathrm{pH}$ alteration in soil. Applied and Environmental Microbiology, 79, 263-272.

King, E.O., Ward, M.K. \& Raney, D.E. (1954) Two simple media for the demonstration of pyocyanin and fluorescin. Journal of Laboratory and Clinical Medicine, 44, 301-307.

Kowalchuk, G.A., Hol, W.H.G. \& van Veen, J.A. (2006) Rhizosphere fungal communities are influenced by Senecio jacobaea pyrrolizidine alkaloid content and composition. Soil Biology and Biochemistry, 38, 2852-2859.

Kowalchuk, G.A., de Souza, J.T. \& van Veen, J.A. (2002) Community analysis of arbuscular mycorrhizal fungi associated with Ammophila arenaria in dutch coastal sand dunes. Molecular Ecology, 11, 571-581.

Krauss, J., Klein, A.-M., Steffan-Dewenter, I. \& Tscharntke, T. (2004) Effects of habitat area, isolation, and landscape diversity on plant species richness of calcareous grasslands. Biodiversity \& Conservation, 13, 1427-1439.

Kühn, J., Rippel, R. \& Schmidhalter, U. (2009) Abiotic soil properties and the occurrence of Rhizoctonia crown and root rot in sugar beet. Journal of Plant Nutrition and Soil Science, 172, 661-668.

Kulmatiski, A., Anderson-Smith, A., Beard, K.H., Doucette-Riise, S., Mazzacavallo, M., Nolan, N.E., Ramirez, R.A. \& Stevens, J.R. (2014) Most soil trophic guilds increase plant growth: a meta-analytical review. Oikos, 123, 1409-1419.

Kushalappa, A.C. \& Ludwig, A. (1982) Calculation of apparent infection-rate in plant-diseases: development of a method to correct for host growth. Phytopathology, 72, 1373-1377.

Landa, B.B., Cachinero-Díaz, J.M., Lemanceau, P., Jiménez-Díaz, R.M. \& Alabouvette, C. (2002) Effect of fusaric acid and phytoanticipins on growth of rhizobacteria and Fusarium oxysporum. Canadian Journal of Microbiology, 48, 971-985.

Landa, B.B., Mavrodi, D.M., Thomashow, L.S. \& Weller, D.M. (2003) Interactions between strains of 2,4-diacetylphloroglucinol-producing Pseudomonas fluorescens in the rhizosphere of wheat. Phytopathology, 93, 982-994. 
Lange, M., Habekost, M., Eisenhauer, N., Roscher, C., Bessler, H., Engels, C., Oelmann, Y., Scheu, S., Wilcke, W., Schulze, E.-D. \& Gleixner, G. (2014) Biotic and abiotic properties mediating plant diversity effects on soil microbial communities in an experimental grassland. PLoS ONE, 9, e96182.

Lapouge, K., Schubert, M., Allain, F.H.-T. \& Haas, D. (2008) Gac/Rsm signal transduction pathway of gamma-proteobacteria: from RNA recognition to regulation of social behaviour. Molecular Microbiology, 67, 241-253.

Latz, E., Eisenhauer, N., Rall, B.C., Allan, E., Roscher, C., Scheu, S. \& Jousset, A. (2012) Plant diversity improves protection against soil-borne pathogens by fostering antagonistic bacterial communities. Journal of Ecology, 100, 597-604.

Latz, E., Eisenhauer, N., Scheu, S. \& Jousset, A. (2015) Plant identity drives the expression of biocontrol factors in a rhizosphere bacterium across a plant diversity gradient. Functional Ecology, in press.

Li, L., Tilman, D., Lambers, H. \& Zhang, F.-S. (2014) Plant diversity and overyielding: insights from belowground facilitation of intercropping in agriculture. New Phytologist, 203, 63-69.

Liu, Z., Liu, G., Fu, B. \& Zheng, X. (2008) Relationship between plant species diversity and soil microbial functional diversity along a longitudinal gradient in temperate grasslands of Hulunbeir, Inner Mongolia, China. Ecological Research, 23, 511-518.

Long, S.R. (2001) Genes and signals in the rhizobium-legume symbiosis. Plant Physiology, 125, 69-72.

Loper, J.E., Hassan, K.A., Mavrodi, D.V., Davis, E.W., II, Lim, C.K., Shaffer, B.T., Elbourne, L.D.H., Stockwell, V.O., Hartney, S.L., Breakwell, K., Henkels, M.D., Tetu, S.G., Rangel, L.I., Kidarsa, T.A., Wilson, N.L., van de Mortel, J.E., Song, C., Blumhagen, R., Radune, D., Hostetler, J.B., Brinkac, L.M., Durkin, A.S., Kluepfel, D.A., Wechter, W.P., Anderson, A.J., Kim, Y.C., Pierson, L.S., III, Pierson, E.A., Lindow, S.E., Kobayashi, D.Y., Raaijmakers, J.M., Weller, D.M., Thomashow, L.S., Allen, A.E. \& Paulsen, I.T. (2012) Comparative genomics of plant-associated Pseudomonas spp.: insights into diversity and inheritance of traits involved in multitrophic interactions. PLoS Genet, 8, e1002784.

Loreau, M., Naeem, S., Inchausti, P., Bengtsson, J., Grime, J.P., Hector, A., Hooper, D.U., Huston, M.A., Raffaelli, D., Schmid, B., Tilman, D. \& Wardle, D.A. (2001) Biodiversity and ecosystem functioning: current knowledge and future challenges. Science, 294, 804808.

Lotka, A.J. (1925) Elements of Physical Biology. Williams and Wilkins Company, Baltimore, USA.

Lugtenberg, B.J.J., Dekkers, L. \& Bloemberg, G. (2001) Molecular determinants of rhizosphere colonization by Pseudomonas. Annual Review of Phytopathology, 39, 461-490.

Lugtenberg, B. \& Kamilova, F. (2009) Plant-growth-promoting rhizobacteria. Annual Review of Microbiology, 63, 541-556. 
Marschner, P. (2011) Marschner's Mineral Nutrition of Higher Plants, 3rd edition. Academic Press, London, U.K.

Marx, M.-C., Wood, M. \& Jarvis, S.C. (2001) A microplate fluorimetric assay for the study of enzyme diversity in soils. Soil Biology and Biochemistry, 33, 1633-1640.

Maurhofer, M., Hase, C., Meuwly, P., Metraux, J. \& Defago, G. (1994) Induction of systemic resistance of tobacco to tobacco necrosis virus by the root-colonizing Pseudomonas fluorescens strain $\mathrm{CHAO}$ : influence of the gacA gene and of pyoverdine production. Phytopathology, 84, 139-146.

Mazzola, M. (2007) Manipulation of rhizosphere bacterial communities to induce suppressive soils. Journal of Nematology, 39, 213-220.

Mazzola, M., Funnell, D.L. \& Raaijmakers, J.M. (2004) Wheat cultivar-specific selection of 2,4diacetylphloroglucinol-producing fluorescent Pseudomonas species from resident soil populations. Microbial Ecology, 48, 338-348.

McCoy, M.W., Stier, A.C. \& Osenberg, C.W. (2012) Emergent effects of multiple predators on prey survival: the importance of depletion and the functional response. Ecology Letters, 15, 1449-1456.

McSpadden Gardener, B.B., Mavrodi, D.V., Thomashow, L.S. \& Weller, D.M. (2001) A rapid polymerase chain reaction-based assay characterizing rhizosphere populations of 2,4diacetylphloroglucinol-producing bacteria. Phytopathology, 91, 44-54.

Mendes, R., Garbeva, P. \& Raaijmakers, J.M. (2013) The rhizosphere microbiome: significance of plant beneficial, plant pathogenic, and human pathogenic microorganisms. FEMS Microbiology Reviews, 37, 634-663.

Mendes, R., Kruijt, M., de Bruijn, I., Dekkers, E., van der Voort, M., Schneider, J.H.M., Piceno, Y.M., DeSantis, T.Z., Andersen, G.L., Bakker, P.A.H.M. \& Raaijmakers, J.M. (2011) Deciphering the rhizosphere microbiome for disease-suppressive bacteria. Science, 332, 1097-1100.

Milcu, A., Partsch, S., Scherber, C., Weisser, W.W. \& Scheu, S. (2008) Earthworms and legumes control litter decomposition in a plant diversity gradient. Ecology, 89, 1872-1882.

Mitchell, C.E. (2003) Trophic control of grassland production and biomass by pathogens. Ecology Letters, 6, 147-155.

Mueller, K.E., Tilman, D., Fornara, D.A. \& Hobbie, S.E. (2013) Root depth distribution and the diversity-productivity relationship in a long-term grassland experiment. Ecology, 94, 787-793.

Müller, M.S., Scheu, S. \& Jousset, A. (2013) Protozoa drive the dynamics of culturable biocontrol bacterial communities. PLOS ONE, 8, e66200.

Neher, D.A. \& Campbell, C.L. (1992) Underestimation of disease progress rates with logistic, 
monomolecular, and gompertz models when maximum disease intensity is less than 100 percent. Phytopathology, 82, 811-814.

Oerke, E.-C. (2006) Crop losses to pests. The Journal of Agricultural Science, 144, 31-43.

Paine, C.E.T., Marthews, T.R., Vogt, D.R., Purves, D., Rees, M., Hector, A. \& Turnbull, L.A. (2012) How to fit nonlinear plant growth models and calculate growth rates: an update for ecologists. Methods in Ecology and Evolution, 3, 245-256.

Pankhurst, C.E., McDonald, H.J., Hawke, B.G. \& Kirkby, C.A. (2002) Effect of tillage and stubble management on chemical and microbiological properties and the development of suppression towards cereal root disease in soils from two sites in NSW, Australia. Soil Biology and Biochemistry, 34, 833-840.

Péchy-Tarr, M., Bruck, D.J., Maurhofer, M., Fischer, E., Vogne, C., Henkels, M.D., Donahue, K.M., Grunder, J., Loper, J.E. \& Keel, C. (2008) Molecular analysis of a novel gene cluster encoding an insect toxin in plant-associated strains of Pseudomonas fluorescens. Environmental Microbiology, 10, 2368-2386.

Pérès, G., Cluzeau, D., Menasseri, S., Soussana, J.F., Bessler, H., Engels, C., Habekost, M., Gleixner, G., Weigelt, A., Weisser, W.W., Scheu, S. \& Eisenhauer, N. (2013) Mechanisms linking plant community properties to soil aggregate stability in an experimental grassland plant diversity gradient. Plant and Soil, 373, 285-299.

Philippot, L., Raaijmakers, J.M., Lemanceau, P. \& van der Putten, W.H. (2013) Going back to the roots: the microbial ecology of the rhizosphere. Nature Reviews Microbiology, 11, 789799.

Pierson, L.S. \& Pierson, E.A. (2007) Roles of diffusible signals in communication among plantassociated bacteria. Phytopathology, 97, 227-232.

Pierson, E.A. \& Weller, D.M. (1994) Use of mixtures of fluorescent pseudomonads to suppress take-all and improve the growth of wheat. Phytopathology, 84, 940-947.

Pineda, A., Dicke, M., Pieterse, C.M.J. \& Pozo, M.J. (2013) Beneficial microbes in a changing environment: are they always helping plants to deal with insects? Functional Ecology, 27, 574-586.

Pinheiro, J., Bates, D., DebRoy, S., Sarkar, D. \& R Core Team. (2014) nlme: linear and nonlinear mixed effects models. R package version 3.1-111.

Pornprasertmanit, S., Miller, P., Schoemann, A., Rosseel, Y., Quick, C., Garnier-Villarreal, M., Selig, J., Boulton, A., Preacher, K., Coffman, D., Rhemtulla, M., Robitzsch, A., Enders, C., Arslan, R., Clinton, B., Panko, P., Merkle, E., Jorgensen, T. \& Chesnut, S. (2014) semTools: Useful Tools for Structural Equation Modeling. R Package Version 0.4-6.

Postma, J., Scheper, R.W.A. \& Schilder, M.T. (2010) Effect of successive cauliflower plantings and Rhizoctonia solani AG 2-1 inoculations on disease suppressiveness of a suppressive and a conducive soil. Soil Biology and Biochemistry, 42, 804-812. 
Postma, J., Schilder, M.T., Bloem, J. \& van Leeuwen-Haagsma, W.K. (2008) Soil suppressiveness and functional diversity of the soil microflora in organic farming systems. Soil Biology and Biochemistry, 40, 2394-2406.

Raaijmakers, J.M., Paulitz, T.C., Steinberg, C., Alabouvette, C. \& Moënne-Loccoz, Y. (2009) The rhizosphere: a playground and battlefield for soilborne pathogens and beneficial microorganisms. Plant and Soil, 321, 341-361.

Raaijmakers, J.M., Vlami, M. \& de Souza, J.T. (2002) Antibiotic production by bacterial biocontrol agents. Antonie Van Leeuwenhoek International Journal of General and Molecular Microbiology, 81, 537-547.

Ravenek, J.M., Bessler, H., Engels, C., Scherer-Lorenzen, M., Gessler, A., Gockele, A., de Luca, E., Temperton, V.M., Ebeling, A., Roscher, C., Schmid, B., Weisser, W.W., Wirth, C., de Kroon, H., Weigelt, A. \& Mommer, L. (2014) Long-term study of root biomass in a biodiversity experiment reveals shifts in diversity effects over time. Oikos, 123, 1528-1536.

R Core Team. (2014) R: A language and environment for statistical computing. R version 3.1.1. R Foundation for Statistical Computing, Vienna, Austria. URL http://www.R-project.org/.

Regehr, A. (2014) Evaluation of Maize and Soybean Intercropping on Soil Quality and Nitrogen Transformations in the Argentine Pampa. Master Thesis, University of Waterloo, Waterloo, CA.

Reich, P.B., Tilman, D., Isbell, F., Mueller, K., Hobbie, S.E., Flynn, D.F.B. \& Eisenhauer, N. (2012) Impacts of biodiversity loss escalate through time as redundancy fades. Science, 336, 589-592.

Ritchie, F., Bain, R.A. \& McQuilken, M.P. (2009) Effects of nutrient status, temperature and pH on mycelial growth, sclerotial production and germination of Rhizoctonia solani from potato. Journal of Plant Pathology, 91, 589-596.

Rochat, L., Péchy-Tarr, M., Baehler, E., Maurhofer, M. \& Keel, C. (2010) Combination of fluorescent reporters for simultaneous monitoring of root colonization and antifungal gene expression by a biocontrol pseudomonad on cereals with flow cytometry. Molecular Plant-Microbe Interactions, 23, 949-961.

Rønn, R., Ekelund, F. \& Christensen, S. (1995) Optimizing soil extract and broth media for MPNenumeration of naked amoebae and heterotrophic flagellates in soil. Pedobiologia, 39, 10-19.

Rønn, R., McCaig, A., Griffiths, B. \& Prosser, J. (2002) Impact of protozoan grazing on bacterial community structure in soil microcosms. Applied and Environmental Microbiology, 68, 6094-6105.

Roscher, C., Schumacher, J., Baade, J., Wilcke, W., Gleixner, G., Weisser, W.W., Schmid, B. \& Schulze, E.-D. (2004) The role of biodiversity for element cycling and trophic interactions: an experimental approach in a grassland community. Basic and Applied Ecology, 5, 107-121. 
Rosenberg, K., Bertaux, J., Krome, K., Hartmann, A., Scheu, S. \& Bonkowski, M. (2009) Soil amoebae rapidly change bacterial community composition in the rhizosphere of Arabidopsis thaliana. The ISME Journal, 3, 675-684.

Rosseel, Y. (2012) lavaan: an R package for structural equation modeling. Journal of Statistical Software, 48, 1-36.

Rousk, J., Bååth, E., Brookes, P.C., Lauber, C.L., Lozupone, C., Caporaso, J.G., Knight, R. \& Fierer, N. (2010) Soil bacterial and fungal communities across a pH gradient in an arable soil. The ISME Journal, 4, 1340-1351.

Rudrappa, T., Splaine, R.E., Biedrzycki, M.L. \& Bais, H.P. (2008) Cyanogenic pseudomonads influence multitrophic interactions in the rhizosphere. PLOS ONE, 3, e2073.

Sambrook, J. \& Russell, D. (2001) Molecular Cloning: A Laboratory Manual. Cold Spring Harbor Laboratory Press, New York, USA.

Schardl, C.L., Leuchtmann, A. \& Spiering, M.J. (2004) Symbioses of grasses with seedborne fungal endophytes. Annual Review of Plant Biology, 55, 315-340.

Scherber, C. (2009) R code: stepAICc. URL http://wwwuser.gwdg.de/ cscherb1/stepAICc.txt

Schippers, B., Bakker, A.W. \& Bakker, P.A.H.M. (1987) Interactions of deleterious and beneficial rhizosphere microorganisms and the effect of cropping practices. Annual Review of Phytopathology, 25, 339-358.

Schnider-Keel, U., Seematter, A., Maurhofer, M., Blumer, C., Duffy, B. \& Gigot-Bonnefoy, C. (2000) Autoinduction of 2,4-diacetylphloroglucinol biosynthesis in the biocontrol agent Pseudomonas fluorescens $\mathrm{CHAO}$ and repression by the bacterial metabolites salicylate and pyoluteorin. Journal of Bacteriology, 182, 1215-1225.

Schnitzer, S.A., Klironomos, J.N., Hillerislambers, J., Kinkel, L.L., Reich, P.B., Xiao, K., Rillig, M.C., Sikes, B.A., Callaway, R.M., Mangan, S.A., van Nes, E.H. \& Scheffer, M. (2011) Soil microbes drive the classic plant diversity-productivity pattern. Ecology, 92, 296-303.

Semchenko, M., Hutchings, M.J. \& John, E.A. (2007) Challenging the tragedy of the commons in root competition: confounding effects of neighbour presence and substrate volume. Journal of Ecology, 95, 252-260.

SIIA. (2014) SIIA: Sistema Integrado de Información Agropecuaria - Inicio. URL http://www.siia.gov.ar/

Sikes, B.A., Cottenie, K. \& Klironomos, J.N. (2009) Plant and fungal identity determines pathogen protection of plant roots by arbuscular mycorrhizas. Journal of Ecology, 97, 1274-1280.

Simon, A. \& Ridge, E.H. (1974) The use of ampicillin in a simplified selective medium for the isolation of fluorescent pseudomonads. Journal of Applied Bacteriology, 37, 459-460.

Smiley, R.W., Gourlie, J.A., Easley, S.A., Patterson, L.-M. \& Whittaker, R.G. (2005) Crop damage 
estimates for crown rot of wheat and barley in the pacific northwest. Plant Disease, 89, 595-604.

Soetaert, K. \& Herman, P.M.J. (2008) A Practical Guide to Ecological Modelling: Using R as a Simulation Platform, 2009th ed. Springer, Dordrecht, NL.

Soetaert, K., Petzoldt, T. \& Setzer, R.W. (2010) Solving differential equations in R: package deSolve. Journal of Statistical Software, 33, 1-25.

Spehn, E.M., Joshi, J., Schmid, B., Alphei, J. \& Körner, C. (2000) Plant diversity effects on soil heterotrophic activity in experimental grassland ecosystems. Plant and Soil, 224, 217230.

Stanghellini, M.E., Kim, D.H., Waugh, M.M., Ferrin, D.M., Alcantara, T. \& Rasmussen, S.L. (2004) Infection and colonization of melon roots by Monosporascus cannonballus in two cropping seasons in Arizona and California. Plant Pathology, 53, 54-57.

Steinbeiss, S., Beßler, H., Engels, C., Temperton, V.M., Buchmann, N., Roscher, C., Kreutziger, Y., Baade, J., Habekost, M. \& Gleixner, G. (2008) Plant diversity positively affects short-term soil carbon storage in experimental grasslands. Global Change Biology, 14, 2937-2949.

Stephan, A., Meyer, A.H. \& Schmid, B. (2000) Plant diversity affects culturable soil bacteria in experimental grassland communities. Journal of Ecology, 88, 988-998.

Stevenson, K.E. \& Segner, W.P. (1992) Mesophilic aerobic sporeformers. Compendium of Methods for the Microbiological Examination of Foods, 3rd ed (eds C. Vanderzant \& D.F. Spliistoesser), pp. 265-274. American Public Health Association, Washington DC, USA.

Sturz, A.V., Carter, M.R. \& Johnston, H.W. (1997) A review of plant disease, pathogen interactions and microbial antagonism under conservation tillage in temperate humid agriculture. Soil and Tillage Research, 41, 169-189.

Tilman, D., Cassman, K.G., Matson, P.A., Naylor, R. \& Polasky, S. (2002) Agricultural sustainability and intensive production practices. Nature, 418, 671-677.

Tilman, D., Isbell, F. \& Cowles, J.M. (2014) Biodiversity and ecosystem functioning. Annual Review of Ecology, Evolution, and Systematics, 45, 471-493.

Tilman, D., Lehman, C.L. \& Thomson, K.T. (1997) Plant diversity and ecosystem productivity: theoretical considerations. Proceedings of the National Academy of Sciences of the United States of America, 94, 1857-1861.

Tilston, E.L., Pitt, D. \& Groenhof, A.C. (2002) Composted recycled organic matter suppresses soil-borne diseases of field crops. New Phytologist, 154, 731-740.

Tomasi, N., Weisskopf, L., Renella, G., Landi, L., Pinton, R., Varanini, Z., Nannipieri, P., Torrent, J., Martinoia, E. \& Cesco, S. (2008) Flavonoids of white lupin roots participate in phosphorus mobilization from soil. Soil Biology and Biochemistry, 40, 1971-1974.

Trenbath, B.R. (1993) Intercropping for the management of pests and diseases. Field Crops 
Research, 34, 381-405.

Uikman, P.J.K., Jansen, A.G. \& van Veen, J.A. (1991) ${ }^{15} \mathrm{~N}$-nitrogen mineralization from bacteria by protozoan grazing at different soil-moisture regimes. Soil Biology \& Biochemistry, 23, 193-200.

Uren, N. (2007) Types, amounts, and possible functions of compounds released into the rhizosphere by soil-grown plants.

Verdelli, D., Acciaresi, H.A. \& Leguizamon, E.S. (2012) Corn and soybeans in a strip intercropping system: crop growth rates, radiation interception, and grain yield components. International Journal of Agronomy, 2012, e980284.

Voisard, C., Bull, C.T., Keel, C., Laville, J., Maurhofer, M., Schnider, U., Défago, G. \& Haas, D. (1994) Biocontrol of root diseases by Pseudomonas fluorescens CHAO: current concepts and experimental approaches. Molecular Ecology of Rhizosphere Microorganisms (eds F. O'Gara, D.N. Dowling \& I.B. Boesten), pp. 67-89. Wiley-VCH Verlag GmbH, Weinheim, DE.

Volterra, V. (1926) Variations and fluctuations of the number of individuals in animal species living together. reprinted in: Animal Ecology (1931). (ed R.N. Chapman), pp. 412-414. McGraw-Hill, New York, USA.

Weidner, S., Koller, R., Latz, E., Kowalchuk, G., Bonkowski, M., Scheu, S. \& Jousset, A. (2015) Bacterial diversity amplifies nutrient-based plant-soil feedbacks. Functional Ecology, in press.

Weller, D.M. (2007) Pseudomonas biocontrol agents of soilborne pathogens: looking back over 30 years. Phytopathology, 97, 250-256.

Weller, D.M., Raaijmakers, J.M., Gardener, B.B.M. \& Thomashow, L.S. (2002) Microbial populations responsible for specific soil suppressiveness to plant pathogens. Annual Review of Phytopathology, 40, 309-348.

De Werra, P., Baehler, E., Huser, A., Keel, C. \& Maurhofer, M. (2008) Detection of plantmodulated alterations in antifungal gene expression in Pseudomonas fluorescens CHAO on roots by flow cytometry. Applied and Environmental Microbiology, 74, 1339-1349.

Van West, P., Morris, B.M., Reid, B., Appiah, A.A., Osborne, M.C., Campbell, T.A., Shepherd, S.J. \& Gow, N. a. R. (2002) Oomycete plant pathogens use electric fields to target roots. Molecular Plant-Microbe Interactions, 15, 790-798.

Wilson, P.S., Ketola, E.O., Ahvenniemi, P.M., Lehtonen, M.J. \& Valkonen, J.P.T. (2008) Dynamics of soilborne Rhizoctonia solani in the presence of Trichoderma harzianum: effects on stem canker, black scurf and progeny tubers of potato. Plant Pathology, 57, 152-161.

Zak, D.R., Holmes, W.E., White, D.C., Peacock, A.D. \& Tilman, D. (2003) Plant diversity, soil microbial communities, and ecosystem function: are there any links? Ecology, 84, 20422050. 
Zul, D., Denzel, S., Kotz, A. \& Overmann, J. (2007) Effects of plant biomass, plant diversity, and water content on bacterial communities in soil lysimeters: implications for the determinants of bacterial diversity. Applied and Environmental Microbiology, 73, 69166929. 



\section{V | Supplementary Material}

In addition to the complete thesis, published papers and supplementaries for all research chapters, original $\mathrm{R}$ data and code files as supplementary information to Research Chapter 2 , can be found as digital copy on CD.

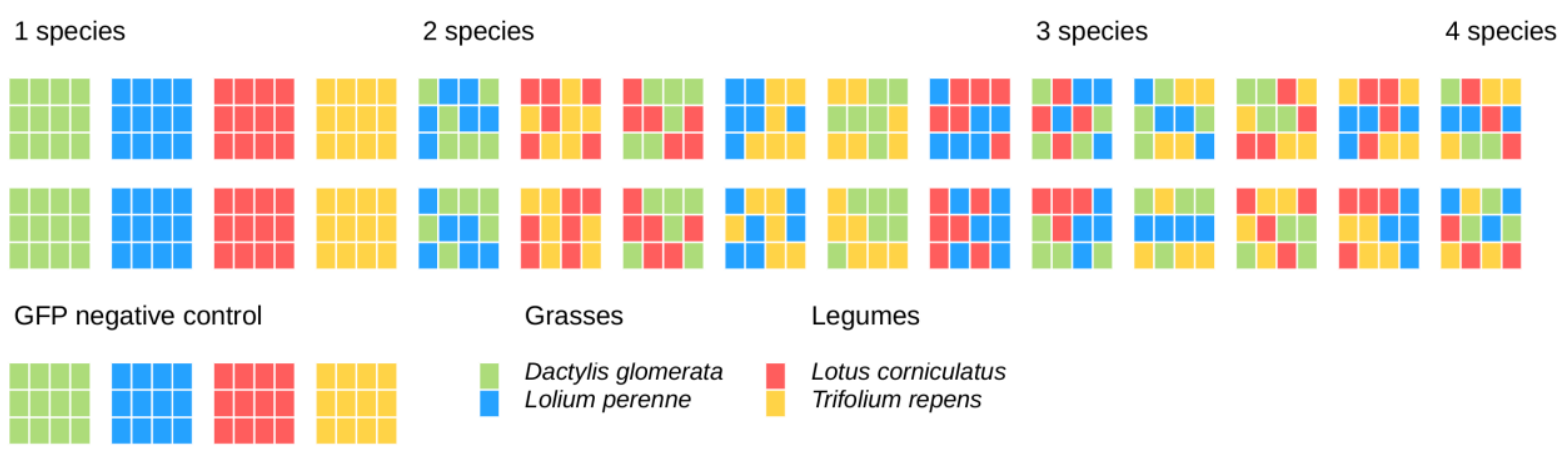

Supplementary Figure 1. Experimental setup of the substitutive, full factorial plant species richness gradient. Displayed is one of the six blocks. Each small square represents one plant individual; each main square represents one plant community. We set up two blocks per bacterial treatment (Pseudomonas protegens inhabiting plasmid pME 7100, pME 7116 and pME 7156, respectively). Each with two replicates per plant species richness level, resulting in a total of four replicates. Four plant monocultures inoculated with $P$. protegens wild-type strain per block served as control (GFP negative control). 

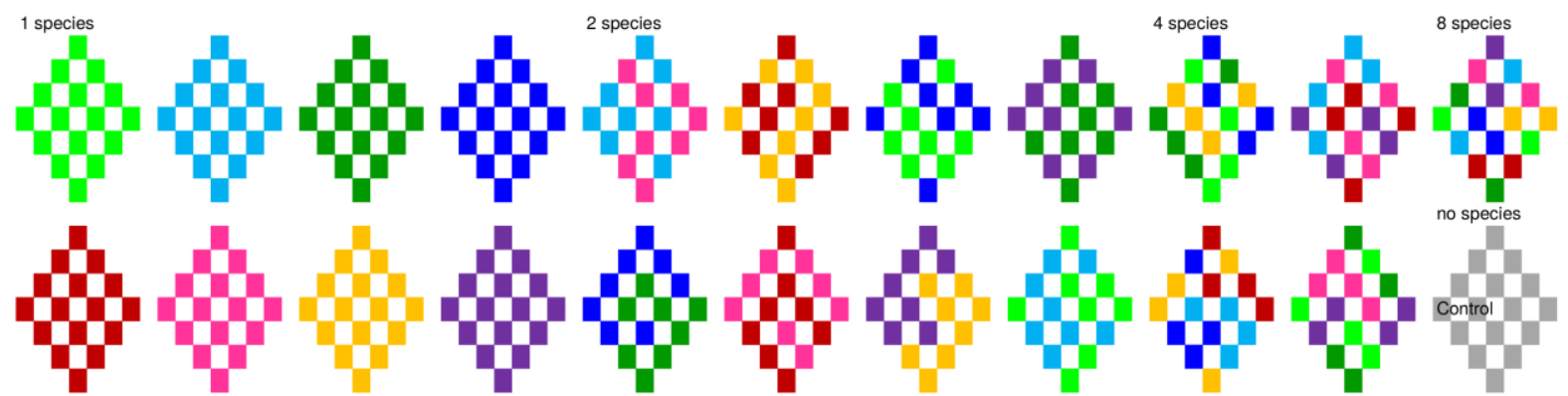

$2^{\text {na }}$ Partition


$3^{\text {ra }}$ Partition
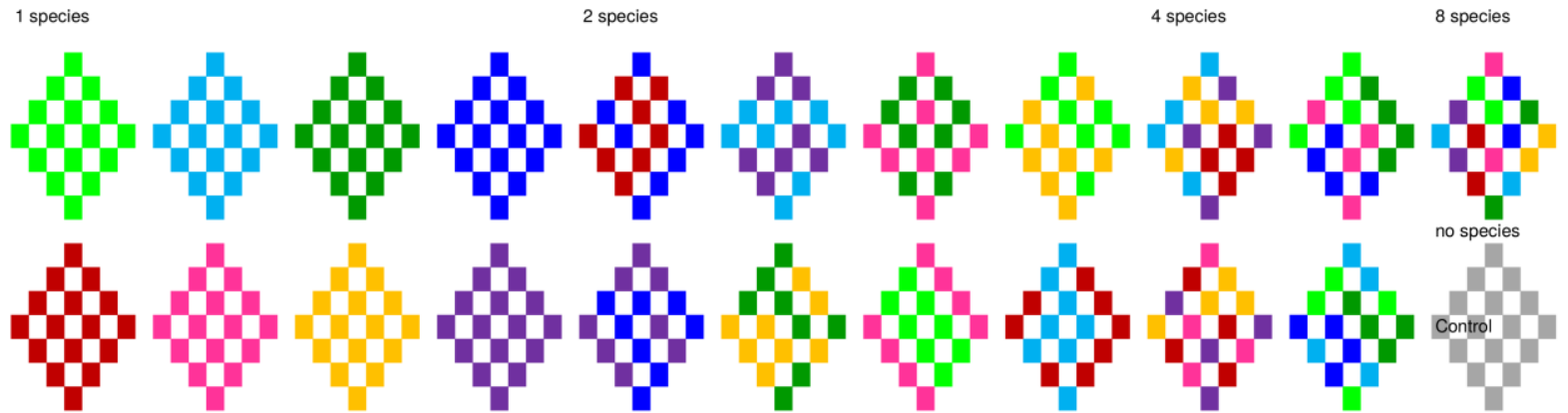

Grasses

Legumes

Bromus erectus
Dactylis glomerata

Festuca pratense

otus corniculatus

Medicago lupulina

Trifolium pratense

Lolium perenn

Trifolium repens

Supplementary Figure 2. Experimental setup of the substitutive plant species richness gradient. Plant diversity was varied independently of functional group affiliation by using the random partitions design (Bell et al. 2009). Displayed is the spatial arrangement of the last plant growth cycle (fifth). Each small square represents one plant individual; each main square represents one plant community. 


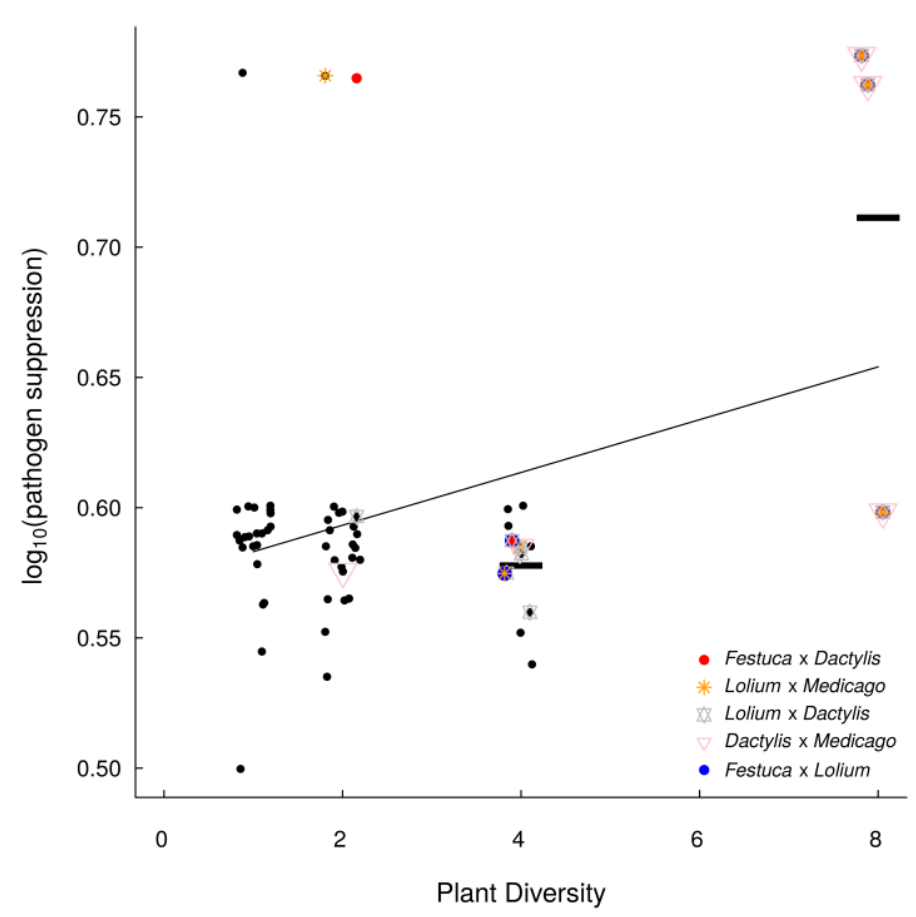

Supplementary Figure 3. To test for plant identity and interaction effects independent of diversity, we used a sequential statistical approach (Bell et al. 2009). In a first step, we used linear regression models to analyse the effect of plant diversity (continuously coded) on pathogen suppression ( $\log _{10}$ [pathogen suppression]). In a second step, the residuals of the first step in the analyses were fitted against the explanatory variables Bromus, Dactylis, Festuca, Lolium, Lotus, Medicago, Trifolium p. and Trifolium r. (presence [1] / absence [0], continuously coded; intercept $=0$ ). In a third step, the residuals of the second step were fitted against plant diversity (factorially coded; intercept $=0$ ). Additionally, to identify explanatory interactions, the residuals of the second step were fitted against $2^{\text {nd }}$ order interactions in a linear regression approach. In the interaction fitting, the most parsimonious model was selected using the stepAICc() function (Scherber 2009).

Diversity increased pathogen suppression (slope $=0.010, P<0.05$ ), whereas none of the plant identities showed a significant influence on suppression (all $P>0.1$ ). Interestingly, pathogen suppression was decreased on diversity level four (slope $=-0.036, \mathrm{P}<0.05)$ and increased on diversity level eight $(0.057, \mathrm{P}<0.05)$ indicating that interactive effects of plants drive the diversity pattern.

Analyses (instead of the third step) using interactions up to the $2^{\text {nd }}$ order revealed that the species combinations Festuca-Dactylis (red dots) and Lolium-Medicago (yellow stars) increased pathogen suppression. The negative effect of the species pair Festuca-Lolium (blue-circle) was most obvious at diversity level 4, where it might have hampered the positive effect of Dactylis-Festuca (red dot and blue circle) and Medicago-Lolium (yellow star and blue circle). In addition, while only being marginally significant, Lolium-Dactylis (grey, crossed triangles) and Dactylis-Medicago (pink triangle) might have hampered the positive effect of Lolium-Medicago. 
Supplementary Table 1. Results of path analyses of Dactylis, Lolium, Lotus and Trifolium presence on root biomass, active bacterial density and gene expression.

\begin{tabular}{|c|c|c|c|c|c|c|}
\hline & & & Estimate & S.E. & C.R. & \\
\hline \multicolumn{7}{|l|}{ (A) ph/A } \\
\hline \multirow[t]{3}{*}{ Root biomass } & $\leftarrow$ & Lolium presence & 0.852 & 0.16 & 5.44 & $* * *$ \\
\hline & $\leftarrow$ & Trifolium presence & -0.719 & 0.16 & -4.61 & *** \\
\hline & $\leftarrow$ & Lotus presence & 0.519 & 0.16 & 3.34 & $\star *$ \\
\hline \multirow[t]{2}{*}{ Bacterial density } & $\leftarrow$ & Lolium presence & 0.690 & 0.08 & 8.86 & $* \star *$ \\
\hline & $\leftarrow$ & Trifolium presence & -0.198 & 0.08 & -2.55 & * \\
\hline \multirow[t]{3}{*}{ phlA expression } & $\leftarrow$ & Lolium presence & 2.994 & 0.83 & 3.63 & $* * *$ \\
\hline & $\leftarrow$ & Dactylis presence & -1.442 & 0.55 & -2.65 & $\star *$ \\
\hline & $\leftarrow$ & Bacterial density & 0.932 & 0.87 & 1.07 & \\
\hline \multicolumn{7}{|l|}{ (B) $p r n A$} \\
\hline \multirow[t]{2}{*}{ Root biomass } & $\leftarrow$ & Lolium presence & 1.022 & 0.21 & 4.89 & $* * *$ \\
\hline & $\leftarrow$ & Trifolium presence & -0.987 & 0.21 & -4.72 & $* * *$ \\
\hline \multirow[t]{2}{*}{ Bacterial density } & $\leftarrow$ & Root biomass & 0.093 & 0.03 & 3.04 & $* *$ \\
\hline & & Lolium presence & 0.444 & 0.07 & 6.82 & $* * *$ \\
\hline \multirow[t]{4}{*}{ prnA expression } & $\leftarrow$ & Lolium presence & 1.447 & 0.62 & 2.34 & * \\
\hline & $\leftarrow$ & Lotus presence & 1.129 & 0.39 & 2.86 & $\star *$ \\
\hline & $\leftarrow$ & Dactylis presence & -1.847 & 0.39 & -4.68 & $* * *$ \\
\hline & $\leftarrow$ & Bacterial density & 5.189 & 0.87 & 5.95 & $* * *$ \\
\hline \multicolumn{7}{|l|}{ (C) $h c n A$} \\
\hline \multirow[t]{3}{*}{ Root biomass } & $\leftarrow$ & Lolium presence & 0.743 & 0.13 & 5.76 & $* * *$ \\
\hline & $\leftarrow$ & Trifolium presence & -0.452 & 0.13 & -3.53 & $* * *$ \\
\hline & & Lotus presence & 0.601 & 0.13 & 4.70 & $* \star *$ \\
\hline \multirow[t]{2}{*}{ Bacterial density } & & Lolium presence & 1.061 & 0.13 & 8.46 & $* * *$ \\
\hline & $\leftarrow$ & Trifolium presence & -0.285 & 0.13 & -2.27 & * \\
\hline \multirow[t]{2}{*}{ hcnA expression } & $\leftarrow$ & Lolium presence & -2.704 & 0.83 & -3.24 & $* *$ \\
\hline & $\leftarrow$ & Bacterial density & 4.931 & 0.56 & 8.81 & $* * *$ \\
\hline
\end{tabular}

Given are non standardized path coefficients (estimates), standard error of regression weight (S.E.) and the critical value for regression weight (C.R.; $z=$ estimate/ S.E.). Asterisks denote the level of significance: . $P \leq 0.1 ;{ }^{*} P \leq 0.05 ;{ }^{* *} P \leq 0.01 ;{ }^{* * *} P<0.001$. For more information of exogenous and endogenous variables as well as on model fit see main text. 
Supplementary Table 2. Hypotheses liable for the initial structural equation model (see methods for details).

\begin{tabular}{|c|c|c|c|}
\hline Dependent variables & Expected effect & Independent variables & Reference \\
\hline \multirow[t]{4}{*}{ Pathogen suppression } & & Actinobacteria / Bacillus / Pseudomonas & Garbeva et al. (2006), Mendes et al.(2011), Latz et al. (2012) \\
\hline & & Soil moisture & Janvier et al. (2007) \\
\hline & & Soil pH & Janvier et al. (2007) \\
\hline & & $\mathrm{C} / \mathrm{N}$ ratio & Janvier et al. (2007) \\
\hline \multirow[t]{6}{*}{ Microbial Biomass* } & & Plant diversity & Eisenhauer et al. (2010a, 2013), Latz et al. (2012) \\
\hline & & Legumes / Grasses & Eisenhauer et al. (2010a), Latz et al. (2012) \\
\hline & & Root biomass & Spehn et al. (2000), Zak et al. (2003), de Deyn et al. (2011), Eisenhauer et al. (2013) \\
\hline & & Soil moisture & Eisenhauer et al. (2013), Lange et al. (2014) \\
\hline & & Soil pH & Eisenhauer et al. (2013), Philippot et al. (2013) \\
\hline & & $\mathrm{C} / \mathrm{N}$ ratio & Kühn et al. (2009), Eisenhauer et al. (2013), Pérès et al. (2013) \\
\hline \multirow[t]{3}{*}{ Soil moisture } & & Plant diversity & Eisenhauer et al. (2013), Lange et al. (2014) \\
\hline & & Legumes / Grasses & Lange et al. (2014) \\
\hline & & Root biomass & Eisenhauer et al. (2013) \\
\hline \multirow[t]{2}{*}{ Root biomass } & & Plant diversity & Spehn et al. (2000), Eisenhauer et al. (2013), Pérès et al. (2013) \\
\hline & & Legumes / Grasses & Pérès et al. (2013), Bessler et al. (2009, 2012) \\
\hline \multirow[t]{3}{*}{ Soil $C / N$} & & Plant diversity & Steinbeiss et al. (2008), Einsenhauer et al. (2013) \\
\hline & & Legumes / Grasses & Pérès et al. (2013), Lange et al. (2014) \\
\hline & & Root biomass & Steinbeiss et al. (2008), Einsenhauer et al. (2013) \\
\hline \multirow[t]{2}{*}{ Soil $p H$} & & Plant diversity & Eisenhauer et al. (2013) \\
\hline & & Legumes / Grasses & no reference found \\
\hline
\end{tabular}

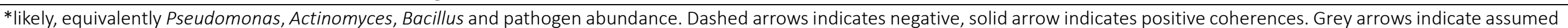
but not proofed effects or effects that gave inconsistent results. 
Supplementary Table 3. Results of the final structural equation model $\left(X^{2}{ }_{21}=17.22 ;\right.$ P-value $\left.=0.698\right)$, showing effects of direct and indirect (through changes in soil pH, root biomass, soil moisture and bacterial abundances) effects of plant community composition on pathogen suppression.

\begin{tabular}{|c|c|c|c|c|c|c|}
\hline & & & Estimate & S.E. & C.R. & \\
\hline \multicolumn{7}{|l|}{ Regressions } \\
\hline Soil pH & $\leftarrow$ & Plant diversity & 0.077 & 0.05 & 1.66 & \\
\hline Soil moisture & $\leftarrow$ & Root biomass & -0.207 & 0.03 & -6.19 & $* * *$ \\
\hline \multirow[t]{2}{*}{ Root biomass } & $\leftarrow$ & Plant diversity & 0.478 & 0.20 & 2.41 & * \\
\hline & $\leftarrow$ & Grass presence & -1.333 & 0.74 & -1.79 & . \\
\hline \multirow[t]{4}{*}{ Bacillus } & $\leftarrow$ & Soil pH & 0.645 & 0.22 & 3.00 & $* *$ \\
\hline & $\leftarrow$ & Soil moisture & 0.443 & 0.19 & 2.28 & * \\
\hline & $\leftarrow$ & Root biomass & 0.308 & 0.07 & 4.73 & $* \star *$ \\
\hline & $\leftarrow$ & Grass presence & 0.797 & 0.30 & 2.66 & $\star *$ \\
\hline \multirow[t]{3}{*}{ Pseudomonas } & $\leftarrow$ & Root biomass & -0.057 & 0.01 & -5.26 & *** \\
\hline & $\leftarrow$ & Grass presence & -0.272 & 0.07 & -4.05 & $* \star *$ \\
\hline & $\leftarrow$ & Legume presence & 0.192 & 0.07 & 2.83 & $\star *$ \\
\hline \multirow[t]{3}{*}{ Actinomyces } & $\leftarrow$ & Root biomass & -0.047 & 0.02 & -3.02 & $* *$ \\
\hline & $\leftarrow$ & Grass presence & -0.323 & 0.10 & -3.33 & $* *$ \\
\hline & $\leftarrow$ & Legume presence & 0.529 & 0.10 & 5.38 & $* * *$ \\
\hline \multirow[t]{6}{*}{ Pathogen suppression } & $\leftarrow$ & Plant diversity & 0.149 & 0.04 & 3.74 & $* * *$ \\
\hline & $\leftarrow$ & Legume presence & -0.442 & 0.18 & -2.47 & * \\
\hline & $\leftarrow$ & Soil pH & -0.291 & 0.10 & -2.86 & $* *$ \\
\hline & $\leftarrow$ & Pseudomonas & -0.428 & 0.27 & -1.60 & \\
\hline & $\leftarrow$ & Actinomyces & 0.547 & 0.20 & 2.71 & $* *$ \\
\hline & $\leftarrow$ & Bacillus & 0.057 & 0.05 & 1.15 & \\
\hline \multicolumn{7}{|l|}{ Covariances } \\
\hline Actinomyces & $\leftrightarrow$ & Pseudomonas & 0.000 & 0.00 & 3.00 & $\star *$ \\
\hline \multirow[t]{2}{*}{ Plant diversity } & $\leftrightarrow$ & Grass presence & 0.002 & 0.00 & 2.32 & * \\
\hline & $\leftrightarrow$ & Legume presence & 0.003 & 0.00 & 2.46 & * \\
\hline Grass presence & $\leftrightarrow$ & Legume presence & -0.001 & 0.00 & -2.82 & $* *$ \\
\hline
\end{tabular}

Given are non standardized path coefficients (estimates), standard error of regression weight (S.E.) and the critical value for regression weight (C.R.; $z=$ estimate/ S.E.). Asterisks denote the level of significance: . P $\leq$ $0.1 ;{ }^{*} \leq 0.05 ;{ }^{* * P} \leq 0.01 ;{ }^{* * *} P<0.001$. For more information of exogenous and endogenous variables as well as on model fit see main text. 
Supplementary Table 4. Effects of plant community composition on pathogen suppression as indicated by additional, sequential analyses (see text for details).

\begin{tabular}{|c|c|c|c|c|c|c|c|c|c|c|c|c|c|c|}
\hline \multirow{4}{*}{$\begin{array}{l}\text { 1. step } \\
\text { Intercept } \\
\text { Plant number / } \\
\text { identity }\end{array}$} & \multicolumn{3}{|c|}{ Number of grasses } & \multicolumn{3}{|c|}{ Bromus erectus } & \multicolumn{3}{|c|}{ Dactylis glomerata } & \multicolumn{2}{|l|}{ Festuca pratense } & \multicolumn{3}{|c|}{ Lolium perenne } \\
\hline & Estimate & S.E. & t-value & Estimate & S.E. & t-value & Estimate & S.E. & t-value & Estimate S.E. & t-value & Estimate & S.E. & t-value \\
\hline & 0.578 & 0.010 & $58.74 * * *$ & 0.591 & 0.008 & $71.99 * * *$ & 0.589 & 0.008 & $71.82 * * *$ & 0.5910 .008 & $71.13 * * *$ & 0.589 & 0.008 & $72.54 * * *$ \\
\hline & 0.016 & 0.006 & $2.50 *$ & 0.018 & 0.016 & 1.17 & 0.026 & 0.015 & 1.75 & 0.0180 .015 & 1.16 & 0.025 & 0.015 & 1.64 \\
\hline $\mathrm{DF} / \mathrm{R}^{2}$ & $59 / 0.10$ & & & $59 / 0.02$ & & & $59 / 0.05$ & & & $59 / 0.02$ & & $59 / 0.04$ & & \\
\hline \multicolumn{15}{|l|}{ 2. step } \\
\hline Intercept & -0.005 & 0.114 & -0.47 & -0.018 & 0.011 & -1.58 & -0.016 & 0.011 & -1.39 & -0.0180 .011 & -1.60 & -0.016 & 0.011 & -1.41 \\
\hline Plant diversity & 0.002 & 0.004 & 0.58 & 0.008 & 0.004 & 1.96 . & 0.007 & 0.004 & 1.73 & 0.0080 .004 & 1.98 & 0.007 & 0.004 & 1.74 . \\
\hline \multirow[t]{2}{*}{$\mathrm{DF} / \mathrm{R}^{2}$} & $59 / 0.01$ & & & $59 / 0.06$ & & & $59 / 0.05$ & & & $59 / 0.06$ & & $59 / 0.05$ & & \\
\hline & \multicolumn{3}{|c|}{ Number of Legumes } & \multicolumn{3}{|c|}{ Lotus corniculatus } & \multicolumn{3}{|c|}{ Medicago Iupulina } & \multicolumn{2}{|l|}{ Trifolium pratense } & \multicolumn{3}{|c|}{ Trifolium repens } \\
\hline 1. step & Estimate & S.E. & t-value & Estimate & S.E. & t-value & Estimate & S.E. & t-value & Estimate S.E. & t-value & Estimate & S.E. & t-value \\
\hline Intercept & -0.016 & 0.011 & -1.41 & 0.593 & 0.008 & $70.87 * * *$ & 0.588 & 0.008 & $71.88 * * *$ & 0.5950 .008 & $71.67 * * *$ & 0.594 & 0.008 & $70.85 * * *$ \\
\hline $\begin{array}{l}\text { Plant number / } \\
\text { identity }\end{array}$ & 0.007 & 0.004 & 1.74 & 0.011 & 0.015 & 0.70 & 0.027 & 0.015 & 1.79 & 0.0050 .016 & 0.33 & 0.009 & 0.015 & 0.61 \\
\hline $\mathrm{DF} / \mathrm{R}^{2}$ & $59 / 0.05$ & & & 59/0.01 & & & $59 / 0.05$ & & & $59 / 0.00$ & & $59 / 0.01$ & & \\
\hline \multicolumn{15}{|l|}{ 2. step } \\
\hline Intercept & -0.013 & 0.012 & -1.08 & -0.020 & 0.011 & -1.77. & -0.015 & 0.011 & -1.38 & -0.0220 .011 & -1.91 & -0.021 & 0.011 & -1.81 \\
\hline Plant diversity & 0.005 & 0.004 & 1.45 & 0.009 & 0.004 & $2.20 *$ & 0.007 & 0.004 & 1.71 . & 0.0090 .004 & $2.36 *$ & 0.009 & 0.004 & $2.24 *$ \\
\hline$D F / R^{2}$ & $59 / 0.03$ & & & $59 / 0.08$ & & & $59 / 0.05$ & & & $60 / 0.06$ & & $59 / 0.08$ & & \\
\hline
\end{tabular}

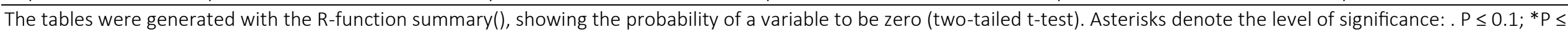
$0.05 ;{ }^{* *} P \leq 0.01 ;{ }^{* *} P<0.001$. DF, degrees of freedom; $R^{2}$ coefficient of determination. 
Supplementary Table 5. Chemical soil properties were determined according to Duval et al. (2013).

\begin{tabular}{lccc}
\hline Chemical indicator & Soybean & Maize & Soybean/Maize \\
\hline Organic carbon content $(\% \mathrm{w} / \mathrm{w})$ & $2.10 \pm 0.14$ & $2.24 \pm 0.01$ & $2.12 \pm 0.08$ \\
COPc $(\% \mathrm{w} / \mathrm{w})$ & $0.30 \pm 0.03$ & $0.33 \pm 0.03$ & $0.30 \pm 0.09$ \\
$\operatorname{COPf}(\% \mathrm{w} / \mathrm{w})$ & $0.26 \pm 0.04$ & $0.28 \pm 0.03$ & $0.25 \pm 0.01$ \\
MOC $(\% \mathrm{w} / \mathrm{w})$ & $1.54 \pm 0.11$ & $1.63 \pm 0.05$ & $1.56 \pm 0.06$ \\
Nitrogen $(\% \mathrm{w} / \mathrm{w})$ & $0.17 \pm 0.02$ & $0.17 \pm 0.01$ & $0.17 \pm 0.01$ \\
Extractable phosphorus $(\mathrm{mg} / \mathrm{kg})$ & $46.4 \pm 8.5$ & $47.3+7.1$ & $49.0 \pm 7.4$ \\
Soluble carbohydrates $(\mathrm{mg} / \mathrm{kg})$ & $117.48 \pm 7.7$ & $111.3 \pm 7.5$ & $111.49 \pm 17.3$ \\
Total carbohydrates $(\mathrm{mg} / \mathrm{kg})$ & $846.5 \pm 29.8$ & $1235.5 \pm 119.6 *$ & $983.7 \pm 19.1$ \\
\hline
\end{tabular}

$*$, total carbohydrate content of maize plots was significantly higher than those of soybean alone or intercropped plots (Tukey's HSD; P < 0.05). POCc: coarse fraction (105-2000 $\mu \mathrm{m})$ containing coarse particulate organic carbon; POCf: medium fraction $(53-105 \mu \mathrm{m})$ containing fine particulate organic carbon; MOC: fine fraction $(<53 \mu \mathrm{m})$ containing mineral associated organic carbon. 


\section{VI | Thesis Declarations}

\subsection{Declaration of the author's own contribution to manuscripts}

RESEARCH CHAPTER 1 is published in a peer-reviewed journal. RESEARCH CHAPTERS 2 and 4 are currently submitted to peer reviewed journals. In all manuscripts except that presented in RESEARCH CHAPTER 2 I am the first author. In RESEARCH CHAPTERS 1, 3 and 4 I have collected and analysed the data, developed the main ideas and primarily wrote the manuscripts, created tables, figures and supplementaries and contributed significantly to the study design (in CHAPTER 4, data collection was done by Simone Weidner and myself, Claudio Valverde has determined Protozoan abundances and ideas were developed cooperatively). The model presented in RESEARCH CHAPTER 2 was developed and written by Björn C. Rall. The idea for the model and writing of the manuscript was cooperative work. Generally, all co-authors contributed to the final versions of the manuscripts.

\subsection{Plagiarism declaration}

I declare that I have written this doctoral thesis independently. All persons contributing to the manuscripts have been named so. All sentences or passages quoted from other people's work have been specifically acknowledged by clear cross-referencing. I have not submitted this thesis in any form for another degree at any university or institution.

Ellen Latz Leipzig, August 2015 



\section{VII | Acknowledgements}

First of all, I thank my supervisor Stefan Scheu, who gave me the opportunity to do this thesis. I greatly benefited from our open-minded discussions, the stimulating atmosphere and his support throughout my PhD. Further, I thank him for considerably improving my writing. I thank my advisor Alexandre Jousset for an unforgettable time. He was who piqued my interest in studying microbes in the rhizosphere. I thank him for many inspiring discussions, taking me to so many conferences and for facilitating my collaborative work. Further, I thank him for marvellous goofing off.

I acknowledge Nico Eisenhauer, who opened up my mind to biodiversity research. I thank him for having an open door for discussions, statistic lectures and especially for supporting me during "harder times". In addition, I thank him for the effort he invested in corrections and comments on manuscripts that greatly helped to improve my work.

I thank Ulrich Brose for not only being my co-supervisor but further opening up his working group for me and always having an open door. Further, I kindly thank him for giving me the opportunity to finish my thesis in Leipzig.

I am grateful to Claudio Valverde who gave me the opportunity to work in his lab and being a wonderful supervisor during my stay in Buenos Aires.

I thank Susanne Böning-Klein, Ingrid Kleinhans, Guido Humpert and Christel Fischer as well as Dieter Nünchert and Bernd Messerschmidt for technical assistance.

I thank Joachim, Johannes, Paul, Anna and especially Simone W, for help in the lab and being supportive office mates.

In addition to many other friends, I would particularly like to thank Ina, Kerstin, Patrick, Simone C, Verena and Doro for their help starting work and feeling at home in Göttingen.

I especially thank Nils, for sharing troubles and good times during work and private life.

Thanks to the whole AG Scheu and AG Brose for providing a pleasant atmosphere to work in. Further, I thank those who read, corrected and commented on this thesis.

I thank my family and my good old friends Jeanine and Nele, who always believed in me and my success. 
Special thanks to my husband Björn, who has spent many nights discussing my thesis, supported my work and helped to shape it, endured my moods, relieved me from daily duties, cooked for me and loved me.

-Gehirnsalat- 